City University of New York (CUNY) CUNY Academic Works

$5-2015$

\title{
The Ecology of School Readiness
}

Miriam Beth Tager

Graduate Center, City University of New York

\section{How does access to this work benefit you? Let us know!}

More information about this work at: https://academicworks.cuny.edu/gc_etds/1151

Discover additional works at: https://academicworks.cuny.edu

This work is made publicly available by the City University of New York (CUNY).

Contact: AcademicWorks@cuny.edu 


\section{The Ecology of School Readiness}

by

Miriam B. Tager

A dissertation submitted to the Graduate Faculty in Urban Education in partial fulfillment of the requirements for the Doctor of Philosophy, the City University of New York 
C. 2015

Miriam Beth Tager

All Rights Reserved 
3This manuscript has been read and accepted for the Graduate Faculty in Urban Education in satisfaction of the dissertation requirement for the degree of Doctor of Philosophy

April 1st, 2015

Wendy Luttrell

Chair of Examining Committee

April 1st, 2015

Anthony Picciano

Executive Officer

Wendy Luttrell

Amita Gupta

Anthony Picciano

Supervisory Committee

The City University of New York 


\author{
Abstract \\ "The Ecology of School Readiness" \\ by
}

\title{
Miriam Beth Tager
}

\section{Advisor: Dr. Wendy Luttrell}

This qualitative study applies a critical and constructivist grounded theory approach (Charmez, 2014) to a narrative inquiry of how White middle-class early childhood educators perceive or make assumptions when identifying school readiness in low-income Black children. The data collection included an online districtwide survey of kindergarten and first-grade teachers $(\mathrm{n}=24)$, interviews of five teacher participants, observations of five identified nonschool ready low-income Black children and two focus groups (participating and interpretative). The findings revealed an ecology of school readiness, in which teachers felt that the increase in standards impacted their quick identifications of non-school ready children. These participants claim that there is a culture of rushing, a pushing down of the curriculum ( $k=1 \mathrm{st})$, an undemocratic atmosphere, a pressure to conform to developmentally inappropriate practices and an inclusion of unreasonable teacher accountability evaluations. They also realized that parents have different expectations, work too many low-wage jobs to be actively involved and can not always help their child at home. Overall, it was determined that school readiness, as a term is a deficit based term that needs to re-imagined and reconceptualize in early childhood practices. 


\section{Acknowledgements:}

This book and the idea and promise of this book is dedicated to a host of people who supported me through this project by believing in me even in the hardest of moments. I am grateful for your belief and overall understanding.

Robin, your encouragement and support made this endeavor possible from start to finish. Thank you for being there, for having my back and for believing that even when I was down I was not out. Thank you most of all for giving me love and compassion and hope.

To my darling Ella, my eldest daughter, who motivated me by teasing me. When I started the program you were only two, and even though you did not know it, your funny statements, like, "Mama is reading Foucault..Foucault..Foucault ..Foucault" inspired me to laugh at the whole process. I treasure you and your wit and even when you burst through my office door and interrupted my rhythm, I appreciated you reminding me what was important in my life and world and that is you.

To the newest member of our family, my youngest daughter Lily, thank you for appearing just when I thought it was never going to happen. Having you now in our family has changed my life. You came at a very hectic time, during my research phase, but you only added joy and love to the process.

Wendy Luttrell has been more than an advisor to me. She is my mentor, my friend and someone I hold dear to my heart. She took me in when I needed her and was nurturing and kind, and yet had very high standards and expectations which made me a better researcher and writer. I am grateful and appreciative to have her in my life, and she will forever be an integral part of my life as an academic and as a person.

I would like to thank the other professors on my committee, Dr. Amita Gupta and Dr. Anthony Picciano, for their honesty, high standards, compassion and encouragement.

Much appreciation and love goes to my academic buddies, Mark, Mikela and Maria P. for all their one on one support and help to get to the other side. And to my two sets of graduate school peeps, who were by my side through it all, Rachel, Edwin, Nelson, Jeremy, Mark, Shannon, Christine, and my wonderful advisee group, Claire, Victoria, Rondi,AnaMaria, Maria, Ivana, Noah, Alisa, Natalia, Emily, Demet. Thank you for enduring the many drafts, and the twists and turns. I am forever in your debt.

To my family who were Dr's before me, and gave me the inspiration to be a part of the family business; my brother Dave, my mom Florence, my dad Jack, my sister-n-law Linda. And to my family who supported me, helped with the babysitting, took the kids on weekends, understood my absence at times and was generally very understanding of my quest (Evie, Evan, Monet, Nicki, Nadine, Liz, Danny, Annie ). Also much love to 
my nieces and nephew, the younger generation that inspires me and is fun to be around (Laila, Olive, Ana Ruth, Alex, Francesca)

Much gratitude and thanks to my teacher participants for sharing their thoughts and concerns with me. You were so candid and thoughtful with your responses and made me realize daily why I loved working with you. Thank you participant 1,2, 3, 4 and 5 . And thanks to my interpretative focus group, 6, 7, 8, 9, 10 and 11. Thank you to all the teachers who took the time to fill out the district wide survey and special thanks to the district itself, for it's support in the project. I am first and foremost an advocate for public school education and a believer in quality schooling for all.

I would be remiss without mentioning Christine Saiah, and her wonderful encouragement, support and warmth over the past 7 years. She will forever be the go to person in the department of urban education and is a great student advocate and believer.

Special thank you to Jennifer Fidlon-Bugat who helped me with her discerning eye and did a wonderful job line editing my manuscript.

Finally, I would like to thank Dr. Blackwood, Dr. Wagmiller and Dr. Grahn for being there through it all and genuinely caring for me and my family. Also I big shout out of thanks to my art therapist, Donna and my holistic nurse, Lynn. 


\section{Table of Contents:}

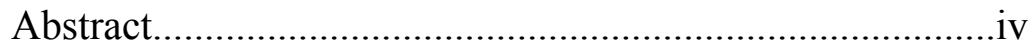

Acknowledgements.....................................................

Table of Contents...................................................... vii

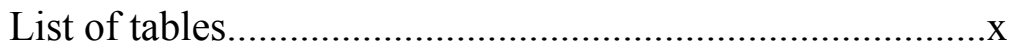

Chapter One - Introduction...........................................

Overview of Study............................................... 3

Research Questions..................................................4

Setting.............................................................. 4

Background of Study.............................................. 6

Chapter Two - Historical/Theoretical Context.......................14

Kindergarten Charity Schools ..................................15

Day Nurseries ..........................................................16

Nursery Schools......................................................18

Emergency Nursery Schools.......................................19

War Nurseries...........................................................20

War on Poverty - Head Start.......................................21

Theory of Cultural Deprivation...................................23

Critical Perspectives: Anti-deficit Theory....................25

Contexts of High Stakes Testing................................27

Political Economy of Early Childhood Education........29

School districts as business models...............................30

Human capital theory of young child..............................31

Commodofication of Early Childhood Education...........34

Chapter Three - Methodology..................................................40

Constructivist Grounded Theory................................40 
Insider status..........................................................44

Ethical Concerns........................................................51

Validity and methods...............................................53

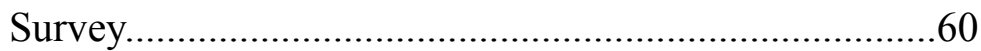

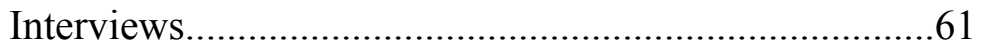

Observations.......................................................63

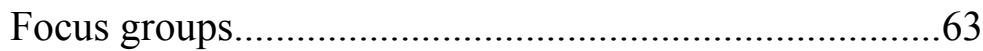

Data analysis.........................................................66

Reflections on research process.....................................70

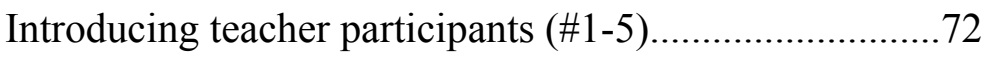

Introducing non-school ready children..........................75

Chapter Four - The Ecology of School Readiness......................79

A snapshot of 5 non-school ready children.....................85

Ability to follow school culture.......................................98

Socio-emotional skills needed.......................................100

The time bind................................................................ 102

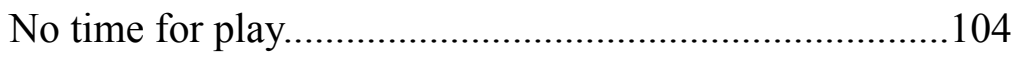

Stick to the schedule......................................................108

Time management and control tools...............................109

No win situation.............................................................111

Chapter Five - "It is so inappropriate" - Higher demands...............113

The Common Core...........................................................118

Increase in assessments/data input.....................................124

Developmentally inappropriate practices...........................126

An undemocratic atmosphere............................................. 134

Lack of district support.....................................................136

Teacher accountability and evaluations.............................. 142

Chapter Six - Teacher perceptions of low-income families................149

Parental involvement/working multiple jobs.........................151

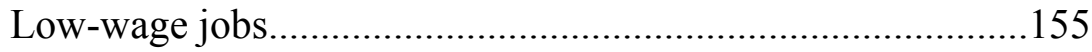

Lack of job flexibility...................................................... 158

Extended kinship networks...............................................159

Stigma of low wage work/Blaming parents...........................161

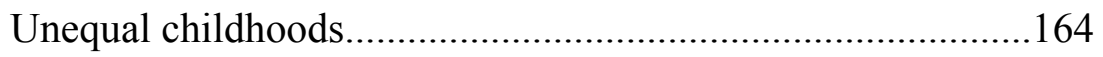


Differing expectations between teachers/parents.

Chapter Seven - "That's a tough question" - issues of race...................176

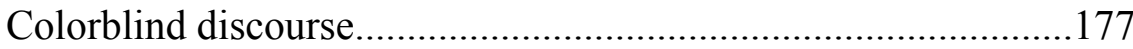

Race is not a factor............................................................. 179

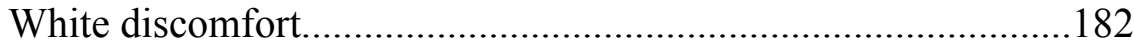

Race and meritocracy.......................................................188

Race ideologies -Shades of Gray..........................................190

Race and socio-economic class..............................................191

Chapter Eight - A Call for Action: Empowering the early childhood educator.....194

Dear local school district................................................................195

The bigger picture: policy and Early Childhood Education................199

The purpose of Early Childhood Education..........................................202

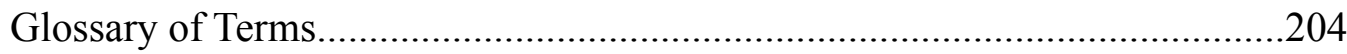

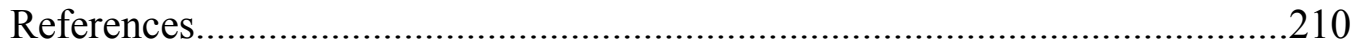




\section{List of Tables:}

Table 1 - Participants Backgrounds.....................................49

Table 2 - Socio-emotional/Academic progress of non-school ready children in study.........56

Table 3 - School Readiness skills..........................................83

Table 4 - Master schedule for Mondays (1st grade)......................107

Table 5- Benchmarks in reading (DRA levels) $\mathrm{K} / 1 \ldots \ldots \ldots \ldots \ldots \ldots \ldots . . . . . . . . . .123$

Table 6 - Ideas for addressing non-school readiness.....................200 


\section{Chapter One}

\section{Introduction}

This study examines the perceptions and assumptions that White middle-class early childhood educators make when identifying school readiness in low-income Black children. ${ }^{1}$ Through this particular study I identify the concept of the ecology of school readiness, which helps us to understand how White middle-class early childhood educators view expectations of school readiness in a child. The ecology of school readiness, as defined, dissected and analyzed in this dissertation, refers to a web of expectations that includes higher pressures and demands from the local school districts. It relates to determining who is ready or not for schooling and refers to how White middle-class teachers relate to and perceive school readiness in low-income Black children in their classrooms. This study posits that the increased demands from the local district have shifted and contributed to a larger educational gap between White middle-class young children and low-income Black young children. This effectively puts low income Black children, who are more apt to be classified as non-school ready, behind the eight ball.

The "pushing down" 2 of the curriculum and the need for more data have directly impacted how teachers view children and the families of these children. The study is also based

1 I employ the term Black instead of African American. I believe I must be as specific as possible and the low-income Black children in my research setting are of different backgrounds. Some are African immigrants, others are immigrants from Haiti, Jamaica and other Caribbean islands (voluntary immigrants), while others are native Blacks who have ancestors that were enslaved here years ago (involuntary immigrants). I also use the term Black because the color of their skin is important in the perceptions that are considered when identifying non-school ready children.

${ }^{2} \mathrm{~A}$ term utilized by the participating teachers in this study. $\mathrm{K}=1$ st grade and $1 \mathrm{st}=2 \mathrm{nd}$ grade 
on an assumption that there are distinct and perceived differences in the values, knowledge and systems of sociocultural beliefs between the philosophies employed by White middle-class educators and those upheld by low-income Black families. This assumption is based on the knowledge that early childhood institutions employ and perpetuate a dominant discourse which is largely based on White middle-class values within their pedagogical practices (Lubeck, 1994; Burman, 1994; Cannella, 1997; Randolph, 2013). It is important to note that $83 \%$ of all public school teachers nationwide are White and $42 \%$ of public school students are Black. It is therefore essential to unpack and examine these perceptions (Randolph, 2013). The intent of this study is to focus on teachers' beliefs about school readiness, utilizing their views as a window to the underlying assumptions and discourses about childhood. My contention is that we all embody differing ideas about childhood that draw on a variety of circulating discourses to perceive, or make meaning of, school readiness in low-income Black children. My goal is to disrupt the everyday identification of school readiness (children who are labeled non-school ready) and question the ongoing usage of this term within the early childhood community. The term school readiness has a variety of similar definitions, but the one I am utilizing relates to "the preparedness of children to learn what school expects or wants them to learn" (Edwards, 1999, p. 1). ${ }^{3}$ Specifically, this refers to reading and literacy skills, math skills and the socioemotional behavior of a child entering kindergarten or first grade. The focus of the study is on how apt the

\footnotetext{
${ }^{3}$ Other definitions include: "a student who is measured as more ready should have greater success in meeting the demands or challenges of a school" (Rock \& Stenner, 2006, p. 16) and "faring better in school' later on (Lara-Cinisomo, et al, 2004).
} 
children are at following school culture. ${ }^{4}$ The expansion of this term includes how children fare at being able to adapt to this normative culture.

As a White middle-class early childhood educator myself, I have questioned my own attitudes and perceptions of a low-income Black child's school readiness. I have noticed in my own classroom that children coming to school with no prekindergarten or limited day care experience do not fare as well during their first-grade academic year. Interestingly, these children have been predominantly low-income Black children. I started to question the term itself and wondered if my White middle-class values based on the dominant discourse of schooling affected how I perceived and identified non-school ready children.

Furthermore, I noticed that all of the children I was referring to the child study team for special education testing were low-income Blacks. Actually, the highest referrers of Black children tend to be White teachers, sometimes at a rate of $30 \%-50 \%$ of their classes (Harry \& Klingner, 2006). In retrospect, I realized that I had neglected to refer several White middle-class students who had exhibited reading issues in my classroom and were later diagnosed with learning disabilities. I was unconcerned about them at the time because of the ample support they received at home. As a result, I unwittingly colluded with mainstream schooling practices and identified them as ready for school when they would have been perceived as non-school ready.

Overview of Study

${ }^{4}$ By school culture I am referring to White middle-class norms 
This study applies a critical and constructivist grounded theory approach (Charmez, 2014) to a narrative inquiry of how White middle-class early childhood educators perceive or make assumptions when identifying school readiness in low-income Black children. The data collection included an online districtwide survey of kindergarten and first-grade teachers $(n=24)$. Five of these early childhood educators (White and middle class) filled out the interest section on the survey and as such were identified as the participants of the study, which included in-depth interviewing. I also observed the five different classrooms of each teacher participant I interviewed in order to follow one low-income Black child per class who had been identified as non-school ready. In addition, there were two different focus groups: one for the participant teachers (in Grayson School) (\#1-5) and one designed as an interpretative focus group at a nonparticipant school in the same district with $\mathrm{k} / 1$ teachers (\#6-11). The main difference in these two focus groups is that in the participant focus group we were co-constructing findings and in the other one we were solely interpreting the findings of the participants.

\section{The Research Questions}

1) How do White middle-class early childhood educators perceive and classify school readiness in low-income Black children?

2) What are the discourses White middle-class early childhood educators draw upon, reject or accept in the identification of school readiness in low-income Black children?

\section{Setting}

The study was conducted in a suburban/urban school district in the New York Tri-State area with 6,532 students in grades K-12. It is located within a few miles of a large metropolitan 
city, which has high populations of low-income Black children. Five elementary schools participated in this study, two of which are border schools with large populations of low-income Black children (55\% and 35\% respectively). The school that is the primary focus of this study is an elementary school that is located two blocks from the border of this large metropolitan city. I refer to this school as Grayson School. The five participating teachers in this study work in this one school. Two of them are multi-age teachers (grades 1 and 2) and the other three are kindergarten teachers. The school's population consists of 533 students in grades K-5, one principal (Mr. Dodd) ${ }^{5}$ and one vice-principal (Mrs. Holland). It is housed in an old building (circa 1913) and the school itself recently celebrated its 100-year anniversary. There are six portable classrooms located in the back of the school near a large field with play equipment and a natural garden where the children grow vegetables. Behind the school there are low-income multi-family houses in poor condition. The neighborhood is a low-income Black area of town. None of the teachers, including those who reside in this town, live in this particular section of town.

Grayson is a designated Title One school ${ }^{6}$ and $43 \%$ of the students qualify for free and reduced lunch, ${ }^{7}$ the highest percentage in the district. This figure would be much higher if there were no opt-in children. ${ }^{8}$ Many years ago this was a majority low-income Black school and the district decided it needed to attract middle-class White families from the other side of town. The

\footnotetext{
${ }^{5}$ All names have been changed

6 Title one schools have a certain percentage of free and reduced students - see glossary

${ }^{7}$ Free and reduced lunch depends on the income level of the parents - see glossary

8 Opt-in means that families have the option to attend this one particular school instead of their neighborhood school.
} 
district changed principals and the school's focus, transforming it into a school related to one theme. ${ }^{9}$ The district gave all families the option to choose Grayson. If they decided to attend they were provided with free bus service to and from the school. Many White middle-class families and a small number of Black middle-class families desired more diversity in their children's school population and were intrigued by this option (and the school's theme) and opted in. This diversified the school to some extent, but during the past few years the percentages of opt-in children have decreased as more families have chosen to send their children to their neighborhood schools. Tours of the school are conducted once a month by the principal for families in the district. If the families are interested in the school, they complete the necessary paperwork at the district office and apply for the free bus service. Some parents also drive across town to drop off and pick up their children, even though they live far enough away to receive the free bus service if they want it. The district is currently deciding whether to restructure the district or create a new theme for the school in order to continue to attract White middle-class families so the school remains desegregated.

\section{Background of Study: School Readiness}

I have specifically chosen to utilize school readiness as a lens for this project because it is a term that utilizes a variety of discourses in order to identify a child as non-school ready. There are intentional and unintentional consequences of this label that deeply affect the school lives of low-income Black children. By exposing the possible discourses that affect the identification of

\footnotetext{
9 By theme I am referring to schools that are related to a specific content area (i.e.; Drama/Arts and or Sciences etc). The specific theme can't be revealed as it will make the school recognizable to the public.
} 
school readiness, perhaps we can make an impact on how White middle-class educators perceive and identify low-income Black children in early childhood settings ${ }^{10}$.

School readiness, as a term, appeared in the 1960s during the implementation of Head Start, a nationally funded preschool program designed for low-income urban young children. The founders of Head Start, including Zigler (2011), utilized the term school readiness to justify the need for Head Start in poor urban areas. The program was designed to give low-income nonWhite families a 'head start' on formal schooling. Many longitudinal quantitative studies (Coley, 2002; Barnett, 1998; Lara-Cinisomo, et al, 2004) over the last forty years have been conducted to prove that children who were classified as 'school ready' fare better in later formal schooling. The belief was that by attending to the issue of school readiness, children would fare better throughout their schooling careers and would also succeed in the job market as adults. This application of school readiness was therefore utilized to attempt to close the gap of inequalities in the early childhood schooling years.

School readiness refers to reading and literacy skills, math skills and the socioemotional behavior of a child entering kindergarten or first grade. The teachers in this study expanded this definition by including myriad social expectations. Examples of such social expectations of behavior (that all the teachers referenced) include children's ability to sit still, listen, keep their hands to themselves, share materials, raise their hands and walk in a line. Since there are children who are unfamiliar with these cultural routines because they have not attended preschool, or have had limited preschool or subpar preschool experiences, there can be a culture clash when they first formally attend school.

\footnotetext{
10 It is important to note that this study does not delve into the population of low-income White children. This another study and future research in this particular area is also important to the field.
} 
Numerous quantitative studies on school readiness conclude that there is a racial disparity in the school readiness skills of White middle-class children and low-income Black children. According to Zigler, 35\% of all entering kindergarten children are deficient in school readiness (Zigler, 2011, 2010). "If students enter kindergarten at a disadvantage, early gaps in understandings of literacy and math tend to be sustained or widened over time; this is particularly true for children of poverty" (Linder/Ramey/Zambak, 2013, p. 1). Therefore, school readiness is an issue for all populations, but is more acutely related to certain marginalized populations (low income non-White populations) due to perceptions and assumptions of the dominant school and teacher culture that tend to be deficit-based. "Teacher perceptions affect student outcomes through self-fulfilling effects, differential teacher practice, differential school climate and impaired recruitment and retention of good teachers at minority schools" (Randolph, 2013, p. 15). In other words, early childhood teachers' perceptions of children, including the identification of school readiness, can undermine a child's schooling progress as it affects how the student is viewed within their own school.

School readiness has been deconstructed throughout this study. It changes in definition depending on the educator. For me, it changed drastically during the research process itself. Before I conducted this study, I believed it was a legitimate term, although I questioned the inequities in school readiness between certain marginalized populations and the dominant culture. In my dissertation proposal I emphatically stated, "this proposed study does not rebuke the idea of school readiness. There is no doubt in my mind that children need to be ready for some type of formal schooling and it is important that it is equally accomplished within all populations of young children" (Tager, 2013, p.4). Towards the end of my research phase I 
began to view things differently. I found myself rebuking the term school readiness and questioning its legitimacy. After interviewing teachers and hearing their perceptions on this topic it became clear to me that the term itself was part of the problem. I no longer recognize it as a legitimate term that needs to be applied more equitably to all populations. Rather, I consider it a deficit-based term that actually perpetuates inequality among populations. School readiness and identifications of school readiness and non-school readiness in children contribute to deficit perceptions of low-income non-White populations, which continue to broaden the educational gap between them and White middle-class children.

The participating teachers in this study had their own conflicting ideas about the term school readiness. The following is an excerpt from their focus group:

Ms. Moore: It's (school readiness) something I pay attention to. I think it's important to kind of scan... make a little graph in your head. It doesn't change what you are going to do..but it's good to know.

Ms. Franklin: But what makes a kid school ready?

Ms. Moore: Oh, what makes one?

Ms. Tager (researcher): Well, what do you think of this term? I mean it's just out there.

Ms. Franklin: I don’t like it.

Ms. Springstein: It's a silly term because some kids are not school ready but like you said (pointing to Ms. Franklin) each kid grows at their own rate.

Ms. Franklin: Or they come from different backgrounds...different expectations. So how can you tell if they are really ready? 
These particular teachers questioned school readiness as a normative term and its role within the early childhood community. In this dissertation I unpack school readiness as a term and examine the multitude of circulating discourses that relate to the ecology of school readiness and how White middle class teachers perceive low income Black children.

In Chapter Two, I examine the historical and theoretical context of this study. In doing so I review the deficit history of early childhood programs for the last 150 years, including the kindergarten movement, day nurseries, ENS (Emergency Nursery Schools) preschools, war nurseries and Head Start. Deficit language, as related to non-White low-income populations, shapes overall perceptions of these programs (e.g., charity kindergartner, disadvantaged, at-risk, culturally deprived, etc.) (Beatty, 1995) My theoretical framework relates to this deficit discourse. It includes the theory of cultural deprivation and the anti-deficit response to this theory. The deficit history of early childhood education continues in the higher standards, testing and accountability movements that follow, although it takes on new forms that I describe below. Neoliberal discourses, including education as a business model, the commodification of early childhood education and human capital theory, also play a part in this deficit historical context. My theory is that the very fabric of early childhood programs is deficit-based and therefore worth dissecting and analyzing based on White middle-class teachers' own understandings of school readiness.

In Chapter Three, I present the methodology of this study, focusing on how a critical approach and constructivist grounded theory were chosen and further utilized. I review all methods utilized (survey, interviews, observations and focus groups) and describe the 
various issues that threatened the validity of the study. Furthermore, I introduce the five participating teachers and the five participating children who were identified as non-school ready by their teachers and whom I observed for this study.

Chapter Four centers on the ecology of school readiness and how it functions within the classroom. Five identified non-school ready children are presented in snapshots, revealing how they have been classified as non-school ready in these teachers' classrooms. Certain factors, such as time constrictions and the culture of rushing, greatly impact teachers' perceptions of school readiness. More advanced socioemotional skills, such as children's ability to sit well on the rug, line up at the door, and listen and follow directions, are now mandatory because every second counts. In addition, due to higher demands and higher standards, teachers are now expected to cover more in the same six-hour day. There is literally no time for free play or the use of developmentally appropriate practices ${ }^{11}$ that these teachers are used to implementing. This in turn, leads to higher numbers of identified non-school ready children, as assessments are harder and done earlier. Chapter 4 is the first of the findings chapters (Chapters 4-7).

In Chapter Five, "It Is So Inappropriate," (a catchphrase used by several teachers in the study), I discuss the participating teachers' frustrations with the increased pressure and higher demands placed on them, which they in turn place on their very young students. They lament the common practice of pushing down the curriculum to the previous grade (e.g., $\mathrm{K}=1$ st grade) in an effort to ensure their children meet the new Common Core ${ }^{12}$ standards of the state. The teachers must now contend with a lot of inappropriate practices that they feel should not be a part of their

\footnotetext{
11 Practices/pedagogy that are identified as developmentally appropriate for certain age groups as proposed by Naeyc. See glossary.

12 Standards that increase expectations on children (k-12) and are consistently practiced in 43 states. See glossary.
} 
day (e.g., utilizing more workbooks and worksheets in kindergarten instead of exploring materials in centers). The teachers noted that more assessments and lessons have been added to the curriculum, but that nothing has been subtracted. Teachers have to input data all year long in reading and math, and this data directly affects their job performance ratings and evaluations. In addition, they feel that they are no longer a part of a democratic system. Important key decisions involving curriculum selection (such as math programs) are now being made without teacher input. These early childhood educators are dissatisfied with the lack of district support and services offered. This effects morale, and how teachers feel about their profession. One teacher stated, "Here bake a cake, but we don't have any eggs," when describing the lack of support from the district office. The teachers are also concerned with being reduced to a number at the end of each year, making them accountable for unreasonable goals in their SGOs. ${ }^{13}$

In Chapter Six, I delve into the theme of home and school connections and low-wage work, and how they dramatically impact the perceptions and expectations of White middle-class teachers. This is largely due to parents not having the time to be directly involved with school functions since they are working multiple jobs or shifts. I will discuss the differing expectations teachers perceive between themselves and wage-poor families. The teachers expressed a desire to collaborate with their families, but the families, who are primarily from Nigeria and Haiti, believe that school, not the home, is the place for learning.

Chapter Seven examines the tough question of race and how it impacts perceptions of school readiness. Multi-layered color-blind discourses are reflected upon within this topic, especially the discomfort of these teachers when discussing race. Issues of differing race

\footnotetext{
${ }_{13}$ School Growth Outcomes - a quantitative measure that rates the progress of the child and gives a numerical value to the teacher. See glossary.
} 
ideologies (including a newly identified one I've named "Shades of Gray"), meritocracy and race, and the combination of socioeconomic status and race, are also illuminated within this chapter.

In Chapter Eight, I reconceptualize the term school readiness by writing a letter to the local school district and listing a variety of ways the participating teachers believe we can address issues related to school readiness or the lack of school readiness in young children. There is also a call to action, i.e., a way to place this study within the context of the literature and research, that reconceptualizes early childhood studies. This includes an examination of the bigger policy picture and the future of early childhood programs in the United States. 


\section{Chapter Two}

\section{The Historical and Theoretical Context of School Readiness}

The historical context of school readiness as it relates to the promotion of deficit-based theory is crucial to the understanding of the ecology of school readiness as defined in this dissertation. In this chapter, I examine the history of early childhood programs and how they specifically perpetuate deficit discourses related to low-income non-White populations. I explore the historical context ${ }^{14}$ of early childhood programs and the rise of school readiness as a commonplace notion. I also unpack the relationship of early childhood education and its deficit context by reviewing the following: the theory of cultural deprivation, the anti-deficit ideology that critiques this theory and the rise of the standards and accountability movements (including the neoliberal school reform movement) that further shapes this ideology.

Historically, early childhood education was in large part stigmatized as poverty-based programs intended to provide services that would later increase productivity and economic prosperity. ${ }^{15}$ The historical context surrounding early childhood programs has not been predicated on the natural right of all children to receive a fair and quality education. ${ }^{16}$ I contend that early childhood programs have been historically deficit-based and designed to alleviate the

\footnotetext{
14 This only refers to the United States history of early childhood programs in the last 150 years.

15 This specifically refers to the Head Start Program in place for over 45 years.

${ }^{16}$ By this I mean a child's right to education as stated by Franklin D. Roosevelt in his 1930s address to the nation. He talked about every child having a right to an education, for the sole purpose of being educated.
} 
stressors of poverty and moral attitudes of poor people instead of designed to address the educational needs of the children and families they serve, especially low-income Blacks.

Furthermore, these programs identified impoverished young children and their families as somehow deficient and perpetuated the perception that these parents did not value education. Immigrant and non-White families were blamed for their young children's lack of school readiness. Philanthropists needed to educate the children to save them from their lack of moral upbringings. As noted below, these various early childhood programs were predicated on charity and the notion that these families lacked the moral fiber to be productive role models for their children.

In order to fully understand the participating teachers' perceptions of school readiness, it is important to review the early childhood programs of the past 150 years (including kindergarten charity schools, day nurseries, nursery schools, ENS (Emergency Nursery Schools) preschools, war nurseries and Head Start programs) and how they have shaped the discourse on the ecology of school readiness.

\section{Kindergarten Charity Schools}

In the kindergarten movement of the 1870s, which was designed by German educator Fredrich Froebel (in Germany and later in the United States), one of the purposes of the charity kindergarten was to help elevate poor non-White children from the devastating affects of urban society. Upper-class and middle-class White women (e.g.; Elizabeth Peabody) believed it was their obligation and duty to help the urban poor uneducated child and their "deficient" parents. Peabody even referred to it as a calling, much like a missionary, and pressed other reformers to 
adopt the cause (Beatty, 1995). In his manifesto, Education of Man, Froebel stated, "God is the source of all things" (Froebel, 2005, p. 2). He believed that fostering a religious spirit in young children would allow them to battle the "storms" of life (Froebel, 2005). Froebel, Peabody and other kindergarten reformers were on a mission to alleviate the stressors of poverty on the young child so that they could embrace dominant religious philosophies (i.e., Christianity). These kindergartens were called charity kindergartens and were based on the idea that a superior religion, morality and culture must be indoctrinated into the "godless." "The object of education is the realization of a faithful, pure, inviolate, and hence holy life" (Froebel, 2005, p. 4).

There were 42 public kindergartens in 1873. By 1898, there were 3,000 (Beatty, 1995). Beatty points out that, "kindergartning continued to be as normative and class biased as other forms of education" (Beatty, 1995, p. 131). Charity kindergartens functioned in large urban cities such as Boston, New York and Chicago, and primarily enrolled low-income non-White children. Whites generally believed that schooling for Blacks and other non-Whites was a charitable cause and not a common entitlement (Tyack, 2007). Therefore, a superimposed segregation existed among middle- and upper-class kindergartners and low-income, non-White kindergartners. This domination and stigmatization of the low-income non-White child continued into the next early childhood movement.

\section{The Day Nursery Movement}

The day nursery movement of the early 20th century was designed and implemented by middle- and upper-class White women. Day nurseries were funded by philanthropic groups such as the New York Charity Organization and were developed out of a direct need to help immigrant 
and other classified non-White children rise out of the depths of poverty. Polakow refers to day nurseries as "a saving strategy—saving children from vice and saving poor defective mothers from abandoning their children and descending into the moral turpitude of prostitution" (Polakow, 2007, p.5). Laura Spelman Rockefeller and Josephine Shaw Lowell worked to raise funds for these centers, which were located in urban centers. Most day nurseries were open six days a week, twelve hours per day and took charge of children aged six weeks to six years old, much like day care today. These White women "expressed great concern for the plight of small, dirty, ill behaved, lower-class children who were left alone daily, often tied to the bed post or to the casual oversight of neighbors or older siblings while their mothers went off to the factory or domestic work" (Steinfels, 1973, p. 41). To these women, day nurseries were seen as temporary havens for the moral socialization of poor children (Polakow, 2007). They were considered temporary because mothers were not supposed to work, and if they had to work, they were expected to do so only for short periods of time until they could raise themselves out of poverty.

Josephine Shaw Lowell, a leader of this movement, believed in social Darwinism and the survival of the fittest. ${ }^{17}$ According to her, "the fit should be encouraged to have children, while the unfit should be prevented through coercive means necessary, from reproduction" (Waugh, 1997, p. 118). She referred to these mothers as 'feeble minded' and in need of saving. She believed that pauperism could be cured through individual discipline. In a letter to a friend, Lowell wrote about Irish immigrants (who were considered non-White at the time) and stated, "with all of the weaknesses, I care very much for them - they are an unselfish and refined

${ }_{17}$ As proposed by Darwin in his book "The Origin of the Species" 
race...They have many virtues, and if they had a little more ballast and common sense it would be better for them and for us" (Lowell, 1883). The depression of the markets in 1873 and again in 1893 left millions out of work and it was up to her and other White middle class reformers to assist in caring for the children of "paupers" (Waugh, 1997). Lowell blamed poor people for their "weaknesses" and therefore felt obligated to help them. Blaming the so-called victim of poverty re-emerged as a theme in the 1960 s. Poverty, to these crusaders, was the result of behavioral failures and required treatment through charity and kindness. They believed that the moral adjustment of the "pauper" not only benefitted the individual but society at large. It was a primary goal of the day nursery movement.

\section{Nursery Schools}

Nursery schools, also developed around this time, were not based on custodial care, but instead were designed to meet the needs of the whole child and provide him or her with educational opportunities. These programs, led by progressives such as Margaret Naumburg, Caroline Pratt, Helen Parkhurst and Marietta Johnson, were based on Western developmental psychology and designed to provide learning experiences for the young child. These programs were either private (e.g., Dalton School, Walden School, Little Red Schoolhouse) or university lab schools (e.g., Bank Street, University of Chicago). In either case, these schools were only available for the middle and upper classes, because of their hefty tuitions.

The economic segregation symbolized by day nurseries and nursery schools illustrates the historical inequity of the two-tiered preschool system that still exists today. Day nurseries "were the embodiment of class stratification where upper class volunteers ran the board meetings and 
managed the nurseries allowing no input from matrons, staff or mothers" (Polakow, 2007, p. 5).

All the power and decision-making processes were in the hands of the wealthy fundraisers. The process and pedagogy of these centers were based on the dominant paradigm of a class-based society, in which one class (i.e., the poor immigrant) was inferior to the other. Day nurseries were created to impose White middle- and upper-class values and philosophies of culture on marginalized populations. The participants (or clients) in this movement were excluded from the process itself. Their voices were not heard or deemed important in the functioning of these centers. On the other hand, the progressive nursery schools modeled progressive education within their own class boundaries and ironically espoused inclusive philosophies even though they did not cater to families from lower income levels. The pedagogy differed as well, as the day nurseries were designed to serve as custodial care institutions that did not necessarily provide pedagogical tools to their children. In contrast, the nursery schools employed a solid play-based curriculum and advocated the exploration of materials and concepts in order for the child to increase their knowledge base (Beatty, 1995).

\section{Emergency Nursery Schools of the 1930s}

In the 1930s, the federal government under the Roosevelt administration recognized the need to help boost the struggling economy by sponsoring a variety of programs that would provide temporary relief to workers. One such program was the ENS preschools (emergency nursery schools). They offered jobs for teachers and helped families on relief receive much needed childcare services. However, the quality of the centers was uneven because some teachers had not been trained to work with young children. Former high school teachers were 
placed with young children only to realize that their job involved more than babysitting (Beatty, 1995).

In the first year, 2,979 schools were established, primarily in conjunction with public school facilities, although some were located within health centers, community centers and settlement houses. By the second year of the program the number of schools dropped to 1,900 (Beatty, 1995). The National Advisory Council of Emergency Nursery Schools was formed in order to attempt to maintain overall quality control of these schools. However, the temporary nature of these schools and the need to help "relief babies" only until families were on their own feet placed them more into the custodial care category than preschool. The Council soon realized that high teacher turnover and the temporary nature of ENS nurseries directly affected the quality of services. According to Mary Dabney Davis of the National Association for Nursery Education, the ENS nurseries "would provide an environment in which children for whom the school system is not now responsible, children under five, would be so normal and happy that they shall be relieved of tensions of worry and despair which are found in many homes suffering financial insecurity or overcrowding due to the depression" (Davis, 1933, p.90). These preschools were just another emergency relief program created to foster a stronger economy. The stigma attached to the ENS preschools as a poverty program for poor and lowincome children furthers the deficit theme of this dissertation.

\section{The Lanham Act - War Nurseries of 1940s}

During World War II, the number of women who entered the workforce increased by $76 \%$ (Beatty, 1995). They worked primarily in wartime factories. It was considered patriotic to serve 
your country by taking over men's jobs on a temporary basis. The war indirectly helped the early childhood programs flourish because they were now indispensable to working mothers. In 1943, as part of the Lanham Act, the Federal Works Agency opened 3,102 preschools (Beatty, 1995). For the first time, the federal government was interested in preschool pedagogy and preparing children for formal schooling. Fostering educational interest and growth were the perceived priorities of these schools, which were modeled upon the previous nursery schools and provided a play-based curriculum. Former ENS schools fell under the umbrella of the War Public Services Bureau. Unfortunately, the interest in pedagogy was only temporary because after the war ended so did the need for these preschools.

Gender norms of the time, which dictated that women return to the home to care for their young children, greatly affected this early childhood movement. Women were the primary caretakers of young children and were therefore responsible for their social and moral competence. Insofar as it was considered "normal" for a mother to maintain a strong attachment to her child, it could be seen as abnormal for a mother to place her child in childcare in order to go to work unless it was government sanctioned. In her research, Hayes referred to this as a paradox of intensive mothering, as working women face the challenge of being simultaneously nurturing to their children and career savvy (Hayes, 1998).

The War on Poverty - Head Start - 1960s

In the 1960s, President Johnson declared a war on poverty. He funded programs that would help alleviate the strains of poverty on urban centers. Sergent Shriver, the initial founder of the job corps, worked with an initial budget of $\$ 50$ million to form Head Start (Zigler and 
Munenchow, 1992). Zigler, one of the co-founders of this program, stated that "just a few blocks from my office at Yale there are children as neglected as orphans, preschool children who wander around outside abandoned storefronts, their very lives at risk" (Zigler \& Muenchow, p. 1992). The idea behind Head Start was to provide impoverished, predominantly non-White children access to schooling and social welfare programs before the age of five so they would be ready for formal schooling. The program was designed to satisfy the complete needs of the preschooler, including parental workshops, health visits, social worker visits and dental programs. There was a dual objective to Head Start, however, which is a paradox, as it deals with school readiness on one hand but was also designed to meet the whole needs of the preschool child (including socioemotional development). The tension in these dual objectives is that a hyper focus on academic readiness can come at the expense of meeting other needs. Ironically, Head Start has never been funded through the Department of Education, but remains regulated under the Department of Health and Welfare. It is categorized as a war on poverty program and not an educational program, even though it is touted as the model preschool program. ${ }^{18}$

Head Start, much like earlier early childhood programs, was based on the notion that a specific population had a perceived deficit. This theme re-emerged from the history of early childhood programs in the United States, when temporary programs were created to enforce imposed assumptions of cultural deprivation. Michael Katz, a historian, openly opposed Head Start because he stated it "was founded on the idea of cultural deprivation" (Ames \& Ellsworth, 1997, p. 4). The notions of cultural deprivation and the imposition of a White middle-class value

\footnotetext{
18 It must be noted here that there was no formalized Department of Education in the 1960's but when it was established later Head Start was still not transferred to this department.
} 
system on marginalized children (such as low-income Black children) were similar to the day nursery movement some 50 years earlier.

Furthermore, these historical early care movements emphasized a deficit-based model, as they were based on economics, naturalization, religion and other mainstream value systems, instead of educational pedagogy. The programs assumed the low-income non-White populations they targeted suffered from cultural deficits. The imposition of normative White middle-class Christian values during the past 150 years is indicative of the nature of early childhood education today as it continues to function in a two-tier society where low-income preschoolers either do not have access or have limited access to quality institutions.

In summary, historical early childhood programs that have informed modern efforts to determine school readiness in young children have been biased and deficit-based. This perceived deficit was not just attributed to the young child but to the child's entire family. This deficitbased model eventually became a theory in the 1950s-1960s that legitimatized today's continued bias against low-income non-White young populations.

\section{Theory of Cultural Deprivation and Critical Perspectives (Anti-Deficit Theory)}

The theory of cultural deprivation is paramount when considering the historical context of the deficit history of early childhood programs. It encompasses the cultural deficits of lowincome non-White young children and their families. Even though the term cultural deprivation gained prominence in the 1960 s, the theory itself related to the entire historical context of early childhood programs dating back more than 150 years. The term postulates that certain populations (non-White and low-income) are both environmentally and biologically deficient 
and are therefore in need of extra support (Bloom, 1964; Herrnstein \& Murray, 1994). The term school readiness relates directly to this premise, as it is also based on the supposed deficiencies of populations. Marginalized populations need school readiness skills (and therefore a head start) in order to function effectively within the school system.

The theory of cultural deprivation is based on the research findings of Bloom, Hunt and McKiver. In 1964, Bloom listed over 116 empirically based research studies as evidence of the existence and importance of the theory. At the 1964 University of Chicago educational conference, key academics presented research papers about this theory and offered specific recommendations to counteract the worrisome increases in the achievement gap or achievement "deficits"(as cited by Bloom, 1964) between low-socioeconomic classes (referred to as "Negros" at the time) and the White middle class. Examples of research studies from the 1950s and 1960s included Empey (1956), whose findings concluded that low-income youth did not aspire to achieve, Vera's (1963) findings that low-income children were unable to acquire or utilize abstract language skills, Krugman's (1961) research that illustrated the effects of cultural deprivation on low reading test scores and Weaver's (1963) findings that "negro" low income children were deficient in auditory learning practices (as cited in Bloom, 1964). These studies emphasized the cumulative deficits of this population in the schooling process, one that they referred to as alienating and disruptive to their possible academic achievement.

At the same time, the Moynihan report,The Negro Family: the Case for National Action, surfaced and received critical attention. Moynihan believed that the Black family itself was a detriment to the quest for civil rights (Rainwater \& Yancy, 1967). The report focused on the socalled deterioration of the Black family (e.g., dissolution of marriages, illegitimate births, single 
mother households, increase in welfare dependency) (Moynihan, 1964). Moynihan and others (Gary \& Klaus, 1965; Hunt, 1961; Riessman, 1962) specifically cited these Black families as culturally deprived due to the following factors: lack of a male figure in the household, lack of interaction with the child, lack of interest in the child's education, low educational levels of the parents, poverty and limited language skills (Bloom, 1964; Hunt, 1961; Gary \& Klaus, 1965; Riessman, 1962; Moynihan, 1964).

\section{Critical Perspectives: Anti-Deficit Theory}

Scholars known as anti-deficit thinkers (Labov, 1973; Pearl, 1997; Valencia, 2010; Keddie,1973) attacked the basic premise of the cultural deprivation model, which essentially blamed the victims (low-income Black students) and their families for their perceived school failure.

Valencia $(1997,2010)$ referred to the theory of cultural deprivation as a deficit model. He concluded that there were six basic characteristics of this deficit model:

1) Blame the victim. The theory chastises the population it is trying to help.

2) Form of oppression. The theory further marginalizes and oppresses the populations involved. 3) Pseudoscience. The evidence, which is based on on prior research, is not necessarily valid.

4) Dynamic model that changes according to historical times. The theory is known as a standby theory because it can be utilized differently during different time periods.

5) Mode for the educability of the child. The theory can be utilized as a way in which to think about the specific pedagogical practices required for this particular population.

6) Controversial by nature. The theory will always be controversial 
in the realm of education.

According to Valencia, this model continued to be utilized in the field of education because it could explain the school failure of economically disadvantaged Black populations within the larger school system (Valencia, 2010).

In his breakthrough book, Keddie (1973) compiled a variety of articles from the time period that refuted the deficit model. Labov directly assaulted the notion of "negro"19 children as being verbally deprived. He contended that there was a great deal of verbal stimulation in their homes, but due to the "caste system" inherent in our society, educational researchers and policymakers could not comprehend the differences in verbal acquisition or language differences (Labov, 1973). This was due to a language hierarchy; all other dialects and slang were considered below standard English. Postman, another anti-deficit scholar, centered his research on the "political act of reading." He believed that schools were "designed to produce one sort of human being rather than another" (Postman, 1973, p.83). His research concluded that the educational system itself was responsible for the reproduction of certain types of values and beliefs (normative practices) and was not inclusive of marginalized populations (Postman, 1973).

Cultural deprivation was, therefore, a product of this inequitable system.

Furthermore, Ryan (1971) and Pearl (1997) both concluded that blaming low-income Black students and their families and identifying them as victims was not the answer to the widening educational achievement gap. Ryan (1973) argued against the notion that any one individual or family could be the problem. Rather, he placed blame on the educational system,

\footnotetext{
19 This is the language originally utilized in the research by Bloom, so many of the anti-deficit thinkers of the 1970 s utilized the same language on purpose.
} 
citing school segregation, inequities in funding and a lack of cultural insight on the part of the teachers and the schools as reasons for this inequity. Pearl (1997) contended that the problem resided within the schooling institution itself and would continue to flourish and mature so long as educators and policymakers needed a scapegoat to explain the ills of the public school system (Pearl, 1997).

The Context of High Stakes Testing/Accountability Movement:

According to Valencia \& Solarzano (1997), the theory of cultural deprivation experienced a resurgence during the 1990s, as educators and educational researchers utilized at-risk constructs and terminology to describe certain underperforming populations. The rise of high stakes testing inflamed the deficit model resurgence as at-risk students (low-income non-White students) were blamed for their lackluster test scores. Valencia referred to this specifically as "a modern form of educational oppression" (Valencia, 1997, p.5).

Furthermore, the No Child Left Behind Act (which was supposed to culminate in 2014) and the Race to The Top program further the deficit approach. The general premise for these measures is to close the gap between normative students (White middle class) and 'deficient' students (low income non-Whites). High stakes testing is supposed to reveal which schools are doing their job and which schools need to be shut down. The individual scores of each student determine whether specific teachers and, by extension, the schools are efficient or not. Ravitch makes it clear that testing alone can not identify and reveal troubled schools.

The problem was the misuse of testing for high-stakes purposes, the belief that tests could identify with certainty which students should be held back, which 
teachers and principals should be fired or rewarded and which schools should be closed (Ravitch, p. 150, 2010).

According to her, the testing and accountability movements do not reform schools and close the educational gap. There are too many factors that interfere with reliable testing results, including widespread cheating by educators, schools where children with disabilities are not tested, schools that transfer children with low test scores to other schools, principals that restricted admission of low-performing students, expansion of the pool of test takers that required special accommodations (so they would benefit from extra time, scribes or one-on-one aides) and schools that spend all year solely teaching to the test (Ravitch, 2010).

The No Child Left Behind Act was designed to fail. By 2014, all children were expected to achieve $100 \%$ proficiency in reading and math. This was an impossible goal to reach. It set schools up for failure and held school administrations, teachers and students accountable for not measuring up. Teachers and administrators felt they had no choice but to do anything possible to save their jobs (including cheating) due to the pressure to achieve perfect proficiency. Furthermore, the allocation of federal funds through Race to the Top was tied to these measures (Ravitch, 2010). Unrealistic goals put more pressure on the teachers, especially educators located in low-income schools with non-White populations.

The goal of accountability should be to support and improve schools, not the heedless destruction of careers, reputations, lives, communities and institutions (Ravitch, p. 166, 2010). 
Everyone lost - the teachers, the administrators and especially the 'deficit' children, who were now more visible and more vulnerable, and officially branded as deficient students. The at-risk constructs were now replaced with terms such as "ineffective" and "not proficient" and deficit children fell more behind as the achievement gap widened.

Later chapters further address the so-called educational reforms of high stakes testing and teacher accountability, which are a product of a neoliberal agenda (see below) that furthers a deficit discourse and neglects to address the macro-economic factors imposed on low-income non-White populations in schooling.

\section{The Political Economy of Early Childhood Education}

The term school readiness is a part of the present day neoliberal discourse surrounding public schools. I utilize Harvey's definition of the term neoliberalism, as a theory of political economic practices that advances entrepreneurial freedoms (Harvey, 2005). His term, 'accumulation by dispossession' refers to corporations/entrepreneurs making a profit while others do not. This is directly tied to the continual marginalization of other populations such as poor/low-income people (Harvey, 2005). The political economy of early childhood programs is based on the marketization of young children. In order for children to succeed as adults in the free marketplace, they need to be school ready. Big business and corporations are a part of this commodification of education as they sell products to aid in children's school readiness (i.e., ABC Mouse, Kuman, Huntington Learning Centers, Sylvan, Kaplan). In the past ten years, public education has begun to resemble a business enterprise with increasing numbers 
of educational leaders boasting a business background (i.e., Bloomberg, Gates, Walton, Klein). The corporate model is now an acceptable practice in the governance of public school districts.

\section{$\underline{\text { School Districts as Business Models }}$}

The teachers in this study express strong opinions about running school districts as businesses. One of the participating teachers (Ms. Springstein) stated, "We are not a business. We are not a business." More leaders and district personnel possess business backgrounds but have spent very limited time in early childhood classrooms.

They think they can fix education by applying principles of business, organization, management, law and marketing and by developing a good data-collection system...with appropriate rewards and sanctions (Ravitch, 2010, p.11)

School districts attract business-minded supervisors and principals. In the district where this study was conducted, the recently departed superintendent was a non-educator and had no classroom experience. His main concern was data and the surveillance of teachers through data controls. During his tenure, he imposed a variety of data controls, including the input of reading and math scores in computerized systems. Before he came to this district he served in a supervisory position at the New York City Department of Education, which was run like a corporation under Mayor Bloomberg. Mayor Bloomberg acted like the CEO of the Department of Education and had total control. Neither he nor his superintendents possessed a background in education. Like Bloomberg, the superintendent of the district where this study was conducted believed that a public school system should be run like a corporation that happens to be in the business of education. However, educational systems cannot be run like businesses. 
Supervisors, superintendents and principals need to understand that they are working for a public school system and not corporate business enterprises.

Furthermore, the business model of education also places a greater value on the school ready child. There must be school ready and non-school ready children for this system to operate. Identified school ready children are going to do well within this business model, because they already understand the culture of school and are prepared to work towards higher test scores (the White middle-class child). The non-school ready child, on the other hand, will not flourish within this model, but instead will be more at risk because he or she will not assess well. This will lead the non-school ready child to special education classification, retention and the possibility of dropping out at a higher grade. If you are not successful in the business world, you are forced out. In education, it is a much longer process, but the non-school ready child is more likely to eventually leave the mainstream system (e.g., special education pull-out, selfcontainment classes, ELL, dropping out).

\section{Human Capital Theory and the Very Young Child}

According to Becker (1994), a member of the Chicago School of Economics and a key player in this discourse, particular investments in humans (such as education) can lead to greater business returns (Becker, 1994). This human capital theory directly affects our current businessoriented educational system. People are only as important to society as their contributions to our growing economy (Keeley, 2007; OCED, 2007: World Bank, 2003). Becker's empirical research reveals that people with a high school diploma generally earn more money and therefore contribute more to a growing economy. 
Keeley's definition of human capital theory postulates that "the years we spend in education generate a form of capital that has the potential to produce a long-term return" (Keeley, 2007, p. 11). Thus, education is the key to forming capital in a child. Without education the child cannot enter the "knowledge economy" and contribute to the growth of the economy. The knowledge economy refers to so-called developed countries, such as the United States, that are a part of the global economy. These countries specifically invest in research and development, including education, in order to fuel the growth of their respective economies.

In their book, The Economics of Investing in Universal Preschool Education in

California, Karoly and Bigelow explore this idea of future investments related to young children. Like Keeley and the Rand Corporation (which published their study), their research reveals that the more tax dollars states (or countries) invest in early childhood education programs the greater the returns to their future economies.

A one-year high-quality universal preschool program in California is estimated to generate about $\$ 7,000$ in net present value benefits per child for California society (public and private sectors). This equals a return of $\$ 2.62$ for every dollar invested (Karoly \& Bigelow, 2005, p. xiv).

If a state (or country) is making a profit of $\$ 2.62$ per each dollar invested in early childhood programs, it is a boost to the economy. Karoly and Bigelow take it one step further as they believe that these economic investments help the state (or country) to better compete globally in the world's economic markets.

The education and skills of the workforce increasingly determine the ability of an economy to compete in the global marketplace. California, with the sixth largest 
economy in the world and one on the leading edge of globalization, is no exception (Karoly \& Bigelow, 2005, p. xxxv).

This means that a further benefit of a stronger local economy (such as California) is to also be more competitive in the worldwide marketplace. Human capital theorists believe in economic growth, return on investments and ultimately being competitive in the larger global economy. Therefore, the entire education system becomes a tool that leads to future economic growth and successful competition in the global marketplace.

Furthermore, this theoretical approach to public schooling becomes more about what the child will contribute to the future economy, rather than the child learning for the sake of learning and developing human relationships that can later contribute to the public good. This ties into the history of early childhood programs, which were tied to economic growth (e.g., Head Start, ENS schools). Being a part of the larger global economy and contributing back to the local economy (through paying taxes and labor) are more important than the individual child gaining knowledge about the world, developing agency and the capacity that allows for agency in early childhood settings. In her research, Adair reveals that agency is a tool for improving learning experiences because it affords a varied and dynamic learning experience to a young child. According to her, this stands in contrast to the overall emphasis on preparing young children for testing (Adair, 2014).

The discourse of human capital theory feeds into the business model approach to public schooling because it emphasizes the importance of children, even young children, mastering all of the administered assessments so they can eventually graduate from high school and contribute to the free market economy. In order for these assessments to succeed, it follows that it is 
essential for the young child be school ready. Programs such as Head Start fuel this discourse by promoting school readiness as their goal. They believe a head start given to low-income and impoverished students will help them achieve better grades and advance further in school.

\section{The Commodification of Education}

Education on the whole, including early childhood education programs, is now a part of the larger educational industry run by the private sector. Profit is generated through educational products and services that promote school readiness in young children. This makes school readiness big business. Private companies (e.g., ABC Mouse, Kuman, Huntington Learning Center, Sylvan, Kaplan Inc., Princeton Review) actually earn huge profits by offering products that are based on the discourse of the non-school ready child. "Kaplan says revenue for its elementary and secondary school divisions has doubled since No Child Left Behind passed" (Meier, 2004, p. 87). It only follows that the adoption of the Common Core ${ }^{20}$ will allow these same private sector companies to continue to reap similar profits. It is important to note here that these big corporations need the adoption of a Common Core, as then they can gear programs to one main set of standards.

These services and programs are highly competitive and costly. They are advertised to low-income families that cannot afford them. For example, Kuman ${ }^{21}$ is a chain of tutoring centers and one is located in this study's school district. Several of my parents (all low-income Black families) utilize these services with the hope that their children will fare better in school.

\footnotetext{
20 The Common Core is the latest set of standards being utilized in 43 states in the USA. - See glossary 21 Prices are not provided over the phone. Parents must go to a center and have their children tested before prices are given for tutoring services.
} 
This program consists of hundreds of drill sheets that children spend hours completing after a long day of school. As a first-grade teacher I have not found these drill sheets to be successful, particularly because they utilize the same style of auditory learning with every child. This method does not work well with children who are visual learners or who have sensory issues. Meanwhile these parents work extra jobs to afford these services and are dismayed when they do not result in improved performance.

Different educational companies (including Pearson and Houghton Mifflin Harcourt) have made enormous profits by selling products that promote school readiness. They sell programs that require individual school districts to purchase updates or additional materials after a few years, which leads to more profit. An example of this is Pearson, an educational conglomerate that sold the school district in this study the Tango application ${ }^{22}$ for the input of $\mathrm{DRA}^{23}$ data. They sold the rights to the district, changed the application a few years later and then required the district to buy the new application since the old one was no longer in service.

The Pearson website promotes a large number of different for-profit programs to help teachers, school districts and other education professionals. Interestingly, several of the key players at Pearson are also developers of the Common Core and other state standards. Skip Fennell and Karen Wixson, both professors at four-year research universities, are promoting Pearson programs because they are specifically designed to complement the Common Core. Fennell also wrote the math standards for the National Council of Teachers of Mathematics,

\footnotetext{
22 This is an application that works in conjunction with the Development Reading Assessment. Teachers either input the data while administrating the test or afterwards. In either case, the district then has the independent and instructional levels of each child in each classroom and can run data more effectively.

${ }^{23}$ Developmental Reading Assessments are tests that measure the each child's independent reading level. See glossary.
} 
which claims to be the "global leader and foremost authority in mathematics" (www.nctm.org).

He is the developer of Pearson's "Successmaker," a math program geared towards early childhood populations. Wixson is the developer of Reading Street, a Common Core-aligned reading program for young children. Pearson promotes these programs (including writing and digital programs) to individual school districts in states that have adopted the Common Core. These programs run at least $\$ 10,000$ each and exemplify how a private publishing company can make sizable profits beyond the textbook market.

Another example is Math in Focus, published by Houghton Mifflin Harcourt. This educational company convinces districts to purchase its product, which requires the purchase of new workbooks on annual basis, and returns two years later to convince districts to buy supplemental programs to help boost their students' math scores. Math in Focus, the U.S. version of Singapore Math, is being highly touted as the math program that will increase test scores. When I attended my first Math in Focus workshop, the representative spent a great deal of time talking about the high math scores in Singapore and how the U.S. needs to compete globally in this area. Thus, allusions to global competition and promises of higher test scores are used as carrots to promote the product as one that is ideal for teaching Common Core standards.

Kumon and other educational tutoring companies are also making huge profits from the states' adoption of the Common Core. If more young children are behind in reading and math, which they inevitably are because the standards have been unreasonably raised, parents will be more desperate to seek help for their struggling children. Kumon promotes itself as "the world's largest after-school learning program" for grades pre-K through 12. It is a franchise corporation, with locations in 48 countries, that reaps huge profits from working parents. Kumon believes it 
provides long-term solutions because it teaches young children how to study more efficiently. The program requires parents to first have their children tested at a center. Once evaluated, the children attend after-school sessions twice a week. The students are also supposed to work on individualized worksheets at home three additional times a week. This is a huge time commitment for young children, who must complete worksheet after worksheet. The philosophy behind Kumon is "point, repeat, look, listen and repeat." Drill sheets (reading/math problems) are completed, checked and repeated. This method is supposed to help the young child to prepare for future standardized testing (www.kumon.com). There are no prices listed on the website, but their programs are costly and add up over time, especially for the low-income parent.

Other digital programs are also geared towards the working parent of young children. These programs (such as $\mathrm{ABC}$ Mouse) also benefit from the adoption of the Common Core and higher statewide standards. ABC Mouse, which airs many television commercials on children's TV stations (e.g., Disney Junior and Nick Junior), provides a complete online curriculum for ages 2-6. The company offers more than 3,000 different learning activities, but is especially known for helping children learn to read (primarily decode) at an earlier age (www.abcmouse.com). ABC Mouse markets these programs as being aligned with public schools in the states that have adopted the Common Core and touts its programs as a way for the young child to get a head start on formal schooling. The company is therefore primarily marketing its programs to preschool-age children so that they are better prepared for the reading assessments given in kindergarten and first grade. It offers a free one-month trial and then bills 
parents $\$ 79$ per year for continued access. Anxious parents who want their young children to be kindergarten ready sign up for these types of programs daily.

There is a direct link to the new Common Core standards and the for-profit education industry. These companies (such as Pearson) need the alignment of common standards nationwide in order to offer programs that meet these particular standards. Also, as the standards are raised and expectations increase, more children are classified as below grade level. In turn, the businesses that provide supplemental services, such as tutoring and computer programs, make huge profits.

In summary, the examination of the historical context of early childhood programs demonstrates that the rise of the theory of cultural deprivation of low-income non-White children and the history of the testing and accountability movements of the 90 s and 2000s all impact how teachers perceive "deficient" low-income Black children in their classrooms. Negative and deficit-based perceptions of these at-risk and disadvantaged children are already assumed before the White teacher evaluates who is or is not school ready. Furthermore, the context of the political economy of early childhood education is very important in relation to school readiness, as the neoliberal discourse furthers this deficit theme by categorizing public schooling as a commodity and therefore as a business enterprise. Corporate networks are making direct profits from these raised standards and are therefore blurring the line between the public and private sector.

In the next chapter, I present the methodology of this research study. I delve into the specifics of constructivist grounded theory within a critical approach and how this research 
methodology frames this study. I also clearly explain the methods involved in this study and how they were utilized and analyzed. I reflect on the research process itself, including all of the validity concerns I encountered. The participating teachers and identified non-school ready children are also introduced in the next chapter. 


\section{Chapter Three}

\section{Methodology}

In this chapter I analyze and synthesize how I chose constructivist grounded theory within a critical approach as the methodology for this research study, and how I used the theory within this research study. I also reveal and reflect upon the ethical concerns and dilemmas that I encountered during the research phase, and how I individually addressed these issues so that they did not conflict with the overall validity of the project. I confront the quest for validity as well as the specific methods I used in order to answer the research questions posed. These methods included a survey of the district's kindergarten and first-grade teachers $(n=24)$, interviews of five early childhood educators, in-class observations of five identified non-school ready children and two focus groups (one with the teacher participants and one with six other K-1 teachers in the district). I also introduce and provide background on each teacher and identified non-school ready child involved in this study.

\section{Constructivist Grounded Theory: How it Was Chosen}

Constructivist grounded theory was not the first method I chose for this research study. Interestingly, throughout my graduate school career, I utilized a critical theory approach to my research projects. After studying grounded theory (Strauss/Corbin) in a qualitative research course, I initially dismissed it as a positivist methodology that did not relate to my own research lens and was too scientifically based and not sufficiently critical. I wrote two different proposals 
for my dissertation project that relied on a critical theory approach. This was before I started my research.

In the spring of 2014, I took a course on research methods and analysis with my advisor. At the same time I started my research for this project and sent out my online survey, and started interviewing and observing my teacher participants. As I progressed, constructivist grounded theory as an approach seemed more compatible with this particular study, as it helped me make sense of the complexities within the data. In a research journal entry, entitled "I am a grounded theorist," I wrote about this revelation:

As I wrote reflections on my own position as a researcher, in "My position is me" and "My life as an outlier," I realized that constructivist grounded theory was in fact the best course to take in this process. In my literature review I came up with several theories on why White teachers may have preconceived notions that portray non-school ready Black children in a deficit light. And then as I started, and now that I am in the thick of it, I realized that I need the data to speak to me, that the answers are from within the data and not from my adherence to previous theories. I also realized that the process needed me to be constantly reflective and theoretically sensitive to my own positions/discourses in order to truly see what is going on here. By being immersed in the data, developing and naming categories that emerge I can build new theories that can answer my specific research questions.

I had not been prepared to be so self-reflective about the data. Constructivist grounded theory forced me to do this, which in turn helped me in the analytical process.

The research phase was transformative for me. I listened and observed, and reflected on my own personal biases. I became sensitive to my own subjectivity and how this could affect my 
research process, which required theoretical sensitivity, flexibility and creativity, all of which intrigued me as a student and researcher. Reflective practice had always been of paramount importance to me, both as a doctoral student and a first-grade teacher. I started to see how these attributes would help me in my research process. I read Charmez (2014) and her groundbreaking work on constructivist grounded theory. I started to read about all of the varieties of coding that would help me analyze my data. I became steeped in my data as I collected it, thinking and reflecting and pre-coding, coding and coding again line by line. I began to see different relationships within the data, which transformed any fixed ideas I had.

Charmez's book, Constructing Grounded Theory, confirmed to me that I was on the right track. Charmez talks about constructions rather than discoveries, and how we, as researchers and people, make constructions based on our own preconceived ideas. This means that I had to be very aware of bringing my own assumptions and subjectivity into the research process. Engaging in reflexivity was mandatory as a researcher and although I thought I was being reflexive in my research inquiry, I realized I harbored presumptions that were clouding my interpretation of the data. For example, I went into the research phase pretty confident that I would uncover a straight color-blind discourse among the teacher participants. Much to my surprise I realized that multiple layers surround the issue of race and how teachers deal with race in their day-to-day lives (see Chapter 7). Writing memos on this new approach and examining all of my preconceived ideas as I started the interviewing and observation process were paramount to the effectiveness of this method of research. It was difficult to do this (which I discuss later in this chapter), but it felt right for the project. As a White early childhood teacher myself, I was part of the world I was studying and therefore had to examine my thoughts and expectations of 
what teachers would say and do within the research process. In order for that process to be a mutual dialogical experience, I had to listen to the participating teachers and what they had to say, instead of superimposing my own assumptions and preconceived ideas on their interviews.

Furthermore, I found that constructivist grounded theory was a perfect tool to act on and interact with the data itself. If I had a question that required further examination (which I did many times), I could go back and ask the teachers to clarify or expand on the discussion. An example of this occurred during the participant focus group. I noticed in my individual interviews that each teacher talked about a difference in value systems (between the teacher and the child's family) and I wasn't sure if the teachers meant that they saw two distinctly different value systems or a single value system that low-income Black families were unable to attain. Digging deeper into this question revealed more complex answers from the participants that I address in subsequent chapters. This process allowed me to thoroughly examine what the teachers said or tried to say, rather than simply inserting into the research my interpretation and analysis of what they said.

Categories and themes had to be constructed from the data itself, and not from me or how I previously thought these teachers would respond (Charmez, 2014). I also had to learn to live with ambiguity and accept that I would not always be able to see my way through the data the first, second or even third time I read through it. I needed to be open to the unexpected. "A flash of insight or instantaneous realization of analytic connections can happen any time during the research process" (Charmez, p. 17, 2014). And it did. I drove in my car and listened to my audiotape interviews, stopping to write my constructions and thoughts in my research journal or record them into a handheld tape recorder. Sometimes I simply wrote a question or notes about a 
detail I needed to further explore or that didn't make sense. For example, I remember speaking at length into my mini-tape recorder as I drove home from an interview, wondering aloud about Ms. Springstein's quick dismissal of the question of race. I played the relevant section of the interview and then spoke into the mini-recorder, analyzing her comments. Once in my office I wrote a summary memo memorializing my response to her dismissal of the topic of race.

I kept a $\log$ of all of my memos so I could later refer to them, by title and letter (e.g.; Memo R, "the school is different than the others"). This helped me to synthesize during the analytic phase of the research.

Memos form the core of your analysis and record how you arrived at it. You write memos throughout your research. Memos provide ways to compare data, to explore ideas about the codes and to direct further data-gathering (Charmez, p. 19, 2014).

I further discuss my memo writing and how it informed my process in the data analysis section below.

\section{$\underline{\text { Insider Status }}$}

As I explained in the Introduction, one of the main reasons I decided to pursue this specific project is that as a first-grade teacher I was interested in exploring how this observation, that more low-income Black children are classified as non-school ready, came to be a phenomenon. I found that I had been contributing to this trend myself by only sending lowincome Black children to the child study and intervention teams. I teach in a school with a large Black population, situated in a low-income neighborhood, and I am, just like my teacher 
participants, a White middle-class female with preconceived ideas about what makes a child nonschool ready. I could have been a participant in my own study.

There were some real positives to my insider research status. As a first-grade teacher myself in the same learning environment, I could relate to the teachers' responses and had an understanding of the language they used. I felt comfortable with the teacher participants in my project, having known them to some degree beforehand. They, in turn, seemed to feel comfortable with me and were very candid in their responses. There was a sense of camaraderie and mutual respect, and an interest in the subject of school readiness. Teachers invited me into their homes, offered me food and drinks, introduced me to their family members and genuinely seemed interested in talking with me. Luttrell, a noted qualitative researcher, states, "people who might otherwise avoid participating in research are often more likely to agree to participate if they are recruited by someone they know, respect and trust" (Luttrell, 2010, p. 7). We had lengthy conversations that were simultaneously open and honest, humorous and serious. We laughed together and shared our private thoughts and hopes for the future of the school district. The project brought us closer together as colleagues and as friends, which I did not expect. This is a strength of qualitative research, as it is a co-constructive process. ${ }^{24}$ This means that we worked together as a team to make meaning from the data. This process was especially effective in our participant focus group where we all looked closely at the data and discussed it.

Before I started the research, I had concerns about my insider status and how it might affect the research process. I thought that it might be awkward for the teachers in my study to be

\footnotetext{
24 I want to clarify my stance as a participant observer and acknowledge my epistemological position that as an insider with local knowledge I am a part of the research process. Thus, throughout this dissertation I utilize this local knowledge as a participant observer and give examples in my own teaching that relate to the overall findings.
} 
observed by me, a fellow teacher. In the beginning, I did notice that some of them seemed a bit uncomfortable. I think they wanted to impress me and show me that they were in fact good teachers, but I reassured them that I was only interested in the non-school ready children and how they interacted with them, and that I wasn't there to judge their teaching or to comment on their educational practices. For example, one teacher was concerned that her children were a bit rowdy when I arrived for a classroom observation because they had just had a birthday party, which included cupcakes. I reassured her that I was not evaluating the children's behavior. After the initial visit, however, they all seemed to relax and go about their lessons, without giving me much thought.

Another previous concern I had was that the teacher participants might be unintentionally offended by or defensive about my interview questions. I did not want to offend them and it was very important to me that we remain on good terms because we work together, and would continue to work together for at least some time. I encountered this in a few areas, especially when discussing race. I noted that they seemed uncomfortable responding to my question on how, if at all, race was a factor in a child being non-school ready (see Chapter 7). I had to be careful in this area, as I did not want to push them and force them to address a topic that might make them uncomfortable. In some cases I had to drop the subject of race and move onto another topic. Race sometimes came up in subsequent discussions but I only pursued it if the teachers were open to discussing it. There was some avoidance of this topic. They were, however, open to discussing other controversial matters, such as lack of district support, district personnel, etc. 
At first I found myself questioning some of their responses, and did recall making some judgments about my participants. I recognize that research is not a neutral process and that my subjectivity would manifest itself. Yet I was surprised by some of their responses. For example, in the background interview, all five teacher participants brought up Christianity and how it shaped their formative years. I was not prepared for this as I had no idea that they all shared a religious Christian upbringing. I wrote about my reflections on this topic in memo B, "The Position of Me." It made me realize in a concrete way that my personal belief system and bias against Christianity might influence the research process.

During the interview, I noticed that I winced inside my head at certain points in the conversation. As the participant spoke about her religion and how going to church was very important to her, I felt comments forming, but I remained quiet. I had to focus and try to stay in the moment of listening to her. I am not a religious person in the first place, but church has never been a comfortable place for me. I grew up Jewish and was very guarded about it, as I had been called names (devil child, Christ killer, Kike, etc.) These are not fond memories (from growing up in Ohio) and all the children around me were Christian and went to church regularly. I distinctly remember girls combing through my curls looking for horns, convinced that I had horns because I was not Christian. I was also forced to stand up in kindergarten, first grade and second grade to say the Lord's prayer every day in school (a public school). This was very awkward for me as I never remembered it. Anyway to this day, I do get tight and a little anxious when I walk into a church.. 
When writing this memo I realized that I was, on some level, different from my teacher participants, and that I needed to be very reflective about my own positions during the research process. I wrote:

I am now really aware of what I bring to the research process. My background, my lens is clouded by my past experiences, whether negative or positive. It is like reader's discourse theory, the reader brings their own understandings and life experiences to their interaction with the text. Well, now I am interacting in the world of research and I am hyper aware of what, I, as the researcher brings to the process. It's about them. And yet, I am always present and must be aware of myself and my own perceptions at all times.

After I wrote this memo, I felt better able to listen to the participants talk about religion and Christianity, and how it affected their upbringings. It made me more keenly aware of the importance of this theme. I even asked them during the second interview to expand on this theme by inquiring how their religion affected them as teachers and how religion presented itself in their classrooms. This is a part of the constructive grounded theory process, as I listened to what they thought was important and then went back and asked them to expand on it.

In memo C, "My life as an outlier," I traced the differences between the participants in my project and me. As I was interviewing them I realized that I was not the same as them, and that I had a variety of different background experiences. The teacher participants were different from each other as well. As I analyzed the initial background interview, I made a table depicting how the five participants related to one another (see Table 1). Upon examining the table, I realized that I did not fit into these categories. For example: 
The participants

raised in mostly White

area

raised in the church

had mom and dad

mom stayed home

lived in suburbs

parents not college graduates
$\underline{\mathrm{Me}}$

diverse area

raised Jewish

only mom

mom worked

lived in city

parents college graduates

Table 1 - Participants background:

\begin{tabular}{|c|c|c|c|c|}
\hline$\# 1$ & \#2 & \#3 & \#4 & \#5 \\
\hline Church & Some church & Church & Church & Church \\
\hline mom home & $x$ & mom home & mom home & mom home \\
\hline From state & From state & From state & $x$ & From state \\
\hline $\mathrm{mom} / \mathrm{dad}$ & $\mathrm{mom} / \mathrm{dad}$ & $\mathrm{mom} / \mathrm{dad}$ & $\mathrm{mom} / \mathrm{dad}$ & $\mathrm{mom} / \mathrm{dad}$ \\
\hline $\begin{array}{l}\text { Parents no } \\
\text { college }\end{array}$ & $\begin{array}{l}\text { Parents no } \\
\text { college }\end{array}$ & $\begin{array}{l}\text { Parents no } \\
\text { college }\end{array}$ & $\begin{array}{l}\text { Parents no } \\
\text { college }\end{array}$ & Parents no college \\
\hline Middle class & $x$ & Middle class & Middle class & Middle class \\
\hline Same house & Same house & Same house & Same house & Same house \\
\hline $\begin{array}{l}\text { Good } \\
\text { student }\end{array}$ & $x$ & Good student & Good Student & Good Student \\
\hline $\begin{array}{l}7 \text { years } \\
\text { home with } \\
\text { children }\end{array}$ & $\begin{array}{l}8 \text { years home } \\
\text { with children }\end{array}$ & $\begin{array}{l}3 \text { years home } \\
\text { with children }\end{array}$ & $\begin{array}{l}10 \text { years home } \\
\text { with children }\end{array}$ & $x$ \\
\hline Work ethic & Work ethic & Work ethic & $x$ & Work ethic \\
\hline $\begin{array}{l}\text { Never lived } \\
\text { anywhere } \\
\text { else }\end{array}$ & $\begin{array}{l}\text { Never lived } \\
\text { anywhere else }\end{array}$ & $\begin{array}{l}\text { Never lived } \\
\text { anywhere else }\end{array}$ & $x$ & $\begin{array}{l}\text { Never lived } \\
\text { anywhere else }\end{array}$ \\
\hline $\begin{array}{l}\text { th } \\
\text { generation }\end{array}$ & 3rd generation & 4th generation & 4th generation & 4th generation \\
\hline
\end{tabular}


A large part of our differences revolved around race and our backgrounds related to race. For example, after leaving Ohio, I grew up in a majority Black community in Brooklyn, New York during the White flight of the 1970s. I was one of two White children in my elementary school classroom and at times it made me uncomfortable. My mom worked at an all Black college and I was always the outsider, the minority, the other. My mom felt that being Jewish helped her gain acceptance into this all-Black world, as she grew up feeling different and outside the mainstream, too. When I was younger and living in Ohio, we struggled with anti-Semitic comments and actions by our neighbors. I remember my mom telling me that I should be proud of my race (she considered Judaism a race) and that I would someday fit in with others. This experience helped me navigate my world in Brooklyn where I had a different skin color. I felt more accepted, interestingly enough, in the Black world of Brooklyn than I previously felt in the all-White Christian world of Ohio.

As I got older I realized that I felt uncomfortable when Black people were absent from the geographical space around me. I still feel this way when I travel and am more aware of this today, as my spouse is Black and my two children are bi-racial. Even with this different upbringing I still experience moments of discomfort around issues of race, because I am not Black and do not fully understand what is it like to be Black in our society. Furthermore, as a White teacher in a classroom where 14 out of 21 children are Black, I reflect on this issue daily and wonder how it affects my perceptions of and assumptions about school readiness.

As I stated earlier, it is also important to note that I perceive myself to be an outlier within this study. I did not, as did my participants, grow up in an all-White environment. Unlike them, I was exposed to discriminatory practices at an early age (acts of anti-Semitism), which I believe 
affected how I understood and acknowledged differences in racial and cultural backgrounds. In addition, my interracial gay marriage to a Black woman has made me more conscious of racial issues, especially within the larger society. For example, I noticed different treatment of my spouse in stores, where she was sometimes followed by employees, and was aware of negative interactions when traveling with her. I believe this awareness extends to my children and how my spouse and I discuss matters of race in our own home. Frankenberg's research reveals that “race shapes White women's lives” (Frankenberg, 1993, p.1). It has definitely shaped my life, as well as the lives of the participants in this study.

Even though I was an outlier in my own study, I began to realize that I could not generalize. White middle-class teachers are not all the same. They have differing backgrounds that may affect their perceptions. This realization made me more sensitive to the other participants and more open to hear them as individuals with different points of view.

\section{Ethical Concerns}

You can plan and prepare for your research phase but then when it arrives anything can happen. In the beginning, I encountered a dilemma I had not previously considered. The only teachers who expressed interest in being a part of my study were located in my school building (Grayson). I had hoped that other K-1 teachers districtwide would volunteer, but none did. Out of 24 responses, only 5 teachers, all from my school, offered to participate. I sent out emails beforehand, introducing myself and asking them to take my survey online. I also gave them information about being a part of the second phase of my research. I suspected it was too much of a time commitment (three interviews, three observations and a focus group). I knew these 
teachers were very busy and inundated with a lot of work. I also thought it might be because they didn't feel that they knew me well enough to give so much of their time. I ran into other first-grade teachers only a few times a year at district workshops and only knew kindergarten teachers by sight from mandatory first-day meetings districtwide. After I emailed my first participant, Ms. Springstein, I asked her if she knew any kindergarten teachers at other schools who might be interested in participating. She contacted a few friends via text and only got negative responses. She was not sure why they were not interested. I then asked participant \#3, Ms. Watson who, as a 20-year teaching veteran was well-connected in the district if she knew of any kindergarten or first-grade teachers at other schools who would be willing to take part in the project. She looked into it and also received negative responses. She said people had no time (an issue that is addressed in Chapter 4) to commit to it. Perhaps they also did not want another stranger coming into their rooms and observing them teach, especially when they were now being observed three times annually instead of one. I was even willing to add to my participant pool and have six or seven teacher participants; unfortunately, however, I could garner no interest.

I finally presented the dilemma to my advisor. We discussed it at length. She felt this was an issue that could affect the validity of my project. We talked about the possibility of going back after the summer and trying to get new candidates from other schools. This, in effect, would lengthen my research phase and since I was on a tight schedule, did not seem like a worthy option. Also, there was no guarantee that any of these teachers would later change their minds and acquiesce. We then considered another option: forming two focus groups instead of one. I thought it might be more feasible to convince teachers to commit to one session on one 
day instead of three different interviews and three different observations. I remembered a contact I had at another elementary school on the other side of the district. The principal of that school had originally hired me when she was the assistant principal of my school and we had a good working relationship. I emailed her and asked her if she could help me host a focus group at her school and she responded positively right away and promised to speak to her K-1 teachers. To encourage participation, she decided to schedule the session on a Tuesday meeting day (we are obligated by contract to meet every Tuesday after school for a variety of meetings). We scheduled it for the last Tuesday meeting of the year in the middle of June. I thought it would work then because it would be at the end of the research phase, when I had preliminary findings to present.

There were additional smaller ethical concerns that cropped up during my research, including the possibility of having someone else help me transcribe my interviews. I decided against this for a variety of reasons. I wanted to hear every word and transcribe the interviews verbatim myself so I could immerse myself in the data. In addition, my IRB application had not included this possibility. Another concern involved participant \#2, Ms. Franklin, who refused to read the interview transcripts for verification purposes. After I failed to persuade her to change her mind I started the subsequent interview with her by talking about our previous session so that she could provide verbal verification that what I reviewed was indeed what we had discussed.

\section{Validity and Methods}

In order to address validity concerns I carefully planned my research methods (see below). I was anxious about questions of validity and therefore re-read quite a few books and 
articles on research methods (Luttrell, 2010; Maxwell, 2005; Hatch, 2002), which helped me think about potential issues before and during the research phase. I wrote down my thoughts and questions about validity in a research journal $(\# 1, \# 2, \# 3$ and $\# 4)$. I re-read my journal entries each week to reflect on my thought process and on any questions and concerns, which were often related to my insider status (see above).

Reflexivity was an integral part of this process. MacNaughton (2005) contends that reflexivity is paramount to the research process and is especially important when studying issues of power, race and socioeconomic class, mainly because researchers must come to terms with their own biases and issues before they try to understand how others may respond (MacNaughton, 2005). Deep critical reflexivity skills are essential to the researcher's process (Luttrell, 2010). I realized that I could not remain neutral or value-free in my interactions with the participants (Rubin \& Rubin, 1995). I kept the journal as a part of this reflexive process, which I then utilized to help draft memos that specifically addressed my concerns. For example:

Feb. 23rd

I must always be aware of my beliefs and my biases when conducting this investigation. It has been pointed out to me that I have made some value statements in my observation memo. It is so hard to see that sometimes even when I read it back again and again. I need to be constantly checking myself. I don't want to be so overzealous that I am afraid to write down my thoughts/reactions right away, but I must look again before I type it up into memo form. This is very hard to do. I need fresh eyes and or to be able to really reflect on my writing so I am hyper aware. I also need to remember that I do not know these identified non-school ready children and not to make assumptions. I am more 
interested in how they are viewed/perceived in the classroom by the teacher.

This entry is related to a response from a peer in my research seminar who stated that I needed to be more careful in my descriptions of identified non-school ready Black children in the study. She was referring to my first memo about an observation in which I described a Black girl's hair as messy and her obsession with her own hair as a descriptor of who she was as a child. I was unaware I was imposing my own perceptions of Black hair, based on my dealings with my own daughter's messy hair. This experience and others led me to write the memo "The position of me," in which I uncovered my own biases from my background and delved into my feelings about matters of race, class and religion.

Furthermore, I used my journal as a free writing space where I could think as I wrote and reflect on various interviews and observations. For example:

5/28 - Reflections on 3rd int - part. \# 5

She spoke a lot about Derek (non-school ready child). She is very attached to him. She is worried about his future as a student. He has made a lot of progress - especially in social skills. He is going to summer school but she worries about August when he will have no help with his reading. She is afraid he will slide back and not be ready for first grade. It is interesting - she has been thinking and processing more about Derek. I need to go back and look at her first two interviews and her observations and see if I can highlight her concerns about Derek's future and progress. Perhaps I need to make a chart showing his progress as indicated by her. 
I later wrote a memo charting the progress of the identified non-school ready children. I then completed line graphs to illustrate their progress and hung them up at the focus groups (see Table 2). The purpose of this chart was to see if the participating teachers thought that these identified non-school ready children achieved actual academic and social growth by the end of the year.

Table 2: Socio-emotional/Academic progress of non-school ready children in study Jay:

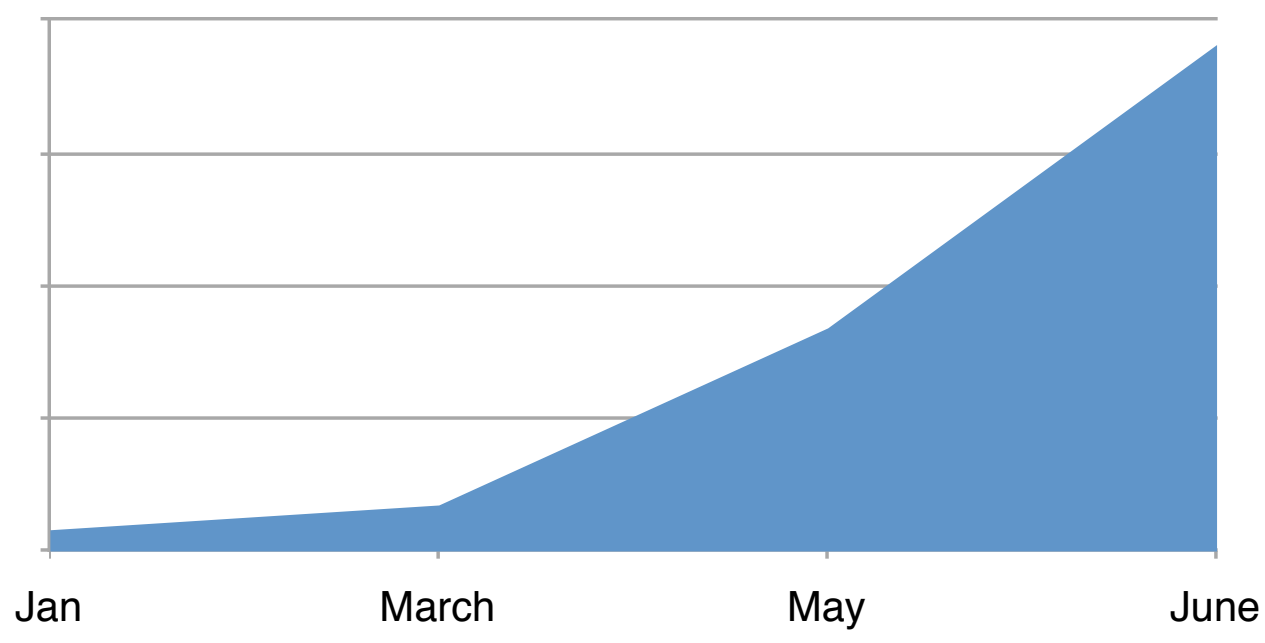


Derek:

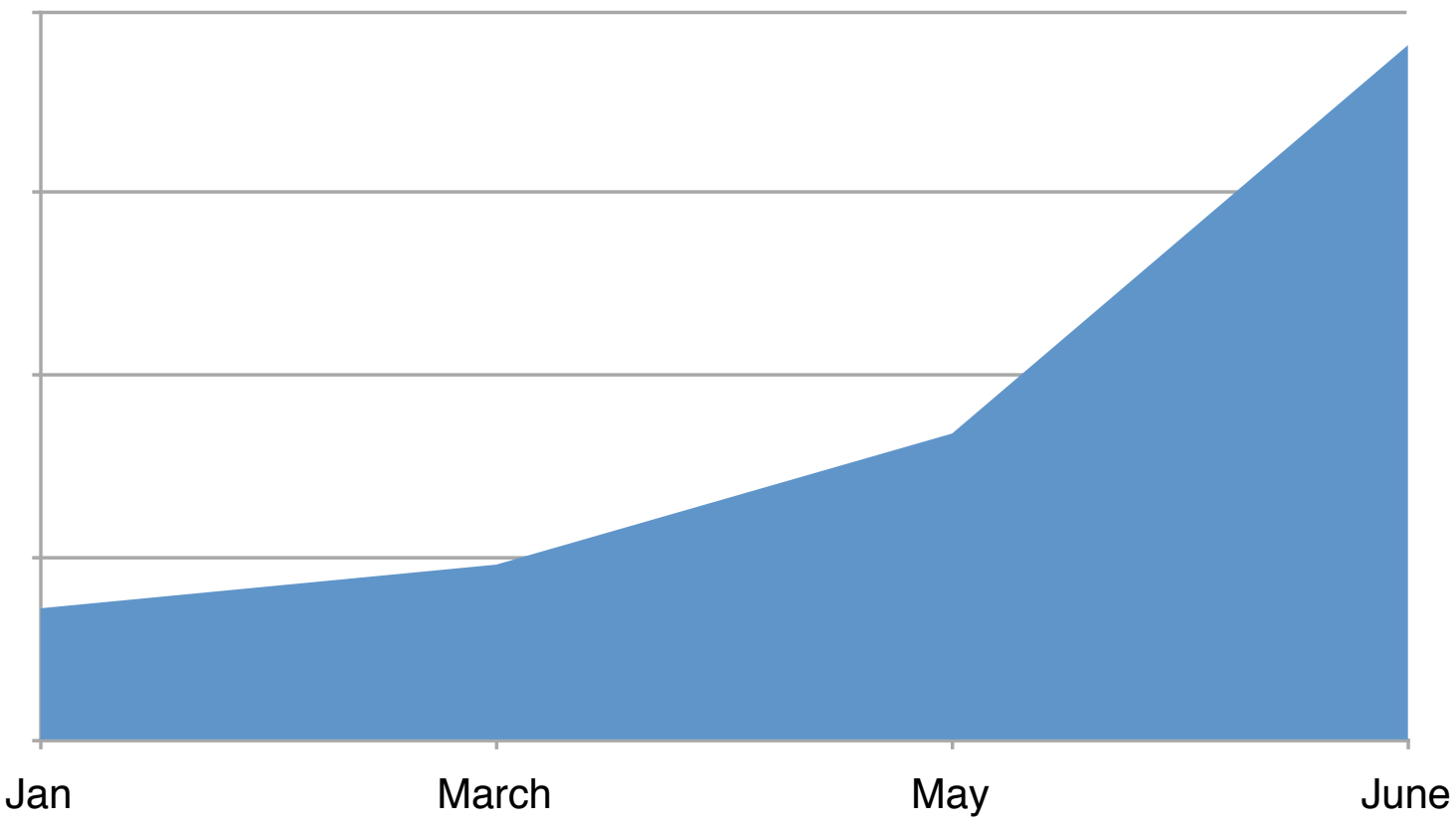

Michael:

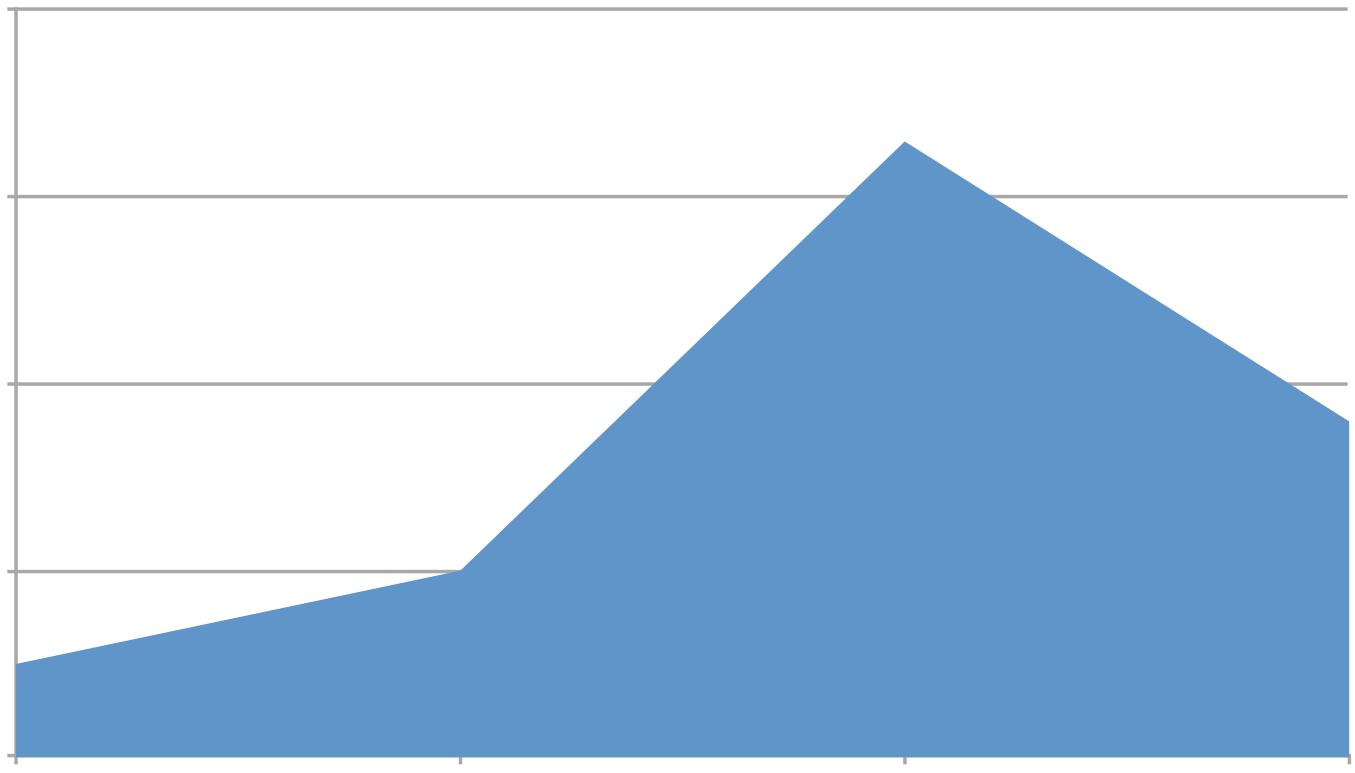

Jan

March

May

June 


\section{Billy:}

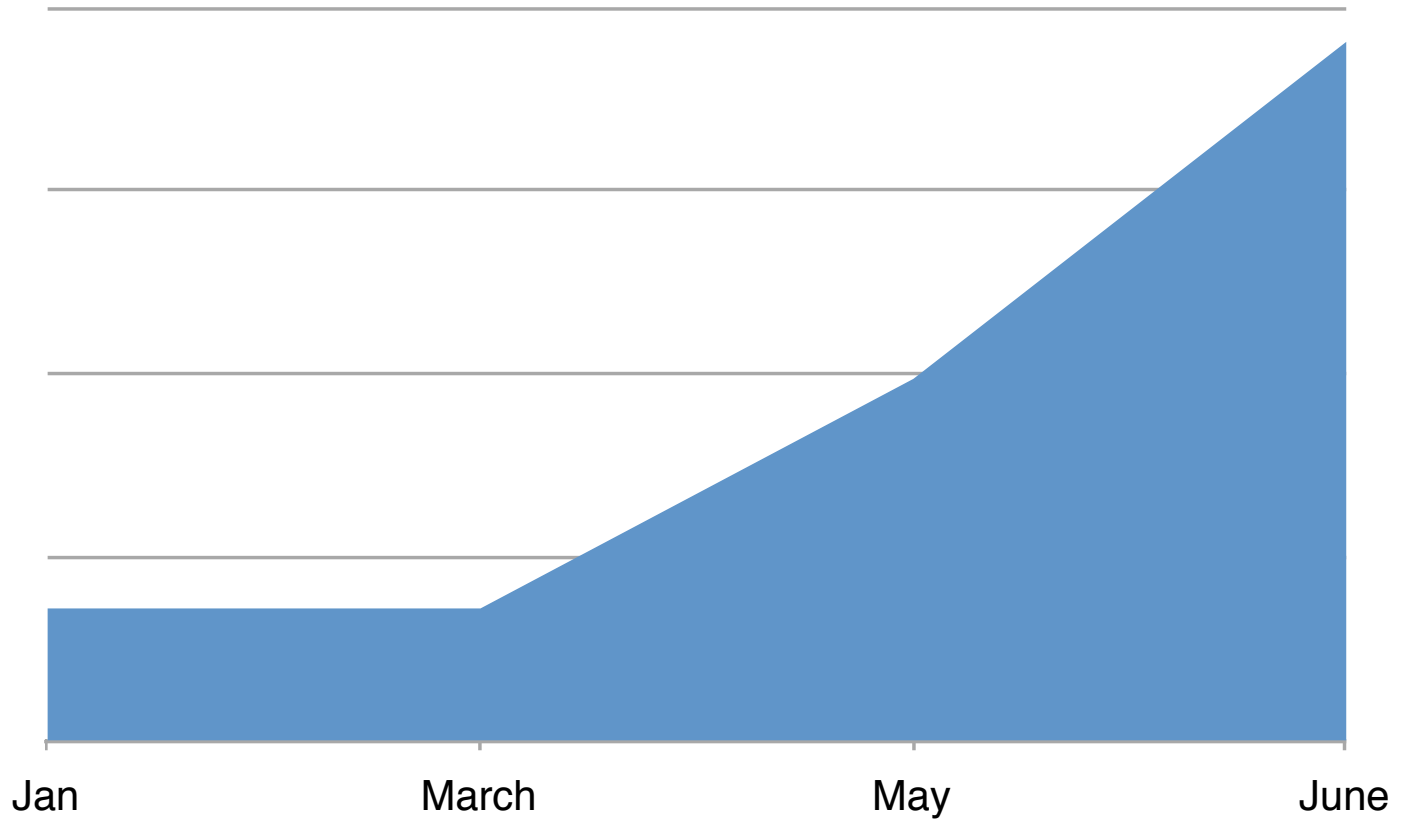

Lina:

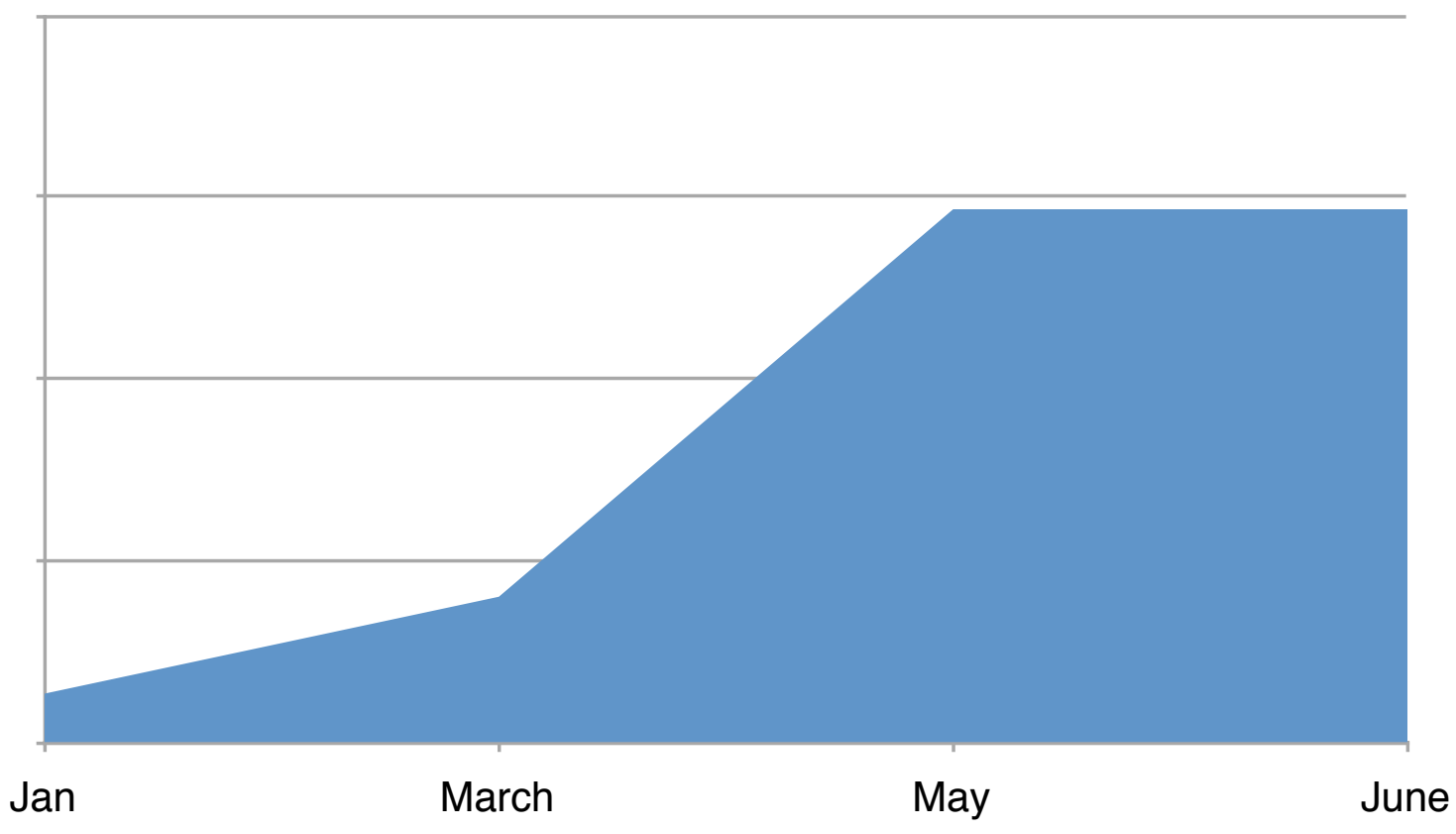


My research proposal contained a list of specific ways to counter validity threats to my project. I referred to this list during the research process and can confirm that I did in fact adhere to it. Following is the list:

\author{
-Verbatim transcripts \\ -identifying and being aware of my own research position \\ -utilizing a focus group for co-analysis and member checking \\ -utilizing an ongoing reflexive research journal \\ -triangulating the data - utilizing at least 3 different methods \\ -utilizing a peer support system to aid in reflection \\ -searching for outliers - keeping track of all data \\ -searching for alternative meanings - revealing complexity in data
}

The last two items on the list were considered during the data analysis (see below). During this time I was in an advisee group that met monthly to share our writing and processes in order to obtain constructive feedback. During the research phase, I attended a research seminar in which I shared several of my research memoranda and additional research-related essays. I also met regularly with a colleague from the advisee group. We shared data and analysis of that data with each other and provided constructive feedback. This supportive peer system was essential to my reflective process. The other items on the above list are related to the methods specifically selected and utilized for this research process, which were a survey, interviews, observations and 
two focus groups. Below are the specifics on each method and how they actually functioned within this project.

Survey

The survey was administered online to all 54 kindergarten and first-grade teachers in the district (including special education teachers). Before sent the survey, I individually emailed each of the teachers to describe my project and ask them to consider taking part in the online survey. A few days later, I sent them the link to the survey located on surveymonkey.com. The highest rate of response was at the end of February (12), the first time it was sent out. The next highest rate of response was in April (6), possibly due to spring break. I received four responses in March and there were no responses in May (a very busy month loaded with report cards, observations and summatives). In May, I also provided paper copies to each school, which did not yield any responses (the teachers were supposed to put the survey in the pony - districtwide mail system and send it back to my school). On June 2, a few more teachers responded online. I received a total of 24 survey responses after sending it seven times. The survey consisted of four pages with four different sections:

1) Background section

2) Topics of importance related to school readiness (Likert scale)

3) Think of one non-school ready child in your class and respond (LS)

4) Interest section (put $x$ in box if interested in second phase of research)

The survey also was designed to be teacher-friendly. A good deal of thought was put into the design of this survey, which was based on an earlier broader survey for one of my previous pilot research projects. With assistance from a professor who is skilled in this area, I added more detailed questions that directly related to the target population. Picciano states: 
Designing a survey instrument relates directly to the

problem or topic being studied and the target survey

population (Picciano, p. 23, 2004).

The average time it took each teacher to complete the survey was seven minutes, although some took as long as 15 and 21 minutes or as few as five minutes. There were two incomplete surveys where participants did not finish the third section.

I would have done a variety of things differently with the survey to achieve a higher response rate. For example, I would have physically gone to the Tuesday meetings at each school (getting release time) to explain the project and distribute the surveys. This requires permission from my principal and the hosting principal, which would have required advance approval. I also would have identified at least one person per building with whom I could physically discuss the project so that they could have spread the word about the survey in their respective schools. In addition, I could have possibly offered some kind of incentive (e.g., Amazon gift cards) for completing the survey, but I would have had to incorporate that into my IRB application.

\section{Interviews}

I conducted three separate interviews with each individual participant, so that I could come back and ask questions about issues that came up in the previous interview. I utilized an interview guide for each session, but veered from it depending on the participant teachers' responses. Each interview was audio recorded and transcribed word for word. The participants read each transcription ahead of time and then commented on it at our next meeting. I consistently asked, "Is this right? Did you say that?" and they confirmed that the transcriptions 
were accurate representations of our discussion. Ms. Franklin, participant number 2, was the only one who refused to read the previous session's transcript. She did not want to read what she had said and said she trusted me to get it right from the audio. We did, however, verbally review our previous discussions so I could verify her responses. I occasionally asked all of the teacher participants to expand on comments they previously made so I could understand them more clearly.

Each interview lasted 60-90 minutes, depending on our conversation. My objective was to engage in a dialogical relationship that produced narratives of value (Seidman, 1998). I asked broad and open-ended questions that encouraged the participants to engage in lengthy discussions. I asked background questions in the first interview so I could better understand where they came from and how they formed specific ideas and values. In the second interview, I asked them about their specific perceptions of school readiness and what skills they valued in children entering their classrooms. The second interview was by far the longest as we delved into how the participants felt about the school (Grayson), the administration (Mr. Dodd and Ms. Holland), the district and the families of the children in their classrooms. It was during this interview when they each specifically discussed a particular non-school ready child in their classes and the child's specific lack of skills. The third and final interview, which took place in June, was a reflection interview, where we discussed the research process and how they felt about their involvement in it. We also discussed each participant's non-school ready child and how much progress the child had made since the beginning of the year. This last interview was also a time for me to follow up with additional questions by using the constructivist grounded theory approach to provoke more expanded responses. 


\section{$\underline{\text { Observations }}$}

During the interview process I observed the participants in their respective classroom three different times. Before I started this process, I asked each participant to identify one lowincome Black child in her class that she had previously classified as non-school ready. On my initial visit I located this child and observed him or her and the teacher while taking field notes. The objective was to observe the identified non-school ready children in their interactions with the teachers and in how they participate in daily school life. I observed three different times for 20-30 minutes each at different times of the day (I kept track of these times in my research journal). I used a notepad (numbered 1-5 - for each participant) and took lengthy notes that I then expanded into field notes (Emerson, et. al 1995). I translated these notes into field notes on the same day of the observation so as not to forget what I witnessed. After each session I quickly debriefed the participant teacher about what I saw. If I had any questions I would ask them during the debriefing. As I compiled the field notes later in the day, I included my thoughts on what transpired. These were reflections on the process since I was not a neutral observer. "No field researcher can be completely neutral, detached observer, outside and independent of the observed phenomena" (Emerson, et al, 1995). In the following days I wrote memos on my observations, and then pre-coded and coded them just like the interview transcripts. They were numbered O-1 through O-15 on top for easy access.

\section{Focus Groups}


My original plan contemplated only one focus group, the participant focus group. This design, as previously stated, was modified to accommodate another focus group, the interpretative focus group. Both were scheduled for the end of the research process. This was done intentionally so that both groups could review the data and findings, make clarifications and expand on topics presented.

The interpretative focus group was held a few days before the participant focus group. It was on a very hot day during the last full week of school. I scheduled it after school so that teachers would be more likely to attend. A few teachers confirmed their attendance via email weeks before and the others arrived unannounced on that day. The session lasted 45 minutes and was audio recorded with their permission. Six teachers participated (four first-grade regular educators, one first-grade special educator and one kindergarten educator). They were given name tags with random numbers (6-11). As they spoke they were reminded to say their numbers, so that when I transcribed the session I could keep track of who was speaking. It was an anonymous meeting and the teachers were never referred to by name. I started off by asking them some of the same key questions that I had also asked the teacher participants (e.g., What skills are you looking for in a school ready child? Why do you think these children are coming to school non-school ready? What are your ideas on what would help solve this problem?). As they spoke I wrote their ideas on experience chart paper. I then proceeded to review the findings. I showed the interpretative focus group teachers tables and charts and asked them for their opinions on various findings. Their thoughts and opinions are included in the findings that I reference in later chapters. 
The participant focus group, on the other hand, was less formal. We all gathered at Ms. Springstein's house (participant \#1), sat around her dining room table and talked about the findings. I covered the walls with charts, diagrams and quotes from each participant. I asked them to walk around the room with post-its and put their thoughts and opinions directly on the data. Some people asked for clarification on some charts (all of this was audio recorded), while others wrote clarifications or made changes on the charts themselves. At one point Ms. Moore stated, "this is like a sleepover," and we all laughed. It was a very comfortable meeting, as everyone was very excited about the culmination of the project and wanted to see the findings up close. To break the ice, I read various participants' quotes and they had to guess which of them had said it. For example, I read Ms. Moore's comment, "Here bake a cake but I will not give you any eggs" and they all laughed. Her remark was in reference to the district and the universal feeling that it could be more supportive to its teachers.

Based on conversations with my advisor, I started the group discussion by asking the teacher participants for clarifications on two points. The first question related to school readiness as a term. I wanted to make sure I understood how they felt about the term and how these interpretations might have changed or evolved during their participation in the study. I then asked them to clarify a conflicting set of views. Were they saying that the children's families adhere to a totally different value system from theirs? Or were they saying that we (the teachers and children's families) all adhere to the same value system but that it is harder for some lowerincome people to meet the expectations of the value system? These were long discussions and the participants were able to further clarify and expand on their views. These findings are included Chapter 6. 
This focus group lasted one hour and forty-four minutes and was audio recorded and transcribed. It was later pre-coded and twice coded like the interpretive focus group transcription. I prepared a summary memorandum on the findings of this focus group transcription, which was also pre-coded and coded. The participant focus group conversation was so honest and interesting that it works well as an introduction to the various findings chapters contained in this dissertation.

\section{Data Analysis}

The analysis of the research data started the moment I began the research phase. I took every interview and every observation, transcribed them (word for word), and, utilizing Saldana's The Coding Manuel for Qualitative Researchers, coded each one line by line. "Coding is not a precise science: it is primarily an interpretive act," (Saldana, 2013, p. 4). I was interested in inductive coding, starting with identifying content and topics in the participating teachers' words. At the same time, I actively utilized deductive coding to determine how the participating teachers used different discourses in their perceptions and assumptions (see research questions).

As with my data analysis in general, I realized that I needed to be aware of my own assumptions and biases when coding data. This complemented my constructive grounded theory methodology, since I was interested in working with the data from the ground up. For me, coding was an "essence-capturing" process. Wearing my analytic lens, I tried to uncover the essence of the data (Saldana, 2013). Line by line coding encouraged me to remain open and look for "otherwise undetected patterns in everyday life" (Charmez, p. 125, 2014). It forced me to attend to images and meanings and to question and reflect on each line of speech. I tried to understand 
the participants' views from their particular perspective. Part of the coding process involved repeatedly re-reading the data, interacting with it and looking for avenues to explore and expand. I pre-coded with a highlighter and then at a later date I coded with a colored pen and used the side margins. After a few weeks or months, I coded the data once more using a different color pen. Every transcription code was dated on the top, so I knew how many times it had been coded. During this time I wrote memos about the themes that emerged from my coding. On the top of each memo was a title, a letter and the exact interviews or observations utilized to compose the memo (i.e.; I-4 or O-6). All memoranda were logged by letter in my research journal. For example: "Race is not an issue" - Memo M - May 31st - I-10/I-6/I-7. When I finished the alphabet I started again this time using two letters in a row (i.e.; Memo $\mathrm{Aa}, \mathrm{Bb}, \mathrm{Cc}$ etc.).

As I coded and wrote memos, categories started to emerge from the data. During this process, which lasted more than six months, the categories became more refined and patterns started to emerge. For example, I wrote a memo on developmentally appropriate practices and how teachers lamented the implementation of the Common Core curriculum and the lack of developmentally appropriate practices involved (Memo Ee). I noticed that I had another memo on how times have changed in teaching (Memo P) and another memo on classroom management and children working too slowly (Memo J). I started to do some visual mapping at this point to see connections between the memos. I realized that memo P, "times have changed in teaching," could be utilized as an umbrella category into which other memos (such as $\mathrm{J}$ and Ee) could fit. I developed three major categories this way, by using visual mapping on a large white board. The categories were: times have changed in teaching, old school values and dissonance in parent 
values. Later, as I started to compile my data I collapsed some categories and expanded on others. For example, I collapsed old school values and dissonance in parent values into one category and expanded the times have changed in teaching category, which ultimately evolved into chain of expectations: higher demands on teachers due to standardized testing/ accountability.

At the end of the interviewing phase I took the time to analyze my survey findings. The idea was to compare the findings from these two different data sources. I first rewrote specific findings in a notebook, as it was harder to analyze the data online. I also used some of the tools on surveymonkey.com, including analyzing trends, response rates, bar graphs and breakdown of responses by time.

As stated earlier, I was interested in the response rate and the breakdown of the response rate (how many teachers took the survey $n=24$, when and how long it took, and who they were specifically). Did respondents fit the criteria for the project? I knew I could not properly utilize the data if they did not fit the set of criteria I had proposed. They did. All were women, 95.65\% identified themselves as White and middle class, and one respondent identified herself as White and upper class. There were 10 kindergarten teachers, 10 first-grade teachers and 4 multi-age teachers (grades 1 and 2). They were all employees of the study's school district.

After I had rewritten all of the data and read through it several times, I started to write up the findings. At first, I also did this by hand in the same notebook. I numbered my preliminary findings 1-19, writing a brief paragraph on each finding. For example: Finding number $11-$ it is not as important to the teacher for the child to come to school knowing his $\mathrm{ABCs}$ or numbers to $20(27 \%$ responded it was of minimal importance). Finding number $12-$ it is important that 
children have the proper social and emotional skills needed for the classroom (e.g., 59.09\%

responded it was very important for children to be able to share when they enter school). This finding was later verified in my interview and focus group data. I then wrote a summary memo on the survey findings. This helped me to think about connections to other forms of data and to see if any patterns emerged. In this memorandum I wrote:

They (survey respondents) also, as did the participants and the interpretative focus group, believed that socioemotional skills should be taught and or reinforced at home in order for a child to be ready for formal schooling. 59.09\% believed that being able to share before coming to school is essential to being ready for school. They also believed that being able to make friends, being respectful and being able to work independently were important indicators of SR. Interestingly, they were less concerned with academic knowledge, such as knowing their numbers 1-20. Only $9.09 \%$ saw this as very important. Knowing their $\mathrm{ABCs}$ was somewhat more important as 54\% thought it was somewhat important, but $27.27 \%$ thought knowing their numbers was of minimal importance. I need to look over the data from the second interviews as I believe they correlate to these specific findings.

In this case, and in others, the data from the survey seemed to support or confirm other findings (from interviews, observations and focus groups) that I had previously uncovered. It made me reengage with the data, especially the interviews and observations, to look for possible connections.

As I analyzed the data, I sought outliers and possible alternate meanings. I repeatedly listened to the audio recordings of the interviews and focus groups. I sifted through the written transcriptions and pondered the various codings. As stated earlier, my realization that I was an outlier in my own research project, which could affect my perceptions of the data, provided 
insight as my outlier status made me more cognizant of differences among the participating teachers as well. I wrote memos addressing this, which helped me to process my own status within the project. I also realized rather quickly when analyzing the data that some of the data could be misinterpreted or utilized in a different context. I needed to

look for how they understand their situations before I judge their attitudes and actions through my own assumptions...see the world through their eyes and understand the logic of their experience which brings (me) fresh insights...(Charmez, 2014, p. 133).

I began to realize that I was constructing possible interpretations, and that even with this awareness, I was bound to make judgments in my analysis. As the researcher, I was constructing categories. There were many different ways I could proceed. In the end I chose a path that manifested itself in the data and in the constructions of the data, but there were other paths I could have taken, as the data was rich and full of various meanings. In other words, I am aware that there were many different books I could have written on the data alone, but because I am not a neutral researcher, one path presented itself more clearly to me and I took it. This path specifically related to the findings chapters in this dissertation (Chapters 4-7).

\section{Reflections on the Research Methodology}

Now that I have completed my research, I am able to reflect on my chosen research methodology and how it aided me in answering my research questions. I did not completely realize how fitting this particular methodology would be for this specific project until I started 
writing about my findings. The key to this process has been my increased sense of being able to follow the data.

Studying your data enables you to learn nuances of your research participants' language and meanings. Subsequently, you learn to define the directions where your data can take you (Charmez, 2014, p. 99).

Following the data is about going back and interacting with the data and following up with the participants. I often followed up on leads and followed up with each of the participants based on our previous conversations. My ultimate goal was to ensure I understood specifically what they were saying. I therefore made a habit of returning, asking for clarification, listening again and asking them to expand on topics. This method was especially helpful when discussing the issue of race, a subject the participants initially hesitated to discuss, so it worked well to keep coming back to it. This process, forming constructions based on the participants' own words and responses, is the essence of constructive grounded theory. I realized that the process was ongoing and that not all constructions of data could be made without revisiting and asking for more data.

This again relates to how I interacted with the participants and whether I truly envisioned it as a dialogical process or not. As a novice researcher, it was a learning process that allowed me to discover more about myself as I listened and tried to understand my participants' views. I uncovered layers of bias and assumptions that I had accumulated over the years and reflected on them in order to be more present in my research. As I previously revealed, I was surprised by the connection that I felt with each participant in the mutual quest to understand a topic related to schooling. It was a truly honest process. They were candid with me, which motivated me to be 
even more diligent in my quest to capture their voices and spirit as early childhood educators. I, in turn, was candid with them, and was grateful to get to know them better as people and educators. I wanted this research study to capture this process and the mutual interest we shared in one topic that captured their true perceptions and thoughts. Charmez states, "your journey through grounded theory may transform you" (Charmez, p. 340, 2014). As previously noted, the strongest transformation was in my realization that I was an outlier within my own study and that white, middle-class, female educators are not monolithic as a category. This helped me to further understand how my own preconceptions and biases (including the differences in religion and race) impacted my research process. In turn, it forced me to be more attentive to each of my participants and see them as individuals who had differences and similarities.

\section{Introducing the Teacher Participants (\#1-5):}

Each teacher in this study (\#1-5) selected the interest section of the survey, indicating that they wanted to be a part of the second research phase (including interviews, observations and a focus group). These teachers all worked at the same school (Grayson) and I knew them to varying degrees. They ranged in age from 27 to 54 . They were the sole teachers in their respective classrooms, with 22 or 23 children per class. As stated earlier, they shared similarities in their backgrounds and in their likes and dislikes, but they were complex individuals, with subtle differences from one another. The following portraits serve as an introduction to these early childhood teachers, so that the reader has a better understanding of who they are before they read the findings. 
Ms. Springstein, participant \#1, was the first person to complete the online survey. She personally approached me and expressed interest in being a part of the study. She has been teaching kindergarten at Grayson for six years and had previously taught in local preschools for more than seven years. Teaching is the only thing she ever wanted to do, and she knew this as a young child. She is married and has two of her own children, but has also raised her husband's sister's kids following her sister-in-law's death. She lives in the district, in the next town over, where she was born and raised. She is very involved in the school and, at this time of the research, was a union representative for the teachers. Many times during our interviews she expressed appreciation for her participation in this research process and felt that it helped her grow as a teacher.

Ms. Franklin, a friend of mine, was the second teacher to declare interest in participating in this research study. She, like Ms. Springstein, has also been very active at Grayson, and was the other union representative on staff. At 54, she is the oldest teacher in this study and grew up in the late 1960s and 1970s. She has taught at this school for eight years, having changed careers later in life (she was a paralegal before becoming a teacher). She is witty, sarcastic and brutally honest. She is also married with two children and lives in the school district in the next town, one block from Ms. Springstein.

Ms. Smith was the next to respond to the interest section in the survey. As a close friend of Ms. Franklin, I believe she decided to become involved because of Ms. Franklin. My only real interaction with her before this process was in the hallway when we exchanged pleasantries. Ms. Smith was new to the school, only in her second year at the time of the research, but had taught for many years a decade ago, before her children were born. She is also married with two 
children and lives in the district in the same town as the school but in a different neighborhood. She was approximately the same age as Ms. Springstein and me, and also grew up in the 1970s. She is the only participant born and raised in another nearby state.

Ms. Watson, a kindergarten teacher, has been at Grayson the longest, 20 years and has only taught in this school. She has also only taught first grade and kindergarten during her career. She taught half-day kindergarten for eight years when her children were younger so she could stay home with them for part of the day. She grew up in this school district in the other town and went to the public high school. Her grandfather built the house she was raised in. She now resides outside of the district and is married with three children.

Ms. Moore, the youngest of the participants at 27 years old, was the last participant to join the research study. She had been teaching at Grayson for three years and was the only nontenure ${ }^{25}$ participant at the time. She had student-taught kindergarten prior to becoming a leave replacement (long-term substitute) during her first year. She had been married for only one year at the time of this study and became pregnant during the interview process. She was raised in New Jersey in a neighboring town and now lives a few towns over. Unlike the other participants, Ms. Moore grew up wanting to be a dancer. She studied dance for many years, majored in dance in college, and worked as a dancer for several years, but went into teaching because she was not able to make a living dancing.

All of the participants' perceptions on the topic of school readiness are reported and analyzed in the findings section of this dissertation (Chapters 4-7). Their words and understandings are paramount to this study.

\footnotetext{
${ }^{25}$ Non-tenured means that she has no seniority and can be dismissed without cause at any time See glossary.
} 


\section{Introducing the Non-School Ready Children I Observed}

The five identified non-school ready children were an important part of this study. Each teacher participant was asked to identify one low-income Black child in her class whom they had classified as non-school ready at the beginning of the year to be a part of the study. Again, it is important to note that all observations of these five children were based on their interactions with the teacher and how they related to the teacher. I was not there to confirm or judge whether a child was indeed non-school ready; rather, I was interested in the specific perceptions these teachers had of each child and how they interacted and responded to them. Also, all the children's and teachers' names were changed.

Lina from Ms. Franklin's class was the first child I observed. She was a first grader in a multi-age setting (grades 1-2 class). She was new to the school and had not attended a public school kindergarten. She went to the daycare where her mother worked until she came to Grayson. When I first met Lina, I noticed she chose to sit closer to the teacher, usually near the front and off to the side. She seemed very quiet and only spoke in whole class settings when spoken to, and even then only gave short responses. She was small in stature and had her hair tied in a ponytail on most occasions. The first time I visited she spent the whole period playing with her hair, taking it out and putting it back into her hair tie. Another time, I was in the room when she came back from AI (academic intervention) ${ }^{26}$ and spent a few minutes alone behind the bookshelves by the coat rack before she was greeted by Ms. Franklin and asked to come join the

\footnotetext{
${ }^{26} \mathrm{Al}$ is a resource room where children with reading issues get extra reading time in small groups -See glossary
} 
class. Still another time, she read her published book (from Writer's Workshop) to the class and half the class did not listen or positively respond to her story, whereas the girl who read after her got immediate applause when she finished. I believe she was shy and had some trouble making friends. Other girls, some older and some the same age, sometimes bossed her around and it was clear she did not like that.

The next child I met was Jay. Jay, also small in stature, had long braided hair and was always smiling. He seemed very happy go-lucky and often laughed or joked around with others. He liked to dance and enjoyed all the songs the kindergarten class sang. He too, liked to use short responses and did not raise his hand until my last observation. He seemed very well-liked, and as Ms. Springstein put it, "is a good friend." He was eager to please and often approached Ms. Springstein to show her what he was doing. He liked it when she gave him praise and worked better with her nearby.

Michael, who was also a kindergartner, was in Ms. Watson's class in a nearby portable. He was tall and had short hair. He was quiet and also only spoke when asked to participate. He seemed very comfortable in math and genuinely liked playing math games with others. He sat at the back of the rug at an assigned spot and seemed to be paired with the same boy during partnering sessions. He did not seem to need extra attention or approval from Ms. Watson. Instead, he seemed to enjoy being left alone to attend to his work.

Derek, another kindergartner, was also tall with short hair. His first language was Creole, and his mother and other relatives only spoke this language. He was tested for ELL (English Language Learner) and passed the test. He was supposed to go to the ELL program at another school in the district but was unable to because of a conflict with his mom's work schedule. He 
seemed to like having jobs in the classroom and responded well to being in charge of materials.

He also seemed to need to be near his teacher, whom he completely adored. He would stand by her table or linger nearby and wait for her to invite him to sit at her table. His assigned rug spot was directly in front of the teacher so she could physically reach down and touch him when he was distracted. He responded well to praise, like Jay and Billy (described below), and his face lit up when the teacher gave him put-ups.

Billy, like Lina, was small in stature for his age (first grade). He was in Ms. Smith's multi-age classroom, and like Derek and Jay responded very well to praise from his teacher. At times he would approach her and ask if he was doing well. He also would show her his work on a regular basis and ask if he was doing it right. He, like the others, only responded when called on and until the last observation did not raise his hand of his own accord. He was sometimes unfocused and had a tendency to distract himself with nearby objects. For example, during one lesson he removed his shoe and put it back on three different times. He called out during my last observation and only stopped when Ms. Smith ignored him. He worked hard for a sparkle (an object she threw to a child who was working on task) and wanted to please his teacher. ${ }^{27}$

In summary, the methodology choice and the understanding of how this methodology works within this project is essential to understanding and accepting the findings presented in the following findings chapters. I reflected on ethical concerns and considerations at length and they were an important part of the constructions. I also considered issues of validity, especially in the

\footnotetext{
27 It is important to note that 4 out 5 children identified as non-school ready were boys, thus furthering the deficit notion of Black boys in particular. Many research studies (Ferguson; 2001; Kolhatkar; 2014) reveal this gender difference and link this to the problem of preschool to prison pipeline and why there are more Black males incarcerated than any other population.
} 
choice of various methods utilized. Constant reflection was a key part of the process for me (journals $\# 1, \# 2, \# 3$ and $\# 4$ ), so that I could re-evaluate and examine my own personal biases and assumptions. The methods and the analysis (mostly qualitative) were designed to complement the choice of constructive grounded theory. The dialogical relationship with the teacher participants was essential to the valid constructions and fostered an open and honest atmosphere where discussions were mutual. I recognized that there are different epistemological positions that researchers can take and that as an insider with local knowledge I had insider knowledge that related to my findings. In my reflections about the research process, I realized that it was a transformative experience for me that will aid me in my further research endeavors.

In the next chapter, I begin the presentation of the findings (next four chapters). This particular chapter is devoted to the ecology of school readiness and how it is identified in early childhood classrooms. Snapshots of the non-school ready children, the culture of the school, time constraints placed on teachers and the overall increase of demands by the district are all examined. 


\section{Chapter Four}

\section{The Ecology of School Readiness}

The teachers are sitting around a large wooden dining room table in Ms. Springstein's house discussing the term school readiness. There are a plethora of charts (my research findings) taped to the walls all around them. They have already gotten up to examine the charts and now they are ready to talk about the term itself.

Ms. Moore: It's something I pay attention to...I think it's important to kinda scan, make a little graph in your head. I mean it doesn't change...maybe it does change what you are going to do...but it's good to know.

Ms. Franklin: But what makes a kid school ready?

Ms. Moore: Oh what makes one?

Ms. Tager: Well not only what makes it ...but what do you think of this term? I mean, it's just out there

Ms. Franklin: I don't like it.

Ms. Springstein: It's a silly term, because some kids are not school ready but like you said each kid grows at their own rate.

Ms. Franklin: Or they come from different backgrounds ...different experiences, so how can you tell if they are really...

Ms. Springstein: But all the different backgrounds that they come from.. even just talking to $M$ [me] about how she brought this focus group to that other school ${ }^{28}$ and they are not even seeing what we think should be school readiness skills those aren't even..

(Pause)

28 This school Ms. Springstein mentioned is located in the wealthier part of the district. Its student population is $20 \%$ Black compared to $55 \%$ at the participants' school and only $6 \%$ of the students qualify for free and reduced lunch compared to $43 \%$ at the participants' school. 
Ms. Springstein: It's totally different, but the curriculums at both schools are the same... so are we working harder...because we have to develop... what we think are school readiness skills for our school? Or do they just get right into the curriculum? and do whatever... What was their feeling of what school readiness was? Coming to school with a lunchbox? I dunno.

Ms. Tager: Well actually, they kept saying...they talked about socioemotional skills...life skills.

Ms. Franklin: (joking) you have to be able to recite the Gettysburg address (laughter).

Ms. Tager: They talked about sharing.

Ms. Franklin: Those types of skills?

Ms. Springstein: Do they think that is important up there?

Ms. Tager: That's what they talked about.

Ms. Franklin: Did we write sharing?

Ms. Tager: I think one teacher said it.

Ms. Franklin: Well remember (mouth full) I am a grade higher, so at this point some of these things can be crossed off the list. But just because a kid comes in and...we wrote listening okay...there are a lot of kids who don't listen in first grade..don't listen in second grade..it doesn't matter...then are they ready for school then?

Ms. Tager: They are just not good at listening?

Ms. Franklin: They are ready for school...they are just not good at listening...or that's why it's hard to do just this blanket school ready...you know what I mean? I personally think though they should be potty-trained..that's one thing that...

Ms. Springstein: (interrupts) But look at all of those things we have in common and we are grades apart (pointing to the chart listing all the skills teachers cite as school readiness skills) ${ }^{29}$.

29 See Table 3 
Ms. Tager: Yeah.

Ms. Springstein: I mean we are kindergarten, first and second grades and look at all the things we do have in common for school readiness.

Ms. Franklin: Well socially immature (reads it off chart) ..what does that mean?

Ms. Springstein: Listening.

Ms. Franklin: Listening to me..I could just pick that right out.

Ms. Tager: You talked about playing with others... also being verbal was very Important...you all wanted them to be highly verbal.

Ms. Franklin: Well I didn't write that.

(Ms. Smith is silent, just observing)

Ms. Tager: You said "talk about a story."

Ms. Moore: Or just talking...or just answer a question in a sentence.

Ms. Tager: Number three said that (points to chart) (Ms. Watson, could not make it as she was in a minor car accident just hours before)

Ms. Moore: I still have kids now...I ask them a question and this is not the case study...he just points and I say "you need to tell me tell me what is in your head," because he just points.

Ms. Tager (to Ms. Moore): So what do you think of the term school readiness?

Ms. Moore: I think it's okay to use it. It might be different at different grade levels but I think its okay to use the term. If someone brought me a student and said he's not really ready then I can kind of assess him with that in mind.

Ms. Springstein: mmmhhhmmmmm (nodding her head)

Ms. Moore: And you can tell on the first day who has had some sort of schooling.You know even if it is not full-on preschool...like three days a week...half day 
Ms. Springstein: You can tell when we bring them in for orientation and when we bring them in for screenings (Briganz test) ${ }^{30}$ You can tell who can't even sit for the 10-minute test we give them

Ms. Moore: Yeah...there's stamina. ${ }^{31}$

(Just then Ms. Springstein's husband walks into the dining room with a big bag in his hand)

Ms. Franklin: (leans into tape recorder) Let it be known that number one's husband came in with White Castle burgers! (laughter)

As noted in the excerpt from the participant focus group, these teachers harbored ambivalent feelings about the term school readiness. They were, however, clear on the specific skills they sought in a child entering their classrooms and had distinct expectations about the mastering of these skills (See Table 3).

The ecology of school readiness relates to how White middle-class teachers perceive school readiness or non-school readiness in low-income Black children in their classrooms ${ }^{32}$. It examines how children, who do not necessarily understand the culture of the school (based on White middle-class norms), can be labeled non-school ready when they exhibit certain attributes and behaviors. The ecology of school readiness also examines the expectations that lead to this identification, which are made rather quickly by teachers (usually by October) as districts mandate the grouping of children in various categories (high, medium, low), through districtwide assessments in reading and math. Through this identification teachers, who are inundated with

\footnotetext{
30 Briganz test is a prescreening for incoming kindergarten children. See glossary.

${ }^{31} \mathrm{~A}$ word used frequently in the curriculum and in assessments and the report card. It refers to how long a child can stay on task.

32 It is important to note that this study does not address the question of how Black middle class teachers perceive school readiness in low-income Black children.
} 
SGOs, PDPs ${ }^{33}$ and a variety of assessment tools (including the DRA), then unknowingly burden their students with the same inappropriate demands from the district.

\section{Table 3}

\section{School Readiness Skills:}

(These are the skills the teacher participants listed as important in the classification of a school ready child)

Ms. Springstein:

Play with others

Be a good friend

Listening

Able to use bathroom

Able to share

Be organized

Can dress self

Walk in a line

Know a few letters

Follow directions
Ms. Franklin:

Socially mature

Getting along with others

Be able to listen to story

Be potty trained

Read to every night at home

Can talk about a story

Knows how to sit

Can unpack/organized

Knows letter sounds

Can wait turn to speak

Follows directions

Ms. Smith:

Socially mature

Able to Listen

Knows books

Can talk about books

Is read to every night

Can give a verbal opinion

Sits well

Knows ABCs

Understands culture of school

Knows numbers 1-20

Get in a line

33 PDPs, or professional development plans, are plans teachers must submit to their administrators in the fall. They include specific goals for teacher development and learning. See glossary. 
Ms. Moore:

Plays well with others

Able to listen

Uses bathroom properly

Knows books

Can talk about books

Can talk to other children
Can control body

Organizes belongings

Follows directions

Knows ABCs

Dresses self

Sits well on carpet

This translates into a widening gap between non-school ready low-income Black children and their peers. The increase in expectations, based on the districts' higher demands, creates a greater number of struggling learners and perpetuates an increase of non-school ready identifications.

In this chapter, I carefully examine and analyze what White middle-class early childhood educators in this study identified as school readiness skills, and how they perceived and identified the non-school ready children in their classrooms. To reiterate, as an early childhood classroom teacher and researcher, I came to this study with an insider's view and entered the research phase with certain ideas about the term school readiness that later evolved into a desire to challenge the term itself. First, I explore this identification process by revealing snapshots from the field of five different identified non-school ready children in kindergarten and first grade. I then further explore different components and factors that relate to this identification, such as the ability to follow school culture, the deficit of socioemotional skills, the time constraints in teachers' daily schedules, the culture of rushing, the obligation of teachers to find different and more expedient approaches to teaching (non-child centered and lacking free play), 
the increased need for time management and control tools, and the overall increase in demands including expansions of curricula that teachers must meet in order to be properly evaluated.

\section{Behind the Eight Ball: A Snapshot of Five Non-School Ready Children}

The following snapshots of five classified non-school ready young children in kindergarten and first grade reveal the specific skills that the teachers in this study defined as school readiness skills. A deficit in these skills often leads to a non-school ready identification or perception. I observed each child in this study on three separate occasions over the course of six months. All five participating teachers individually selected these specific children out of classes of 22 or 23 students. The selected children had to be low-income, Black and identified by their respective teachers as non-school ready. It is important to note that, for purposes of selecting the children participants, the participating teachers used their own definitions of nonschool ready. ${ }^{34}$

\section{$\underline{\text { Lina }}$}

Ms. Franklin said Lina looks more like a kindergartner than a first grader. She immediately noticed that Lina was not ready for school. Lina had trouble using the bathroom properly and sometimes had an accident in the classroom after returning from the bathroom. Ms. Franklin was very frustrated with Lina, which was clear when I observed them the first time. "Lina are you with me?" she called out several times during her lesson to make sure Lina was listening. Lina untied her ponytail and repeatedly fixed it She did not raise her hand, another

\footnotetext{
${ }^{34}$ As the researcher I had no part in the selection process.
} 
key indicator of non-school readiness cited by the teachers, and Ms. Franklin frequently had to call on her or she would not participate (raising hands and participating in whole class discussions are fundamental indicators of school readiness). Lina was behind academically. Ms. Franklin believed it had to do with her lack of kindergarten experience. She did not attend the school's kindergarten, but attended a daycare at her mother's job site (a large pharmaceutical company). Her mom brought in portfolios and showed them to Ms. Franklin and was shocked to hear that Lina was so far behind academically. Ms. Franklin stated:

They were upset when she came to this school because we tested the reading and it was low. She was shocked that she was so low...uh, when you look at this child she looks younger than other children. She looks about a year younger.,,to me...than the other kids. She speaks a little bit like a baby...she has baby talk. For instance everyone would ask can I use the restroom and she still said, "I need to go potty."

To Ms. Franklin, Lina's lack of language skills, her small stature and her baby talk were all factors in her determination that Lina was non-school ready. This was more obvious to her because the child did not attend a public school kindergarten. The mother, who is very proud of her work's daycare, was upset because Lina was not adjusting to her new school environment.

Meanwhile, Lina was working too slowly and even having trouble locating her classroom in the large school building. She was also in a crowded classroom with 23 first- and second-grade children and was not used to such a large class with only one teacher. One day, I noticed that Lina was hanging back at her table trying to finish her coloring work when another girl came over, acted like she was helping her-even though she grabbed crayons out of Lina's hand—and told her what to do. "Two minutes," yelled Ms. Franklin from the rug. Children were already heading over there but Lina was still trying to finish. "I need more pink," she said 
to the other girl, who had just taken the pink from her. "No you need purple," replied the girl. Lina shook her head no. "I am helping you," said the girl. Lina seemed frustrated and tried to grab the pink crayon. "Come over for Writer's Workshop," ${ }^{35}$ called out Ms. Franklin. To the girls she said, "... and Lina it is time." Lina tried to hurry and finish. She finally dropped the crayon and ran over to the rug. Her work was left unfinished on the table.

When I spoke to Ms. Franklin about this incident, she claimed that Lina never finished her work on time. She always had to sit with her and help her personally. This was really hard for her to do because she had a lot of children with multiple needs who also required her attention. Lina's slowness and lack of independence were difficult for Ms. Franklin to manage, especially with limited time (see "Time Bind" later in this chapter). She always had to rush through activities because she had so much work to cover in one day. As a result, Lina never finished her work.

Time constraints were a problem for Lina and Ms. Franklin. The rushed schedule and the expectation to finish quickly directly affected how Lina fared in the classroom. If Lina had more time, perhaps she would catch up, but there was no additional time. Ms. Franklin had to keep the schedule moving because she had a lot to cover in the six-hour day (see the "Culture of Rushing" section). She had no assistance in the room (i.e., no paraprofessional ${ }^{36}$ or student teacher ${ }^{37}$ ) and faced many challenges to meet all her children's needs.

\footnotetext{
35 Writer's Workshop is a method of teaching writing to young children (from Teachers' College Writing Project). See glossary.

${ }^{36}$ A paraprofessional is an aide or a teacher's assistant. See glossary

${ }^{37} \mathrm{~A}$ student teacher is a volunteer teacher who works in the classroom for college credit. See glossary.
} 
The factors related to Lina's identification as non-school ready were: working too slowly, being nonverbal, lack of participation, not following class rules and being in a large classroom with only one teacher.

$\underline{\text { Jay }}$

Jay was dancing by his table and showing off to his friends. "Look at me...look at me!" he called out to a girl at his table. He was smiling and laughing, and was in a good mood. Ms Springstein saw him dancing and raised her voice. She was not sure if Jay was listening. It was time for Writer's Workshop and Ms. Springstein was ready to start her mini-lesson. Jay danced over to a spot on the rug and sat down. Later, during our conversation about him, Ms.

Springstein stated, "Every day is an example of how Jay is non-school ready." When I asked her to elaborate, she recalled a moment during that March day when he did not act in a school ready fashion.

We were sitting in our circle and we were doing our greeting... responsive classroom. ${ }^{38}$ We do a share and then we do our morning greeting. This morning we did a greeting where I have all their pictures in a basket in the middle of the circle and their names written on the pictures...to help them. It is more for the beginning of the year to correlate the names with the faces. The child goes over to the basket, picks a picture and says 'good morning...' and they would high five each other...okay...walk back to your seat and sit criss-cross applesauce ${ }^{39}$ and wait for all the other ones. He (Jay)

\footnotetext{
38 The responsive classroom is a specific management technique utilized by some early childhood educators. See glossary.

39 This is how most teachers expect children to sit while on the rug. Their feet are crossed and they are sitting up.
} 
throws it into the basket...runs across the room and slides into his seat...like not even realizing the other kids around him.

Ms. Springstein was upset that Jay was not following the class rules (walk to your seat and sit nicely while respecting others' space). Indeed he was very active, but she did not think he had ADD. ${ }^{40}$ As an experienced early childhood educator, I saw how Jay could be mislabeled as such, but I did not believe that he fell into that category, either. According to Ms. Springstein, he ran, jumped and danced, and had trouble listening. In addition, he did not know how to cut with scissors, write his name smaller or properly handle a book. He worked very slowly (something other teachers also listed as a non-school ready indicator). Ms. Springstein described her concerns about Jay:

He kind of goes with the flow. He just sits at his desk and continues to do it (cutting with scissors)... even when we are on the rug... and he knows...okay I am going to finish my work. Sometimes I just let it go and he does not have to finish it because I just want him to be a part of the group.

She worried about his slow work pace and his inability to finish his work. She also had concerns that he would be left out of the whole class discussion if he continued to work until he finished.

Jay was, on the other hand, "a good friend," said Ms. Springstein, which she felt was an important school readiness skill. Overall, however, she was concerned that she would have to retain $^{41}$ him, but she was not sure. Teachers generally want to promote all their children to the

\footnotetext{
40 Attention Deficit Disorder

${ }^{41}$ Retention is when the teacher decides the child is not ready for the next grade level, due to academic or social issues, and therefore does not recommend promotion. See Glossary.
} 
next grade. The teachers in this study have rarely retained their students (Ms. Franklin and Ms. Springstein have done it twice, Ms. Watson has done it three times, and Ms. Smith and Ms.

Moore have never retained students). In order to retain a child, the teacher must provide detailed documentation that proves the child is unable to master the material of his or her grade level. It is generally viewed as a negative mark on the child's academic career and is not viewed positively in most schools.

Clearly, Jay’s active behavior was a distraction for Ms. Springstein. She wanted him to sit quietly because she had limited time to get to her curriculum. Her classroom space, a very small portable room behind the main school building, ${ }^{42}$ was also of concern to her. There are 23 five- and six-year olds in this small space, which makes it hard to move around or find sufficient personal space. Jay sat at a rectangular table designed to hold four children maximum, but there were six children at his table.

It's tiny (the portable) and we can't fit...if you notice other portables have different tables. They have large flower tables, so they can fit six kids at a table. I have rectangular tables...that really can fit four to work comfortably. Everything is a logistical nightmare. I do rug writers (children who write at the rug) because there is no room to write at the tables.

During her six years at this school, Ms. Springstein's only classroom has been this small portable, so she is well aware of its physical limitations. As a child who loves sports and movement, Jay needed more space. Perhaps he was dancing and running around to achieve an

\footnotetext{
42 There are six portables behind this particular school building. This is a common practice in this district when space in the main building is at capacity.
} 
illusion of more physical space. At the beginning of every school year, Ms. Springstein has requested to be moved to a larger classroom, but she remains in the small portable.

The factors related to Jay's identification as non-school ready were: limited classroom space and the resulting lack of physical space, and time constraints placed on the teacher and the child. The culture of rushing is not conducive to the academic success of a child like Jay, who worked at a slower pace. Ms. Springstein had to keep him on task so he could advance to the next task on time; otherwise he was always behind.

\section{Michael}

Michael sat perfectly at the back of the rug listening to Ms. Watson's Writing Workshop mini-lesson. His hands were in his lap or on his chin. Ms. Watson said that he was "reluctant to raise his hand" and had a "strong hesitancy." She wanted him to raise his hand of his own volition more frequently. She stated that he was in the bottom third of her class, and that because he had been absent so often earlier in the year, he had slipped back and was far less ready for school than he was at the beginning of the year. According to her, he had missed 24 out of 180 school days. She felt that he was "more with it" when he attended school consistently. This reveals that the label of non-school ready is not necessarily a fixed one, as Michael had been considered school ready at the start of the academic year. His absences, however, contributed to his being labeled non-school ready by mid-year.

On one of the observation days, Michael worked quietly with his math partner and clearly understood the concepts. He laughed, smiled and shared the math materials. He seemed content and interested in the lesson. He rubbed his short hair and intently played the math game, and 
sometimes helped his partner. They took turns placing a random number (between 1 and 10) of bees under a cup and the other child had to guess the number of hidden bees by counting the number of bees outside the cup (if four were on the table, for example, they knew that six were hiding under the cup). He seemed to be very good at math, but he was still classified as nonschool ready. Was it because he was quiet? Or because he was absent too much? When I asked Ms. Watson why she identified him as non-school ready she admitted that she selected him because she knew the family and had taught the older brother, and that she wanted to help Michael succeed. She had concerns about his progress and felt strongly that his many absences affected his progress. In January, she noticed that instead of writing a sentence he drew circles on his writing paper. She knew he could do better. "I think that after he has been absent for awhile...he'll come back in and he'll lose motivation," she said, "and it's my job to get him back on track."

Michael excelled in math, but seemed to have some issues with writing. He had not met the expectations of the teacher in this area and she worried about his progress. He also did not raise his hand often and was not vocal in the classroom. Ms. Watson was primarily worried about his absences. She felt that being present in the classroom was very important to his academic growth and was frustrated when he was absent because she could only encourage him when he is in school. To some degree, Ms. Watson discounted Michael's abilities in math, which is interesting because research (Moses \& Cobb, 2002) indicates that being good in math is a strong indicator of school readiness. In addition, math is an important civil right for Black children, as they need to understand it in order to contribute successfully to society later on (Moses \& Cobb, 2002). 
As I re-read my field notes, I thought that if Michael had been more verbal in class, perhaps he would not have been classified as non-school ready. He seemed quiet and softspoken, and did not raise his hand during the three observations. Instead, Ms. Watson called on him to answer her questions, which helped her determine whether he truly understood the lesson. At one point in our discussion, she revealed to me that she was surprised by how much he raised his hand while I was in the room. She even discussed it with the student teacher and they both questioned whether he was doing it to show off in front of me. When I referred back to my field notes, I noticed that there were no notations to indicate that Michael ever raised his hand in my presence. When I mentioned this to Ms. Watson, she insisted that he did raise his hand. I was sure Ms. Watson truly believed that Michael did take the verbal initiative because she wanted so much for him to voluntarily be a part of the discussion. This was interesting because part of the school culture is raising one's hand, taking the initiative to say something and participating in discussions on one's own terms. Clearly, Ms. Watson and I differed in our perceptions of Michael's participation levels in class. Class participation is an important trait that is graded in kindergarten and appears on the report card. Shy or quiet children who do not take initiative, for whatever reason (e.g., cultural differences, personality differences), will not meet the school's expectations and will receive lower grades.

The factors related to Michael's identification as non-school ready were: his lack of participation, his excessive absences from school and his reticence in whole class settings. The fact that Michael excelled at math was not enough. He needed to excel in reading and writing, too. It is also interesting to note that Michael sat perfectly on the rug and at the table, which is another school readiness indicator presented by the participating teachers. This was an 
interesting case, because despite demonstrating some key school readiness indicators, Ms.

Watson still labeled Michael non-school ready. Furthermore, she believed that although Michael started the year more school ready, his many absences caused him to fall behind. As a result, his status changed. This case revealed the arbitrary nature of school readiness identification.

Billy

The second time I entered Billy's class I had trouble locating him because the children were in different seats. He was very quiet, lying on the table with his head in his arms. He didn't raise his hand either, a consistent theme with all five child participants. He looked up and listened but said nothing. On my third visit a month later, however, he was a different person. He raised his hand and called out constantly. He seemed more comfortable in the classroom space but he was still having trouble following school rules. At one point, Ms. Smith reminded him that he was not asking a question but was making a comment, and cut off his narrative. Calling out (not being able to wait to speak) was another non-school ready indicator that the teachers cited. He also lacked control of his body. During my third observation, I watched him remove his right shoe three times and wipe his foot with his hand. Later, when I told Ms. Smith about his movements, she said, "Oh, I didn't notice that...he's not usually." She later told me that she has the ability to tune out things when it gets too hectic in her classroom.

Like the other teachers, Ms. Smith was teaching a class of 23 young children all by herself. In order to keep things moving, she had to limit students' calling out and not responding in a proper manner (e.g., making long comments instead of asking questions). She was on a strict schedule, like her colleagues, and needed to cover a lot of material by the end of the school day. 
She wished she had time to listen to her children's comments and give them real time to evaluate and respond, but she needed to move on. She, did, however, use fewer control tools than Ms. Watson, Ms Moore and Ms. Springstein. Clearly, different styles of teaching also affect school readiness perceptions, because different teachers have different capacities for tolerating nonschool ready behavior (such as calling out).

Billy, who was just starting to participate, was still having trouble navigating the culture of the school (e.g, raising hands to speak, not calling out). He finally engaged in the lesson, but was still unsure about how to do it. Ms. Smith praised him when he raised his hand and called on him frequently, but she ignored him when he called out to send him the message that calling out was not allowed. If there had been more time, she would have been able to linger over his comments, instead of cutting him off, but she felt the pressure to move forward for the sake of all 23 children, even if they were all receiving and engaging in the lesson at different rates.

During our last interview in June at the end of the school year, Ms. Smith pointed out that she was surprised by his progress. He had come a long way and she was no longer sure if he remained non-school ready or if he ever truly was non-school ready in the first place. She had started to think he was simply on the immature side when he entered first grade and that he had grown and was more ready by the end of the year. By her own admission, Ms. Smith was unsure about the term school readiness and felt it was an imprecise identification. In the end she was content with Billy's academic and social progress. She realized through this exercise that school readiness is less important in long run than progress over time. 
The factors related to Billy's identification as non-school ready were: his inability to follow school culture (e.g., not being able to raise his hand without calling out), being non-verbal and working slowly.

\section{Derek}

Like Jay and Billy, Derek was also highly active and constantly distracted himself. During one observation, he threw rubber bands as he made geo-board designs. It was math time and everyone was working in different centers. He was creating designs with shapes on the geoboard. He talked, laughed and smiled, and flicked rubber bands into a pile. Ms. Moore shouted his full name and he stopped Derek loved Ms. Moore. He walked over to her and stood by her whenever he could. She said that if he could, he would sit by her all day long just to be near her. When he went to the bathroom, she reminded him to turn off the water in the sink. When he came out, she reminded him to fix his belt. He diligently pulled up his pants, which revealed his boxers, and returned to his seat.

Derek is Haitian and speaks Creole. Ms. Moore said that he sometimes spoke Creole to other Haitians in the classroom, but stopped whenever he saw Ms. Moore looking at him. He was classified as ELL (English language learner) ${ }^{43}$ and was eligible for an ELL inclusion classroom (located at another school in district), but he could not attend because his mother had no one to meet him at the bus after school (he lives alone with his mom; his father was dead). Ms. Moore continually worried about him, particularly his entering first grade the following year. Yeah, I think he is going to have some difficulty settling

${ }^{43} \mathrm{ELL}$ are children identified through testing to be English language learners. They speak another language at home. See glossary. 
in to a new teacher, new procedures...new routines... and new material on top of it. I am worried about him. He is like the one that was on my mind all year....like one of those kids that you are just constantly assessing...reassessing...double thinking yourself. What kind of progress is he going to make? Is he going to hit that wall where maybe...he's comfortable here but he won't be comfortable with first grade?

Clearly, Derek's teacher had concerns about him being non-school ready for first grade as well. Ms. Moore had a special bond with him but what if the first grade teacher did not? She was afraid that he would be perpetually identified as non-school ready. She constantly assessed him and reflected on his progress in academics and his adjustment to school culture, because she knew he would struggle in the next grade if he did not make progress in these areas.

Derek was exceedingly likable. He had a great working relationship with Ms. Moore, which helped his progress. He clearly needed to be physically near his teacher. Again, this was hard for her because she had a class of 23 kindergartners, all with different needs that warranted her attention. She bemoaned the fact that she was the only teacher in the room. She felt very strongly that there should be two teachers for every 20 children. She just couldn't do it all. She felt overwhelmed by all of the pressure from the district and believed she did not receive needed support. Like her classroom neighbor Ms. Springstein, she was also located in a very small portable, with limited physical space. Ms. Moore could only utilize rectangular tables, around which five or six children squeeze, because there was no room for additional tables. You could hear noise from the neighboring portable, which was very distracting, but she had to make the best of it. She organized the space by giving children rug spots and designated table seats, and 
tried to keep them from physically bumping into each other. Like Ms. Springstein, she would have liked to move inside the main school building but all those classrooms were also occupied.

The factors related to Derek's identification as non-school ready were: his inability to follow school culture, his difficulty working independently, his inability to adapt to routines and his surroundings, being non-verbal and the lack of physical space.

\section{The Ability to Follow School Culture}

The above snapshots of identified non-school ready children reveal the importance of fitting into school culture. ${ }^{44}$ Ms. Smith referred to this as the ability of a child "to understand how a classroom is run." Following school culture means that the children know what is expected of them and are able to follow these guidelines without being redirected. Ms. Smith equated knowing and understanding school culture as being school ready.

They [school ready children] understand the school community and the school responsibility...like for themselves. They know... and I am not talking about organization...but they know...they understand little things...like their homework folder... where they put their homework...that they have homework every night...that they read every night...and they may just throw all of their stuff in their bookbags. But they understand what they need to do.

Ms. Smith highlighted above the main premise of school culture, which is knowing how to "do school" properly. This point was important to the teachers in the study, because even though

\footnotetext{
${ }^{44}$ By school culture I am referring to White middle-class norms of schooling.
} 
they realized they must teach aspects of how to do school, they still wanted the children to arrive having some knowledge of the school's culture and how it effectively works.

Ms. Springstein, a former preschool teacher, believes that learning how to do school and follow school culture should be a part of a preschool program, so that children are ready to enter formal schooling. To her, school readiness includes being able to be a good friend, work cooperatively, sit for a period of time, raise one's hand (not call out), walk in a line, listen and follow directions. "I want my kids to do school so they are ready for school," she said. In other words, the prior school experience of children entering kindergarten and her classroom is of extreme importance because that is where they should have been exposed to the culture of school. It is important to note the paradox of this statement, as children need school experience in order to be school ready, yet when they come to school for the first time they are often identified as non-school ready.

In reality, however, first grade is the first mandated grade of education for children who live in this state. Therefore, children are not obligated to attend school on a regular basis before this age. Preschool and kindergarten are optional, and not necessarily a part of every child's experience, especially low-income or poor children. When I conducted this research there was only one free preschool classroom in the district, and it was limited to special education students. Families must pay out of pocket to send their children to school before kindergarten. In addition, children are not mandated to attend kindergarten, which is why Lina and others enter first grade from non-certified kindergarten programs. ${ }^{45}$ Furthermore, all preschools are not equal and do not cover the same material. Some are storefront daycares (like the ones Jay and Derek attended) and

\footnotetext{
45 Uncertified kindergartens are programs that are not sanctioned by the state and do not have to follow the curriculum and standards (core curriculum) of that state.
} 
others are affiliated with churches. Some only provide half-day programs while others are expensive, full-day child-centered preschools. Some children do not attend any preschool or daycare prior to kindergarten (like Michael and Billy) and therefore have difficulty adjusting to a full-day schedule (for example, Billy hid under the table and cried for the first few days of school). Thus, the ability to follow school culture is not a given or uniform, and is not necessarily being taught or experienced by the child before the child enters these teachers' classrooms.

\section{$\underline{\text { Socio-Emotional Skills Needed }}$}

According to the participating teachers in this study, in order to be able to follow the culture of the school and be able to do school properly, children need to be socially mature and be able to play well with others; be a good friend; listen; manage and control their bodies; sit well on the rug or at the table; use the bathroom properly; walk in a straight line; give a verbal opinion; talk about books and handle them properly; follow directions well and organize their belongings. These abilities are all indicators of school readiness for these teachers. Children who are not able to do these things are classified as non-school ready. They must also be able to follow the culture of school and respect and obey authority.

Having socioemotional skills (knowing how to behave socially) is very important to the teachers in this district. $59.09 \%$ of teachers surveyed $(n=24)$ felt that it was very important for children to be able to share with other children. Interestingly, only $27 \%$ felt that it was important for children to know their numbers to 20 before entering school. Overall, the possession of academic skills and knowledge before entering school were less important to these teachers than 
socioemotional skills. The interpretative focus group made this point very clearly. A kindergarten teacher (\#6) stated, "I think when you are talking about early childhood you are talking about [socioemotional skills] first, because without these things...the academics can't come if the kid is not ready to receive it...socially, emotionally and developmentally." When talking about the additional academic demands and expectations placed on teachers and therefore on students, these teachers made a point to state that it was more important to teach socioemotional skills to their children. A first-grade teacher (\#11) stated:

It's (the Common Core) expanding the gap of social skills...just being...going from me-centered to other-centered. Or how to negotiate when you are playing with someone, so if you don't get what you want you don't throw something. There is no time to spend the effort to have children learn those...instead you are learning more academic...but those, if they are not mastered...the children have gaps.

This teacher made the case that without necessary socioemotional skills, children cannot move forward and achieve academically anyway. If children come in with varying degrees of socioemotional skills, the gap widens over time within the school because teachers must now concentrate so heavily on increased academic expectations and meeting higher standards. ${ }^{46}$ The participating teachers, in their own focus group, agreed with this analysis and felt that socioemotional skills were more important than prior academic knowledge for children entering their classrooms. Ms. Smith emphatically stated, "I don't care if they know their letters at all." Ms. Springstein responded, "Right, because you can teach them that." They felt that children should be more organized, be able to pack up their bookbags and locate their homework,

46 The Common Core curriculum (effective in the 2013-2014 school year). See glossary. 
and be good classroom citizens (for example, by saying put-ups, being respectful, helping people, etc.). According to the participating teachers, academics will follow, but only if these socioemotional skills and organizational skills are in place.

\section{The Time Bind - The Culture of Rushing}

A huge factor that relates to the classification of the non-school ready child is the lack of time for instruction and assessment the teachers have in their daily schedules. Time is highly constrained and teachers have to make the most of these restrictions. The challenge of time and the culture of rushing affect their daily routines and what they can actually cover in a six-hour day. This in turn, impacts the identification of the non-school ready child because all children must move forward at the same time even if they are not all ready.

Harvey (1989) refers to increased time constraints as time-space compression. He believes this occurs as a direct result of advances in technology within economies, which includes increases in production speeds. Cultural changes can alter the relationship of space and time (Harvey, 1989). He claims:

We have been experiencing, these last two decades, an intense phase of time-space compression that has had a disorientating and disruptive impact upon political-economic practices, the balance of class power as well as upon cultural and social life (Harvey, p. 284, 1989).

Schools, too, are affected by this time-space compression, because they are a large part of our cultural and social life. Therefore, the need to speed up in order to cover more material in the same time period directly impacts teachers' everyday lives. 
For example, all teachers in this district must complete a master schedule and give it to their administrator at the beginning of each school year. Teachers are required to teach a certain amount of minutes of each core subject daily (90 minutes of math, 90 minutes of reading/writing, 30 minutes of social studies and 30 minutes of science). There is also a 55-minute lunch block (that includes recess), a 50-minute special ${ }^{47}$ per day, and 15 minutes for morning announcements and the morning meeting, all of which add up to exactly six hours, with no minutes to spare. ${ }^{48}$ There is no time in the schedule for snacks or unpacking, which happens regardless, since young children need breaks to eat and time to unpack and pack up their belongings. In addition, there is no time for transitions, ${ }^{49}$ especially if you have to walk your class to the art room on the other side of the building. This schedule was labeled by the participating teachers as "works of creative fiction" (Ms. Franklin's term). They must create a schedule that is in line with the expectations of the administrator, whether or not they adhere to it in their classrooms. All master schedules must be approved by the administration and are put on file in the school building (a copy is sent to the district office). The master schedules allow the administrators to know what is being taught at a specific time during the day so they can stop by the classrooms for unannounced observations. ${ }^{50}$ Thus, it reflects poorly on the teachers if they are not doing what is indicated on their master schedules.

In the participant focus group, several teachers admitted to fudging their master schedules and sometimes going "rogue" (Ms. Smith and Ms. Franklin's term) or taking the risk to venture

\footnotetext{
47 Specials in Art, Music, Gym and Library

48 Six-hour days are mandated in this state.

49When children move from one area to another or start a new activity. See glossary.

50 Unannounced observation happens twice a year. See glossary.
} 
beyond their planned lessons and the confines of their master schedules to do something more creative with their class. ${ }^{51}$ Because the teachers can shut their doors and not be bothered, they are occasionally able to conduct different activities. They acknowledge that this is sometimes risky but they believe in fostering creative learning experiences, even if they stray from the mandated curriculum. Their practices are usually within the curriculum (e.g., writing poems about space or painting pictures of planets) but may not be part of the actual lessons they are expected to cover. Ms. Franklin referred to this as doing things that she knows in her heart are appropriate for the children and beneficial to their learning, even if they fall outside her mandate. "I feel like you wind up doing things that you feel are not right to do...I feel like as a teacher....at some point you have to know what you need to do for your kids." Teachers need to take time back into their own hands. Due to higher expectations and demands, they are being pressed into service and must adhere to unrealistic master schedules, which in turn adds more demands on their children, including their struggling learners.

\section{No Time for Play}

Furthermore, the culture of rushing allows no time for free play (e.g., blocks, Legos, puppetry, dress-up, etc. $)^{52}$, which is no longer an acceptable part of the scheduled day for early childhood classrooms since there is literally no time for it. Many of the teachers who participated in the study believed this to be problematic as it changes the nature of the classroom from childcentered to teacher-directed. "I think that in kindergarten you should be learning through

\footnotetext{
51 Teachers have to hand in their lesson plans to the principal every two weeks.

52 It is important to note here that 'free play' is a complex term that has a variety of definitions. In this instance I refer to it as play that involves free choice, or agency on the part of the child. This differs from teacher directed play activities.
} 
play...you should have a kitchen area and a block area," said \#10 in the interpretative focus group. "It should not be a place where little people at five years old are sitting around and holding a pencil," she continued. Both focus groups spoke about the inappropriate nature of the new curriculum and felt that there was no longer any time for creative play. When speaking about the kindergarten classroom a decade ago, \#9 stated:

We were much more child-centered based...it was more social. They learned with each other...together. They assisted each other in their learning. It wasn't just teacher-based...now it's much more individually focused with the new workshop model.

The teacher was referring to the switch in curriculum to Reading Workshop (Lucy Calkins/ Teachers College) and Math in Focus, the new math curriculum. Both programs reinforce more individual learning time than shared learning time. The shift to individual instructional time is key to the present neoliberal agenda as it is corresponds to an emphasis on individual achievement (including test scores). This comes at the expense of shared learning time.

In the past, according to the participants, there was a Vygotskian or shared approach to learning, which gave the children more opportunities to work together and learn from each other. With this approach, learning through play is socially constructed and children scaffold their knowledge through cooperative work. The teacher's role is to support the children's learning within their ZPD (zones of proximal development) so the children can co-construct meanings with others through engaging in materials (Jordan, 2009). Considerable flexibility of time in the daily schedule is needed for this approach, as its success depends on the each child's particular interests and having large blocks of time to explore different learning centers without teacher interference. Jordan states, "Co-construction thus places emphasis on teachers and children 
together studying meanings in favor of acquiring facts" (Jordan, 2009, p. 43). According to Jordan, learning happens when children and teachers co-construct meaning, not when children participate in drills of facts. The teacher participants wished they had time in their schedules so children could learn through this child-centered approach. Instead, they are limited to administering paper and pencil drills.

As a first-grade teacher myself, I am not ashamed to admit that I fudge my master schedule in order to allow more free play in the schedule (see Table 4). In order to meet the daily math requirement (90 minutes per day), I claim that I do 20 minutes of calendar math in the morning (it is more like five minutes) and do math games in the afternoon for 20 minutes (after a 45-minute math lesson). Instead, I have choice time after the math lesson, where children get to choose different activities and learn through play (Legos, blocks, painting, board games, PlayDoh, music, etc.). By doing this, I am also going rogue as I am purposely devoting time to something that is no longer sanctioned but that I believe is essential for children's learning process. This is not necessarily going on in other rooms, as teachers try to stick to the sanctioned time requirements. They are reasonably afraid that if they venture too far from their schedules, they will get in trouble. 


\section{Table 4}

\section{Master Schedule for Mondays}

1st grade - Ms. Tager's classroom

\section{Schedule 1 (for office)}

Morning Announcements

AM Meeting

Calendar Math

Reading Workshop

Writing Workshop

Recess

Lunch

Special

Math

SS/Science

Math games (IMI)

HW

Dismissal

\section{Schedule 2 (real one)}

Unpack

Morning Announcements

AM Meeting and Calendar Math

Introduction to Artists

ICARE

Reading Workshop

Writing Workshop

Recess

Lunch

Special

Story time

Math and IMI

SS/Science

Snack

Choice

Goodbye circle

HW and pack up

Dismissal

*Story time - I read one chapter of a book to them.

*ICARE is a 10-minute game that emphasizes important social skills (e.g., sharing with others, being a peacemaker, using active listening skills, etc.).

*Introduction to Artists is a 10-minute lesson that explores great art masterpieces and artists' lives (e.g., Van Gogh, Monet, Pollock, O’Keefe, etc.).

*IMI is individualized math instruction that consists of math games in small groups.

*Choice is when the students get to choose from different rotating activities in class (Play-Doh, Legos, blocks, watercolors, puzzles, games, etc.). 
*Goodbye circle takes place at the end of the day. We pass a beanbag around the circle and thank the people who were nice to us that day.

\section{Stick to the Schedule: The Culture of Rushing}

Time is limited within the teachers' daily schedules and it therefore must be adhered to as much as possible. Otherwise, they will not be able to cover the new and demanding curriculum in its entirety. For example, the Math in Focus program contains 19 chapters for first-grade teachers to cover, which include a pre-test and a post-test for each chapter (the tests must be recorded in Power School for district examination). ${ }^{53}$ The program offers a breakdown of how many days a teacher should be teaching and reviewing each chapter. Whether all of the children understand the concepts or not, the teacher must move on in order to get through all of the chapters. In reality, this is impossible. Some teachers skip parts of chapters or quickly review them in order to catch up and some teachers simply do not cover all the chapters. A culture of rushing through the curriculum is now commonplace and within this culture an identified nonschool ready child stands out more and is left further behind their peers.

The culture of rushing is intensified by the high-stakes testing and teacher accountability movements. Although the time in the day to teach has not changed (it remains six hours), the amount that has to be covered in a day has increased considerably. Ms. Smith stated:

When I came back from not teaching for 10 years I was in shock about how much kids had to do. When I left teaching we taught four writing units in an entire year. When I saw that there were six or seven for second grade I was... and the time...deadlines...shocking!!”

53 Power School is a data entry system. See glossary. 
There are now too many units, too many chapters and generally too much material to cover, and there is not nearly enough time in the day. Ms. Smith later admitted, “....although I am going rogue and being creative and somehow making it all work now." She was trying to make the limited time work for her, but in order to do this and continue to be a creative teacher, she said she works very long hours, until six p.m. (dismissal is 3:15 p.m.). In order to make more time in her schedule to be 'creative' and go 'rogue,' she needs to use her own personal time to plan for it.

In essence, Ms. Smith is accomplishing more with less time, but for the same amount of money. This is the essence of global capitalization, and in this case the school district is squeezing more out of its working teachers. The district expects more in less time, like a factory production line. Devault states, "The new economy is bringing new stresses to working life. Many jobs are changing and mostly not for the better" (Devault, 2008, p.25). According Devault, there is a "climate of pressure" in which workers (teachers in the case of this study) are asked to do more with less (i.e., accomplish more work in less time). The climate of pressure impacts these participating teachers as they are under the gun and struggle to keep up with the increased expectations of the district.

\section{Time Management and Control Tools}

Time limitations call for proper time management on the part of teachers and are also a huge factor in the identification of non-school ready children. Teachers therefore must keep the class on task through different techniques in order to conserve time. Every minute counts. An example of this is when my administrator, Mr. Dodd, actually timed the transition in my lesson that he observed. He later told me in my post-observation conference that my class spent over 
two minutes transitioning from the tables to the rug (they were cleaning up before going to the rug). He considered this to be a detriment to my teaching because he believes that every minute of instructional time counts and none should be wasted on transitions. As an early childhood educator, I disagree with this philosophy because children need transitions, and they need time in between activities to think, socialize and simply be young children.

As the tight master schedule in Table 4 above indicates, each second of instructional time counts, especially if teachers have a lot of material to cover. Thus, the teachers in this study utilized different management techniques (or control tools) to keep their children on task, such as singing songs, hitting wind chimes, flickering lights, finishing word patterns, etc. In one observation, a kindergarten teacher used more than nine control tools in a 25-minute period. A tightly controlled class means more engagement with learning and the ability to cover more material. There is no time for children who need to review material before they completely understand it. There is no time for laughing or fooling around with friends. "All eyes on me!" is a phrase I heard over and over again during the observations because there is no time to slack off. There is also no time to stretch or move, which is essential for young children. The participating teachers are not trying to be mean. Nor do they lack compassion for the struggling five- or sixyear old child. They are just under pressure because every second counts.

Expansion of curricula and the addition (without the corresponding removal) of material also affects this time crunch and impacts the culture of rushing for these teachers. During the seven years I have taught in this district, teachers have been given new material for each set of curricula on a yearly basis. That translates to approximately two to three new curriculum units per year. In all that time, only one unit (a writing unit on poetry) was removed from the 
curriculum and discarded (although I still do it) because it is not aligned with the Common Core standards. Therefore, new units and lessons have been added across the curriculum but no time has been added to the teaching day. Teachers are expected to incorporate and cover additional new material even when they are having trouble covering all of the existing material. This added pressure places even more time constraints on the teacher, which in turn creates more struggling learners who are unable to keep up.

\section{No Win Situation}

Teachers' perceptions of non-school ready children are closely intertwined with multiple factors (such as time, physical space and district demands) that I refer to as the ecology of school readiness. The skills that teachers are looking for in young children all need to be in place so they can successfully cover all of the daily required material. These skills include a variety of socioemotional skills (being able to sit, listen, share and work with others) related to the culture of school that are necessary for the teacher to actually teach the mandated curriculum. There is a strict limitation on time and therefore teachers must use more time management techniques to continue to advance. Not a minute is to be squandered, as every minute counts. The new culture of rushing greatly impacts how these teachers proceed through their expanded curricula. They have to abandon child-centered learning through play (including blocks, Legos, dress-up, puppets, etc.) in order to cover the basic material mandated by the Common Core standards. More uniformity in socioemotional school readiness skills needs to be in place for all children, despite their individual needs and capacities, than is realistically achievable. If children do not know how to sit on the rug, it will affect their progression with the daily lessons. Time 
management and control tools are now more important than ever since every second is already accounted for and there is no wiggle room. There is no time for a short walk in the garden (unless it is within science instruction), no time for extra minutes on the playground on a sunny day, no time to stretch or eat snack, no time for creative play and no time to socialize and learn through exploring materials with classmates. There is a strict timed agenda and the teachers in this study are all well aware of it. They are under the gun and per their SGOs, they have to bring every child up to a certain level in math and reading, which makes non-school ready children in their classrooms liabilities rather than an opportunities for growth. Furthermore, there is the problem of limited physical space, as these teachers have filled-to-capacity classrooms that are hard to navigate. Noise levels are higher and children have less space to learn.

In the next chapter, I address these higher demands on teachers in more detail, including the pushing down of the curriculum, the unrealistic demands of the Common Core standards, the increased assessments and data input, the developmentally inappropriate practices, the undemocratic culture, the lack of district support and the unreasonable evaluative teaching measures. All of these issues relate to how White middle-class teachers identify and perceive school readiness or the lack of school readiness in already marginalized populations of lowincome Black children. 


\section{Chapter Five}

\section{"It is so inappropriate" — Higher Demands on and Expectations of Teachers}

We are seated around the long wooden table in Ms. Springstein's dining room. It is getting late and it is hot. Ms. Tager's forehead is perspiring and the food is almost gone. The teachers, even with the heat, are anxious to talk more about the district and the demands put on them.

Ms. Moore: The lack of district support (heavy sigh) it is so obvious...common sense...ridiculous.

Ms. Franklin: What kind of support?

Ms. Springstein: They walk around...

Ms. Franklin: That's number one who is interrupting.

Ms. Springstein: I am sorry.

Ms. Moore: support...not one teacher and 23 kindergarten children wetting themselves...with anger problems...on top of teaching... you know to a level $6(D R A)^{54}$. You know it's just like blinders LALALALALA (loudly)

(laughter)

Ms. Franklin: And that is number five.

Ms. Tager: Please note that she is covering her eyes.

Ms. Moore: And that's it... and by the way put all the Briganz scores ${ }^{55}$ on this form and send it back to me by Monday.

Ms. Springstein: Right.

${ }^{54}$ Developmental Reading Assessments. See glossary.

55 Briganz screening is a test for incoming kindergarten children to determine the skills they are lacking before entering school. See glossary. 
Ms. Moore: This is my first job...I have never worked in another district. I don't know... maybe it's like this everywhere.

Ms. Smith (quietly): No it is not. ${ }^{56}$

Ms. Moore: It's just so obvious to me...it really gets my goat.

Ms. Springstein: Yeah, she gets really upset...like even with the emails from yesterday.

Ms. Moore: After lunch we got an email from the principal.

Ms. Springstein: Now we need the Briganz ...the new scores for the children coming in. We need these scores on this spreadsheet by this afternoon.

Ms. Moore: And also an email from the math supervisor. ${ }^{57}$

Ms. Springstein: And the language arts supervisor ${ }^{58}$...this is what you need in your language arts portfolio... Why are you telling us three days before the end of school?

Ms. Moore: And we get a letter from [math supervisor].

Here's a letter now you gotta go on ST Math ${ }^{59}$ and write down the percentage of each child and that has to go home in the report card.

Ms. Tager: I think I ignored that email.

Ms. Springstein: Two days ago...but that's the level that we are talking about...like stop...stop ...no more...you can't keep sending all that stuff to us while we are trying to teach.

Ms. Franklin: Well, obviously.

Ms. Springstein: With no help!

\footnotetext{
56 Ms. Smith worked in another state over ten years ago and was referring to that district at that time.

57 The math supervisor is in charge of the math curriculum for all K-5 schools.

58 The language arts supervisor is in charge of the reading/writing and social studies curricula.

59 STMath is a supplemental computer program for learning math. See glossary.
} 
Ms. Franklin: It's all about the data...it's all about the data. ${ }^{60}$

Ms. Springstein: We have been asking for smaller class sizes... and our principal says no no no, absolutely not.

Ms. Franklin: That's the kind of support we...

Ms. Moore: (interrupts) Well...so our PLC ${ }^{61}$ was on how to close the gap in our kindergarten students.

Ms. Tager: In reading?

Ms. Springstein: Because we have...how many kids? 30...35 kids are seen...35 kids are pulled out of kindergarten.

Ms. Tager: Is that almost half?

Ms. Springstein: Yeah.

Ms. Moore: So we came up with at least six suggestions on our PLC...emailing administration almost every week and "no...no...no."

(Ms. Springstein yells something at her husband in the kitchen doorway and comes back to the table)

Ms. Moore: So that's why I was saying...he wants us to fix this.

How can we get less kids in academic intervention?

Well we need more support. "No...you can't have that" Okay, well look at this book they put in our mailbox...on the Common Core.

Ms. Springstein: (imitating principal) "No you can't have that."

Ms. Moore: "No, we can't get the book"...okay (laughter) How about we (the kindergarten team) come inside (the building)... "No...no... no...you can't come inside..." Okay, it's just one thing after another! And he buys us the B books'22... and then I said, "Mr. Dodd...they can't open their books on the table." (laughter)

60 Data is in reference to children's test and assessment scores.

61 Professional learning community is a teacher learning community that meets once or twice a month over the year. See glossary.

62 Bbooks are communication books that go home to the parent each night. See glossary. 
Ms. Tager: Because the tables are too small?

Ms. Springstein: Yes.

Ms. Tager: Does he even say anything about that?

Ms. Springsten: No.

Ms. Moore: No and that was it.

Ms. Springstein: We asked him about the kindergarten report card.

Ms. Tager: Right.

Ms. Springstein: Can we please change the kindergarten report card?

Ms. Moore: At least for November?

Ms. Springstein: The 75 indicators ${ }^{63}$ for the kindergarten report card... I don't think we need 75 indicators. I mean that's my opinion.

Ms. Tager: You know when I was a kid...it was can they zip their coat or tie their shoes.

Ms. Springstein: Right./.that's still on it, but there's also ones like...[waits turn to speak]...that's good...that's fine.

Ms. Moore: Organizes personal belongings.

Ms. Springstein: Perfect...they need to be able to do that.

Ms. Moore: Uses beginning and ending sounds when writing independently.

Ms. Springstein (laughing) Yeah...uses developmental spelling.

Ms. Tager: In November?

Ms. Springstein: Uses beginning sound...uses ending sound...uses middle and ending sounds.

${ }^{63}$ The number of marking areas that the teachers must grade each child on three times per year. 
Ms. Moore: Uses the rest of the sounds.

Ms. Springstein: Uses CVC sounds ${ }^{64}$.

Ms. Moore: Like it's just silly.

Ms. Tager: Every sound?

Ms. Moore: Yeah, also the DRA in September is very tricky.

Ms. Springstein: If you don't know your letters and your sounds.

Ms. Moore: You don't know how to read.

Ms. Springstein: They might end the DRA in September...because the new assistant superintendent ${ }^{65}$ I think she's normal.

Ms. Tager: Do you think it is the change in district personnel?

Ms. Springstein: Yes, because I think that assistant super that we had for the last year...

Ms. Moore: She's only been here one year hasn't she?

Ms. Tager: I remember the other one...

Ms. Smith: Two years.

Ms. Springstein: Oh, okay, so she's only been here two years? And she changed a lot of things this year...like really fast... and I am going to say it...so INAPPROPRIATE!!!

Ms. Franklin: Yeah, that is what our superintendent ${ }^{66}$ is...totally inappropriate!

64 Consonant/vowel/consonant (e.g., bug, jar, mop)

65 Assistant Superintendent of Instruction.

66 The superintendent of the past six years quit the month before and at the time of this writing the district is looking for a new one. This old superintendent was known for embracing data and teacher surveillance tools. 
The comments above, made by the teachers in the participating teacher focus group, clearly demonstrate that higher demands from the district affect early childhood educators' everyday teaching lives. The early childhood educators in this study spoke often about these added pressures and how they impact their daily lives.

In this chapter, I unpack and examine the higher demands from the district (which trickle down from the state) that are placed on early childhood educators and analyze how these demands and web of expectations negatively impact the teachers' perceptions of non-school ready low-income Black children. Drawing from individual and group conversations (like the one above) the teachers identified the following issues: expansion of curriculum and adherence to Common Core standards (the pushing down of the curriculum); the increase in math and reading assessments and data input; the requirement to use developmentally inappropriate practices; an undemocratic culture and atmosphere; and an increase in teacher accountability systems without the provision of additional district support (such as early intervention services and technological support). These higher demands, as I demonstrate below, are relatively recent developments and are a direct result of the standards and accountability movement.

\section{The Common Core}

The Common Core is now being implemented in 43 states. It is a product of the standards movement. Governors and education chiefs from each state wrote these higher standards. The Common Core is designed to ensure that the standards for learning in grades K-12 are consistent from state to state. The premise of the Common Core is that every student will be 
exposed to the same standards and curriculum, thus ensuring equal access to education throughout the United States. As a consequence, regardless of where children live in the United States, they will all be exposed to the same quality educational content. This thinking, however, is flawed because each state still spends different amounts of money on each child's education (for example, Massachusetts spends $\$ 14,285$ per pupil and Oklahoma spends only $\$ 7,631$ per pupil) (www.nces.ed.gov). This means that some districts and schools have more money to spend, while students in states that allocate less money per pupil can suffer inequities that affect educational quality.

Furthermore, property taxes also vary from state to state (New Jersey and California are the highest) and district to district. ${ }^{67}$ Since the taxes are tied to the funding of states' school systems, they greatly impact the amount of money schools receive to invest in resources to aid in their curriculum goals (e.g., technology, materials, books, etc.). Property taxes also pay teachers' salaries, which results in a wide discrepancy between teachers' salaries from state by state and from district to district. ${ }^{68}$ Thus, even if the Common Core had been adopted by all 50 states, each state and each district would be trying to meet the Common Core's goals with wide variations in funding. It also means that some districts will be more successful implementing the Common Core and adhering to its goals while others will continue to founder.

The Common Core also inadvertently pushes down the curriculum, by adding more assessments and higher level testing benchmarks ${ }^{69}$ in the earlier grades. Therefore, first graders

\footnotetext{
${ }^{67} \mathrm{~A}$ three- to four-bedroom house in this district has an average annual property tax of $\$ 20,000$ to $\$ 40,000$, which is considerably higher than other districts and townships, even in this state.

68 In Arkansas, the average salary is $\$ 46,500$. In New Jersey, it is $\$ 66,612$ (www.teacherportal.com). ${ }^{69}$ Benchmarks are predetermined goalposts in the assessments that each child should reach by a certain point in the year. See glossary.
} 
are being given second-grade work and kindergarten children are expected to learn first-grade work. This pushing down of the curriculum greatly impacts the teachers since they are now expected to assess children's abilities that may not be developmentally appropriate (e.g., reading and writing entire paragraphs in kindergarten, regrouping of subtraction in first grade, etc.) The teachers who participated in this study believe that kindergarten is no longer kindergarten and that the expectations on both the teacher and the child are not appropriate. A kindergarten teacher (\#6) in the interpretative focus group stated, "I really think it [the pushing down of curriculum] needs to be a top-down thing...that administrations and boards of education need to remember that five is five and four is four." The pushing down of the curriculum was one of the teachers' biggest laments and was present in multiple discussions on their teaching practices. Ms. Smith stated:

$$
\begin{aligned}
& \text { You know kindergarten is not kindergarten } \\
& \text { anymore. It's now...there's no more nap times } \\
& \text { there's no more half days. It's almost like } \\
& \text { kindergarten is the new first grade and first } \\
& \text { grade is the new second grade and that's how } \\
& \text { I look at things. }
\end{aligned}
$$

Above, Ms. Smith spoke to the changes in teaching and how kindergarten looked very different just four or five years ago. It should be noted that the kindergarten teachers I observed did not use nap or rest times. Ms. Moore's utilized a "working rest time" after recess, during which time children worked quietly with the lights out. When I joined this district seven years ago all kindergarten teachers and some first-grade teachers included a rest period, but over the years that changed as more curriculum was added and expectations increased. Five- and six-year old children still need a rest period, however, and the participating teachers said that without one it is 
hard for the children to stay focused during such a long school day. Ms. Moore believed that some kind of down time is essential, as the children are not able to focus on their work by the end of the day. They have to sit and be actively engaged for so much instruction time that they easily tire. It should be noted that the kindergarten in this district went to full day (this is not mandated by the state and there are still half-day programs in a smattering of districts) six years ago, as part of the increase in standards. With the implementation of the Common Core, a full day is essential.

Ms. Springstein also believes that this pushing down of the curriculum is harmful to the young child:

Ms. Springstein: We used to have to start guided reading ${ }^{70}$ in January [kindergarten] and now they [the district] want us to start in October.

Ms.Tager: Right.

Ms. Springstein: It is really not appropriate for kindergarten.

Ms. Springstein's concerns are legitimate. She knows that establishing reading groups (by reading level) so early in the year, when most of the children do not know their letter sounds, is a recipe for failure. Young children (five-years old) who are not necessarily ready for reading groups, founder and do not know what to do because they cannot yet decode words. It is also hard on the teachers because they must give guided reading lessons to a small group while the other $17+$ children work on another task. This is a logistical nightmare for the teachers, who

70 Guided reading is small group instruction at the teacher's desk. See glossary. 
require several months simply to train the young children to stay on task without interrupting them during the guided reading group.

These teachers were also very troubled by how the new and increased standards put more pressure on the teacher to produce higher results (DRA levels). This means that at every testing point during the year all children must meet previously determined benchmarks; otherwise they are considered below grade level (kindergarten and first grade are not testing grades and do not have a history of enforced testing or assessment). ${ }^{71}$ An example of this is the higher expectation for DRA scores. With the adoption of the Common Core, the DRA benchmarks increased by one or two levels, depending on the grade level. In kindergarten the teachers are now supposed to get their students to level 6, instead of level $3 .^{72}$ In first grade, children who came in at a 4 in previous years were right on grade level, but now they need to be at level 6 . At the end of the year they must also be reading at 18, instead of 16 (see Table 5 below). This increase in levels is very difficult for the teacher because there are now more children who are considered to be performing below grade level. This means that more children leave the classroom for academic intervention services (which is a scheduling nightmare) and are labeled as non-school ready. I have personally had to explain these changes to anxious parents who didn't realize that if their children had attended first grade only a year before, they would have been classified as school ready and been on grade level, but because of the mandated increase in levels these same children are now identified as non-school ready and below grade level. With the increases in levels, the new SGOs (which are a product of the Common Core curriculum) are harder for the

\footnotetext{
71 Elementary school testing grades in this state are 3rd, 4th and 5th grades.

72 Level 3 books change patterns at the end and are therefore harder for children to master. Children then lose points in their scoring because the predictable pattern has changed and they cannot decode the new words.
} 
teacher to meet by the end of the year. In other words, in order to meet their SGOs, teachers must help all their students increase their reading levels by a certain number. This is harder to accomplish if the benchmarks have also increased.

Table 5

DRA Benchmarks in Reading:

$\begin{array}{ll}\text { Kindergarten } & \text { First Grade } \\ \text { Entering - level 1 } & \text { Entering - level 6 } \\ \text { November - level 2 } & \text { November - level 8 } \\ \text { January - level 3 } & \text { January - level 12 } \\ \text { March - level 4 } & \text { March - level 14 } \\ \text { June - level 6 } & \text { June - level 18 }\end{array}$

Ms. Springstein felt that the district's requirement that young children reach certain levels on their DRAs was "inappropriate" and added too much pressure on five-year olds:

Well, I feel like kindergarten is just too much for them right now and what we are asking these five-year olds to do is too much and it is trickling...I don't want to say down...up to the upper grades but they are being pushed so far and so hard in kindergarten to read past a level 4. 
Above, Ms. Springstein reacted to the reality of increased district demands and the implementation of the Common Core with testimony about how these factors negatively impact young children.

\section{Increase in Assessments and Data Input}

The teachers in this study were troubled by the amount of data they are now required to track. As the math and reading assessments increase, so does the amount of data input. Teachers in this district are required to input all DRA assessments (at least two different levels per child) ${ }^{73}$ in October, January and June. This means that all tests are recorded on a computer device. The DRA is administered to each child individually and the data are recorded as the test occurs (including a running record of their reading and comprehension questions). Previously, this was formally done on an iTouch device, which was later printed out and reviewed by the principal and the district. Today, the data are now expected to be input using an iPad (given to each teacher in the district) and a special app. The district oversees this data input and if any teacher is behind they receive an email and a visit from the administrator. The data are then discussed with all of the administrators and reviewed by the district to look for patterns. The administrator of each building subsequently sits down with each teacher (at the summative) ${ }^{74}$ and reviews the data. In this review, the administrator questions the progress of each student, especially the students below grade level. There are specific levels that each student should reach at certain times of the year and if these benchmark levels are not met, the administrator questions the

\footnotetext{
73 The independent level (which measures how well children read without assistance) and the instructional level (which measures the level at which the teacher is teaching).

${ }^{74}$ The end-of-year evaluation at which the teacher is rated by an administrator. See glossary.
} 
teacher and demands an explanation for the lack of progress. This in turn can affect a teacher's overall rating and become a surveillance tool capable of harming the teacher's standing.

In math, the new curriculum (which is at this time in its second year) requires additional work to record all the data from each assessment. Teachers are required to input both the pre-test and post-test results for each child in their classroom for 19 chapters, which represents 38 different inputs per child in the class and 871 different inputs of data per year (for a class of 23 children). This takes more than 10 hours of extra time that the teacher does not have. They end up having to work on this on their own time, after school and weekends, because it is so timeconsuming. The math supervisor then examines the data and looks for patterns within the data, but does not reveal to the teachers how the results are ultimately used by the district. Unlike the DRA data, the statistics are not currently used to evaluate the teachers, but they could be in the future.

Another piece of math data is related to ST Math, a computerized math program intended to support the Math in Focus curriculum. However, it also demands more data collection on the part of the teacher. Ms. Moore stated:

And we get a letter from the math supervisor...Here's a letter (to the parents) Now you have to go to ST Math and write down the percentage of each child (how they are doing on program) and that has to go home with the report card.

In other words, the teacher now has to look up the computerized data for each child and record the percentage score (which explains the student's progress) on a letter that goes into the report card three times a year. In response to a conversation about the demands for data, Ms. 
Springstein stated, “Stop...stop...no more. You can't keep sending all that stuff to us while we are trying to teach." Ms. Springstein made it clear that all the district's demands for data cut into her instructional time and planning.

Ms. Franklin astutely stated, "It's all about the data," because she knows that the district revels in data collection. The data are one way the district keeps tabs on teachers and students. The district can examine the various data (for upper grades the data is provided by results of the statewide tests) and extrapolate different conclusions. Although administrators can see the gap between the different populations in the district, what are they really doing with all the data? It is unclear what the districts' intentions are, but the data collection takes up more time and space in the teachers' daily lives and interferes with their already limited teaching time. Ravitch states, "Our schools cannot be improved with blind worship of the data" (Ravitch, 2010, p.228). According to Ravitch, districts that are data-driven are not necessarily better informed in their instructional practices.

\section{Developmentally Inappropriate Practices}

The teachers in this study contended that the district, as it stands now, is either intentionally or unintentionally promoting developmentally inappropriate practices in early childhood grades. Thus, the pushing down of the curriculum and the implementation of the Common Core standards directly relate to the participation of young children in developmentally inappropriate practices. 
As a term, "developmentally appropriate practices" (DAP) is a creation of the NAEYC ${ }^{75}$ and is considered a universal standard in early childhood education. These principles and guidelines are based on a "commitment to certain fundamental values that are deeply rooted in the history of the early childhood field," which includes the knowledge of Western child development and its practices (Bredakamp \& Copple, p. 7, 1997). The main goal of DAP is to provide developmentally appropriate socioemotional, cognitive and physical practices for teachers in early childhood education, so that there is a uniform standard for quality early childhood programs. These particular practices are based on Western developmental psychological practices (such as Piaget and Erikson), which have for many years been considered a part of the normative discourse in early childhood education.

There are some important identified appropriate practices that directly relate to the issues that these particular teachers (and others) currently face in the world of early childhood education. An example of this is in the teacher:student ratio. According to the DAP, the ratio should reflect individualized and age appropriate programming. DAP recommends that for every 20 children (four- and five-year olds), there should be two teachers in the room. It is inappropriate practice, therefore, to have the ratios that the participating kindergarten teachers had (one adult: 23 children). This particular state, however, does not adhere to these developmentally appropriate practices as it allows up to 23 children with one teacher in the classroom. It is important to note that once the class reaches 24 students, the district is required by state law to provide another teacher, which is why many early childhood classes are capped at 23.

75 National Association for the Education of Young Children 
In the interpretative focus group, a kindergarten teacher (\#6) stated:

You know as the academic standards have become more rigorous and demanding the developmental needs have been squashed to the side...from birth to age six the development is like no other time in a person's whole life...it's now being condensed and squashed and four-year old brains are still four-year old brains.

This early childhood teacher made it clear that she sees the increase of demands by the district and the state as a problem in the consideration of the developmental needs of young children. She believed that all administrators and district workers should be more aware of the developmental needs of young children. Free play (with child agency) and participation in developmentally appropriate activities (like playing with blocks, creating a puppet show, etc.) are appropriate for these children and thus, should not be excluded from the curriculum ${ }^{76}$. A firstgrade special education teacher in an inclusion ${ }^{77}$ classroom stated:

I think that at the early...preschool and kindergarten...you should be learning through play. You should have a kitchen area and a block area...a little writing station that has crayons and stamps...things like that. It should not be where little people at five-years old are sitting and holding a pencil. Their bodies should be moving. It's not a developmentally appropriate curriculum anymore. Kids are not learning through play. Kids are learning through sitting down and listening to a teacher talk. There is not a lot of room for movement...no learning through centers...because that's where you teach social skills...two kids playing in the blocks and I knock down your blocks that's a natural

\footnotetext{
76 These teachers are referring to 'free play' as a child centered activity that is not teacher directed. 77 An inclusion class has two teachers, a special education teacher and a regular education teacher. They work as a team. See glossary.
} 
way to teach...well what could you have done differently? It's hard to teach social skills when you are dealing with pencils!

Again, it is important to emphasize that these teachers believe that 'free play' and the development of social skills are essential and developmentally appropriate. This particular teacher did not believe that young children should be expected to do large amounts of seat work, using paper and pencils. Instead, she called for movement and for bodily kinesthetic activities that are more relevant to the young child's developmental needs. According to her, learning about social interaction and the growth of social skills (how to cooperate and work with others) are developmentally appropriate activities. This particular teacher is a special education/ inclusion teacher, which means that her job is to modify different assignments and make them more accessible and appropriate for young children with IEPs ${ }^{78}$ and $504 \mathrm{~s} .{ }^{79}$ It is easier for her to work within the confines of the IEP by utilizing developmentally appropriate practices such as bodily kinesthetics with her young charges because these children need a variety of activities outside of the strict structure of the curriculum.

It is important to acknowledge, however, that there is some controversy attached to the idea of Developmentally Appropriate Practices, as prescribed by the DAP. These particular practices are based on Western developmental psychological practices (such as Piaget and Erikson), which are considered to be a part of the normative discourse in early childhood education. In this case the DAP position statements $(1997,2009)$ are the dominant discourse in early childhood education that reflect the present culture of early childhood institutions.

\footnotetext{
78 Individualized Education Plans are plans created by the child study team and the parent in order to meet the specific needs of the child. See glossary.

79 Medical action plans are based on a diagnosis. See glossary.
} 
Discourses are never neutral and instead shape/reflect and define culture (Allen, 2010).

Therefore, the written text of these position statements perpetuate an already existing ideology of the culture of the schools, a Western middle class normative discourse. In the DAP $(1997,2009)$ it continually refers to this premise of Western child developmental psychology as the only possible ideology to utilize in the teaching of young children. "DAP is not based on what we think might be true or what we want to believe about young children. DAP practice is informed by what we know from theory and literature about how children develop and learn" (NAEYC, 2009, p.9). This quote is revealing because it shows a monocultural view of child development. Western child developmental psychology, according to them, is based on science, which is absolute and can not be refuted (Penn, 2008). This leaves no room for other cultural perspectives on child development and therefore is controversial in the field of Early Childhood. Thus, it is a complex multi-layered topic and as such can be seen as controversial to label certain practices in early childhood education as 'inappropriate.' Who is defining this practice as appropriate is very important when ascribing what is appropriate and what is not appropriate. It is important to keep this in mind when examining what these teachers find inappropriate for this age group.

According to the participant teachers the overall day and the curriculum itself are, at times, developmentally inappropriate. The district's added demands and higher expectations (e.g., bringing the kindergarten child up to a 4 or 6 in the DRA), and the time commitment required for paperwork and learning are overwhelming. Several of these teachers lamented that they have had to give away their blocks, Legos, puppets and other play materials because there is no longer any time in the day for them. Children have less time to explore math and science materials, and instead are limited to filling out worksheets and workbooks. There is no time to negotiate play. In its place is more individual learning time, which the teachers felt is not 
appropriate for kindergarten or first grade. Furthermore, the principles of 'free play', which have been part of the early childhood curriculum for generations, are now being undermined by these new regulations.$^{80}$ This affects the mastery of social skills and life skills that each young child needs to acquire. A kindergarten teacher in the interpretative focus group (\#6) stated:

I think it actually sets the kids up for failure in life because most successful people aren't necessarily the smartest. They are able to work with other people....and enter from a different point of view....life skills... at a time... when most kids are ready to receive and practice those things its being squashed...squashed...squashed. So it's really a pervasive problem I think.

This teacher felt that the socialization of the young child and the acquisition of life skills through interactive play in the classroom were essential to the child's future as an adult in the workforce. There is less and less time for this, because of the added demands and expectations. As a result, the individual child is not experiencing developmentally appropriate practices that will aid him or her later on in life.

Ms. Springstein's catchphrase, "It is so inappropriate," was utilized in this context numerous times. To her mind (and to Ms. Moore, who also used this term regularly), the district is not aware that they may be fostering developmentally inappropriate practices. When speaking about the kindergarten screening process, Ms. Springstein lamented that the district did not understand young children and what was appropriate for them to know.

Two years ago, they (the district) threw this other test (besides the Briganz) on us. It's

\footnotetext{
${ }^{80}$ Again, this term relates to child's agency and the quality of their choice in picking activities to engage in. This is based on Western developmental child development and is not necessarily the general practice of children in other countries (such as India, China and etc.)
} 
the language arts department. It is soooo inappropriate...sooo inappropriate...that the kids get so upset and they can't do it. Okay so for example...I have to give...some of these kids are four years old...I am going to give you a set of three words and you have to tell me which two have the same beginning sounds, mouse...dog...mouth..They can't remember mouse. It's too much to remember. It's a lot for those little brains to take in....and right off the bat those kids are like behind the eight ball."

Ms. Springstein, during this particular conversation, was frustrated with the district for creating new tests and assessments for very young children (four years old) that are not developmentally appropriate. To her, children were getting upset because they did not know how to respond to the tests. They were not ready to distinguish between first sounds (this is actually a part of the firstgrade curriculum) and as such, the test could be seen as unfair and inappropriate. This is another example of how the imposition of non-developmentally appropriate practices on young children creates a wider educational gap between different populations of children. According to the teacher participants there is a direct link between the increase in non-developmentally appropriate practices in the classroom and the increase in non-school ready children. As. Ms. Springstein stated, it places more children "behind the eight ball."

Ms. Moore, Ms Watson and Ms. Springstein, all three kindergarten teachers, made it clear in their interviews that the kindergarten report card as it currently stands (with 75 different indicators) is a developmentally inappropriate assessment of young children. During the past 
few years they have spoken unabashedly on this topic to their administrator with no results.

When discussing this topic, Ms. Moore stated:

It's too much! I even think in November...the report cards are too much. I just think it's inappropriate... it's not appropriate...it's not appropriate! They are not ready. They are just not ready to come and sit at a table with the teacher one on one. You can see them...they are looking around...am I done... can I go back?

Above, Ms. Moore was referring to the assessments that the kindergarten teachers need to give each individual student so that they can rate the child a 1,2 or 3 on the report card. ${ }^{81}$ In this case, she felt that the children are not even ready to focus on the assessments themselves as they are still acclimating to school and the long full day of kindergarten.

Ms. Watson, on the other hand, believes that the language in the kindergarten report card is the issue. To her, the report card is not that understandable or helpful to the parents of the child.

It (the report card) is so inappropriate to send home especially to the population we are trying to teach and make them understand about how kids learn here... because the language of the report card is not worded for parents to understand.

811 = below grade level; $2=$ =some concerns; $3=$ on grade level 
According to Ms. Watson, the report card is an inappropriate tool to summarize a child's knowledge because it is not easily understandable. Instead, she suggested that the kindergarten teachers write narratives that explain the child's progress or lack of progress. She felt such narratives would be a more appropriate assessment method, one that the parents would be more able to relate to as well. The narrative ${ }^{82}$ captures the whole picture of the child by discussing specific academic and social strengths and weaknesses that are particular to that child and therefore provides more concrete advice about what the child needs to work on.

\section{An Undemocratic Atmosphere}

School districts' added demands and higher expectations directly affect the democratic atmosphere for teachers. Curriculum purchases (as noted earlier) and expanded data collection relate to the promotion of an undemocratic atmosphere. Teachers are expected to do more, cover more, input more data, use time more efficiently and fill out more paperwork. Yet they find that they have less say in issues that matter. This impacts teacher morale, as they feel that their voices do not count. As a result of a MetLife survey, over $50 \%$ of teachers nationwide expressed low morale, the highest level of dissatisfaction in teaching since 1989 (www.topicalteaching.com, 2012).

As noted in the participant focus group excerpt at the beginning of this chapter, the teachers expressed frustration about not being heard. On many occasions over the past few years the district has asked for teacher input. However, in the end the district has done whatever it felt was most beneficial for the district. This includes, but is not limited to the purchase of a new

\footnotetext{
82 The narrative is a one page written report on the child's progress. See glossary.
} 
math curriculum, iTouch devices for DRA input, a computer math program, a new social studies program and Google Chrome books to replace iPads for younger grades; and changes to the language arts and science curricula. Committees of teachers have met to discuss these changes and purchases, and each time the district seems to make decisions regardless of teacher input. Sometimes the changes and purchases cost a significant amount of money (e.g., technology purchases), only to be quickly replaced by new and more expensive systems. For example, in order to meet data mandates, the district purchased Palm Pilots (at a cost of approximately $\$ 100,000)$ for all the K-2 teachers in the district. After only two years, they were no longer compatible with the DRA program and were replaced by iTouch devices, which were bought for everyone in the district. Meanwhile, teachers have always preferred the iPad, because it is easier to use. Several years later the district finally had to buy more iPads because the DRA program is no longer available for the iTouch. In terms of curriculum, the district paid teachers (including me) to write curricula and then later changed the curricula again, wasting all of the money they paid the teachers for their work. Today, all subjects must be aligned to the Common Core so the district added new science, math and social studies programs without teacher input.

Every day more bureaucracy and paper pushing are added to the teachers' already demanding jobs. There are new kindergarten screenings, new data input systems, new assessments to give to the children, new systems to address the home-school connection (e.g., blue folders containing writing samples and checklists that are sent home after each writing unit), new interim report forms to complete, behavior report updates, etc. All of these elements have been added to the teachers' schedules and no one asks the teachers how they, as professional educators, feel about these new systems and assessments. 
The hardest part, according to the teachers, is that the district claims to be inclusive. The district say it is interested in teacher input but it continues to make decisions that negatively impact teachers. As a result, the formation of teachers' committees is counterproductive. The committees only serve to make teachers seem like they are part of a democratic school system when, in fact, it is essentially the opposite.

\section{Lack of District Support}

Lack of district support, which is related to the description of the district as undemocratic, was a common thread throughout the interviews with the teachers. According to the teachers, the district is unaware of their needs and does not always understand what is in the best interest of young children. These teachers also believed that the district does not provide enough support to their teachers in the field. Such support includes providing appropriate materials and books, sufficient early intervention support, teachers or paraprofessionals to aid in the classroom and equal distribution of technology.

Ms Moore lamented about not receiving materials needed for kindergarten teachers and about being relegated to a physical space that was too small for the size of her class. She said the administrator either does not respond to her emails or emphatically says no. She also emailed the district supervisor in language arts, who referred her back to her assigned administrator.

Can you get this book for kindergarten? Not even a reply... and then I sent an email again...(typing on table) no reply...then with the outside...he said (uses a deeper voice to imitate principal) write it up...send it to me. We all stayed after school and wrote up a really nice proposal... to go inside (the main building)...the benefits...we tried to make it not negative...like we are not just like being I don't 
want to be outside...like there are reasons. It's dangerous.

So we wrote it up...nothing...no response....and I'm like (typing with her fingers again) I will email him again. (she laughs) so I did...so I was like hey any word? no response...so it's like you fix the problem...but we're not going to help you...or give you...you gotta take care of it yourself.

Ms. Moore, a third year teacher, was one of the most vocal participants on the topic of the district's lack of support. At one point in the focus group, Ms. Springstein said that Ms. Moore had had enough (with the district not attending to the needs of the teachers), which was surprising since she had just started her career. Ms. Moore believes that it is "common sense" for the district to be supportive and she was surprised by the district's lack of common sense. To her, it is common sense to have two teachers supporting and teaching 23 kindergartners, especially with the location of her classroom outside the main building. She needs someone to help children put on their hats and coats in the winter, or to take the students to the lunchroom or art room. If children need to go to the nurse, no one is around to escort them to the main building. In addition, there have been times that her school phone hasn't worked, requiring her to use her own cell phone to reach the main office. She was also confined to a small physical environment that lacks space for children to sit and work comfortably.

Derek, the boy Ms. Moore referred to the study, was eligible for the ELL program, but because it is in another school and the bus home from that school does not return to his neighborhood at the same time as the school he now attends, the mother could not send him there. When describing the intervention meeting ${ }^{83}$ with the mother, Ms. Moore stated:

83 IRS intervention meetings are with the teacher, parent and administrator. They are designed to find new strategies to help the child succeed both academically and socially. See glossary. 
His mom is sitting in the meeting crying. She wants to help him but she can't...or she's frustrated that she can't help him. She started to get emotional because no one could pick him up from the bus and that's why he is not in the ELL program... because the hours don't match her hours...no one can pick him up from the bus. There is no one home. I feel personally like it's just swept under...and that's it. I don't feel like there is individual attention...and I'm frustrated because I feel it would be a help for him and if there is a problem beyond language it would be found quicker with a smaller class size and two teachers (ELL program)...he would be getting all the help he could get.

Ms. Moore felt that the district could have been more helpful and found a way for this boy to attend the ELL program since he qualifies for it. She felt the district was not providing the best possible educational services for this particular child.

Ms. Springstein was also, at times, a critic of the district. When referring to the district she said, "When we find something like glaring...nobody does anything about it." She was referring to the lack of support the kindergarten teachers receive, especially when it comes to the neediest populations (children with IEPs, 504s, reading issues, etc.). When discussing the Briganz screenings of incoming kindergartners, she said:

Like there have been children who come in and we say this kid doesn't speak English...like why is that even getting past central office? And nothing ever happens they don't go to ELL...it doesn't happen.

Ms. Springstein expects the district to take more interest in the incoming kindergartners and is upset when it does not take the advice of the screener (i.e., the teacher) and place children in the 
proper classroom environment. She was also frustrated by the lack of intervention for children with special needs. The following was an excerpt from our second interview:

Ms. Tager: So in kindergarten...it is very hard to be classified?

Ms. S: Yes...extremely.

Ms. Tager: Explain. Why?

Ms. S: I feel like they will not even come look. And this is not a bash against our child study team ${ }^{84} .$. 'cause I love the people on our child study team. Their hands are tied as well. I feel like it just trickles down...from the boss down.

Ms. Tager: Do you feel like they listen to you? If you say, 'I have somebody that needs to be going to the team?'

Ms. S: Sometimes we do and sometimes we think that they are not... it's frustrating. And when we go...we're like...listen to us...between all of us (the kindergarten team of four teachers), Ms. Moore is the only one with three years' experience. But Ms. ------has 20 years and Ms. Watson has 20 years and I have 15 years of teaching.

Ms. Springstein clearly felt that the teachers, who are in the trenches, have a better idea of who might qualify for services, and yet the district did not respond to her opinions. This represents another example of how increased demands and expectations are de-professionalizing teachers. Overall, the new systems that disregard teacher input are flatly refusing to take into account the expert knowledge of the professionals in the field.

In the districtwide survey, $47.83 \%$ of participants stated that they would only send a few of their identified non-school ready children to intervention or child study team, whereas $8.7 \%$

${ }^{84}$ The child study team includes several district professionals. See glossary. 
said they would send most of them. This could be directly related to the fact that teachers are discouraged in the early grades to send children to intervention or the child study team because of the district's wait-and-see attitude.

Another example of the lack of district support manifests itself in the ongoing problem of teachers trying to identify or investigate children whom they believe live outside of the district. ${ }^{85}$ Ms. Springstein said that this is a huge problem in the early grades and felt the district should be more eager to investigate the teachers' claims, as such children should not be attending the school at all. These investigations would likely result in smaller classroom sizes. When asked about this problem, Ms. Springstein stated:

One year I had like three kids that I got...and I ask them do you live here? Line up if you live in ------ (town in district) Now line up if you live in -----(neighboring town outside of district). One little girl is like...I live in (the neighboring town outside of district). The problem is you report it to the district and they don't do anything about it, so you still have to teach them..They are telling us now that the guy that does the investigating (district person) is out...so nothing's getting done.

The district is failing to comply with its own regulations. If the person in charge of these investigations was actively looking into cases of children residing outside the district, these children would have to leave and the teachers would have smaller class sizes.

When asked about district services, kindergarten teachers stated they are lacking in the early grades. During my interviews with Ms. Springstein and Ms. Moore, they both made it clear that kindergarten does not get the attention from the district that it deserves. There is no

85 Only children who reside at an address inside the district can attend district schools. 
Apex tutoring, ${ }^{86}$ which would help struggling kindergartners, no reading friends ${ }^{87}$ and no summer school for incoming kindergartners. In addition, services are minimal for kindergartners when it comes to the child study team. For example, students can be referred to a social worker for counseling upon approval from the parent, yet this is rarely done in kindergarten. There is, according to the kindergarten teachers, a common district discourse of wait and see. Teachers must wait until the problem is more prevalent (i.e., wait until at least first grade) before services can be accessed. This means that kindergarten teachers must record behavioral and emotional issues that interfere with the child's learning and hope that the child receives the services in first grade. Interventions become more about what the teacher can temporarily change in the classroom and less about how the school and the district plan to support the child's overall learning style.

Another example of the lack of district support is the inequity in technology. Certain schools in the district have more technology than others (mostly due to PTA fundraisers) ${ }^{88}$. Instead of the district balancing this unfair distribution of technology, it pretends it does not exist. This has become a pet peeve of these particular teachers, who feel that the district should acknowledge its technology gaps and support the teachers in acquiring what is needed. When attending district workshops with the other four elementary schools these teachers are confronted with other teachers who possess the necessary technology (Elmos, SMART Boards, document cameras, iPads, etc). Ms. Franklin felt that this was unfair and consistently broached the topic.

\footnotetext{
${ }^{86} \mathrm{~A}$ free tutoring service within the district funded by a private foundation.

${ }^{87} \mathrm{~A}$ program where high school children come to elementary school children and read with them. 88 PTA fundraisers differ from school to school and when there is a majority of middle class children fundraisers take in more money than in low-income schools.
} 
“That's why we need to have a share around the room...so let's share...you go first...how many iPads do you have?" This received a hearty laugh in the focus group because it was known that other schools have class sets of iPads, whereas their school had only one class set of iPads for the entire school (K-5). This aggravated the teachers during their discussion of ST Math (the new mandated computer math program) because they do not have enough access to technology in their building. During the school year I conducted the research, the eight kindergarten and firstgrade classrooms shared one cart of 25 Chrome books, which made it very hard to achieve the mandated time of ST Math in the classrooms. Meanwhile, other schools in the district have iPads for every child. They are easier for the children to use, which makes it easier for the teachers to successfully implement ST Math. When the teachers in the study, who lack technology, brought up this discrepancy at professional development workshops, the district math supervisor downplayed their concerns and said that they have just as much access to technology as the other schools do.

\section{Teacher Accountability and Evaluations}

Over the past few years, the teacher evaluation system has changed considerably in this particular district. The district has adopted the Charlotte Danielson teacher evaluation system, ${ }^{89}$ which is being adopted in many different districts nationwide. The system scores teachers in different domains of teaching (Danielson, 2009). For example, domain 3C is "engaging the students in learning." This particular domain relates to pacing and how the teacher best addresses the pacing of her lessons and practices. If she "communicates that time is a valuable

${ }^{89} \mathrm{~A}$ specific teacher evaluation system utilized by this district. See glossary. 
resource and models efficient use of time, uses clocks effectively and does not have any student downtime," she is categorized as proficient or effective (a score of 3). If, however, transitions within lessons are too long (depending on the evaluator's definition) or some children are finished before others and are not engaged in other materials, the teacher is categorized as basic or partially effective (a score of 2). In order for a teacher to receive a distinguished or highly effective score (a score of 4), she must prove that the students themselves are monitoring their own time effectively and are continually self-reflective about these practices. Proof includes the use of student checklists, preferably designed by the students. This is very hard to accomplish in an early childhood classroom as children are just learning to read and write, and therefore cannot always create their own checklists or monitor their own time effectively. Early childhood teachers in the district feel that it is harder to realistically achieve a 4 in domains that call for student self-monitoring of activities.

Just last year this same system was expanded to include more observations per teacher and a direct correlation of these observations to the SGO and to the numerical score given to the teacher at the summative year-end meeting. Tenured teachers (those who have taught in the district for at least four years) now undergo three observations by administrators or supervisors instead of one. Two of these observations are designated unannounced observations ${ }^{90}$ for which the teacher has to be prepared at all times. The announced observations ${ }^{91}$ are longer and include a pre-observation meeting with the teacher's supervisor, the observation itself and a postobservation conference. In the post-observation conference, the supervisor rates the teacher on a

\footnotetext{
90 Unannounced Observations occur with no warning. Administrators can walk in at any point of the day and observe the teacher for 20 minutes. See glossary.

${ }^{91}$ Announced Observations include a pre-observation with the administrator and are planned in advance. See glossary.
} 
scale of 1 to 4 for each of the four domains observed.$^{92}$ All observations are included in the teacher's personnel file and can be used to deny tenure or to challenge tenure status.

Ms. Moore, in reference to this topic, stated, "I love teaching...it's everything else..." Everything else is what the district demands (i.e., the web of expectations), including teacher evaluations, SGOs and an official score that is now representative of the teacher's effectiveness. When talking about the profession as a whole, Ms. Franklin stated:
I will stay in teaching although I am not agreeing on how the whole process is moving forward...I feel it is very hard to teach now...things have changed quite a bit...you know the story.

Part of this change to which she refers is the increase in teacher accountability. Teachers are constantly being judged, documented, observed and evaluated as teaching professionals.

One of the major problems with this specific teacher evaluative system is the random assignment of supervisors. Many teachers, including the teachers in this study, believe that the individual assigned to observe them can negatively or positively impact their evaluations. This, they believe, is unfair because a teacher who has the same evaluators year after year cannot improve his or her scores. In this particular school, the teachers are especially upset when they are assigned the school principal, Mr. Dodd (the only male evaluator in the queue). They feel that he can be unduly critical and frequently gives them lower scores, which affect their overall scores at the end of the year. Even though he states that he wants to help them grow as educators, he starts off every post-observation referring to the negative aspects of the lesson (instead of the positive). It is important to note that Mr. Dodd has only three years' experience

\footnotetext{
92 Depending on the supervisor, either the teacher selects two of the four domains or the supervisor selects all four.
} 
classroom teaching, whereas the other three women supervisors each have over 15 years' experience as classroom teachers. The following is an excerpt from the focus group:

Ms. Tager: That was the first time I became a number. ${ }^{93}$

\section{Ms. Springstein: Yeah.}

Ms. Tager: And I have been teaching awhile.

Ms. Springstein: I took the easy way out and gave myself $3 \mathrm{~s} .{ }^{94}$

Ms. Tager: So you didn't have to fight?

Ms. Springstein: I couldn’t fight him...I couldn’t fight him...and I know everyone else did.

Ms. Franklin: I fought him. ${ }^{95}$

Ms. Moore: And I think the discrepancy between evaluators is...

Ms. Smith: Absolutely...absolutely.

Ms. Tager: Do you think other schools have people with higher numbers?

Ms. Smith: Yeah...because of the administrators

Ms. Moore: First of all a principal who is supporting

\footnotetext{
93 The number refers to how the teacher is evaluated overall at the end of the year. If the teacher does not get a 3 or higher, he or she can be put on probation.

94 Teachers score themselves in different domains and then give their scores to the supervisor, who can effectively change the scores.

95 Ms. Franklin actually had a verbal argument with her evaluator, threw the Charlotte Danielson book on the floor and later returned with a pile of papers to prove her self-evaluative score. She did not receive an increase in her score.
} 
you... who is rooting for you...says how can we get you a 4 ...the administrator (Mrs. Holland) I worked with for my summative said...there has to be something... and she walked around the classroom..what can we do? because she wants you to do well...it's not like holding your head under water.

Ms. Springstein: It's a horrible feeling to know that so many other people are getting these $4 \mathrm{~s}$ but I can't like I just don't have it in me...this year.

Ms. Springstein, like many teachers in this district, was too overwhelmed to even challenge her ratings, even though she felt she deserved more than $3 \mathrm{~s}$. She merely accepted the lower score because she realized it was too stressful to prove otherwise. ${ }^{96}$ Interestingly, Ms. Moore commented on how much more supportive the female administrator was in contrast to the male principal. She felt lucky to have her as an evaluator because she knew that her administrator wanted her to succeed and attain the highest possible score.

The year-end score is a new phenomenon in teaching. Teachers are now reduced to a number. Children are also reduced to a number in this new world of high-stakes testing. In higher grades, the number directly refers to the standardized test scores of the teachers' children as well as the teacher observations. In lower grades, the number reflects the SGOs, the observation scores and the summative conference. A teacher in a lower-scoring class overall will receive a lower score. A teacher who gets an overall score of 1 or 2 , even if he or she has tenure, will be put on probation. If teachers receive a 1 or 2 rating two years in a row, their tenure can be challenged or they can be dismissed. In the participant teachers' focus group, when the teachers

\footnotetext{
96 Teachers have to bring proof (in either paper or photographic form) of their given score. Sometimes these binders can be huge.
} 
debated the importance of their overall number and discussed how it does not represent them as teachers or define how they teach, Ms. Franklin stated, "You better care about your number." This number directly relates to how a teacher is perceived by the district and is therefore actionable even if it is based on biased or arbitrary results.

Ms. Springstein's wall is a good metaphor for how higher demands have affected early childhood teachers. In order to comply and prove that she has taught all that is required (as mandated by the Common Core standards and The Charlotte Danielson evaluation system), she has completely covered her walls with anchor charts and other evidence. There is very little, if any, blank space on her walls; the charts look like wallpaper. When discussing the physical space and her covered walls she stated:

Because the curriculum calls for all those anchor charts and all that stuff... You know Mr. Dodd (principal) comes in and asks 'where's your evidence?' How do your kids self-assess so I have this huge chart made of poster board...when they can read a word they color in the box with the word in it. That's a self-assessment...because I got slammed a couple of years ago because my kids were not self-assessing!

Ms. Springstein's crowded chart-covered walls serve as a metaphor for the higher demands of the standards and accountability movements. The charts take up too much time and space.

In summary, the higher demands and the web of expectations that emanate from the district and filter down to the teachers affect how the teachers teacher and how they are evaluated. New evaluation systems are surveillance tools that help the district control the teachers. Meanwhile, as educators with large classes, the teachers feel that the district is 
unaware of their needs and does not provide them the much-needed support they feel they deserve. In their opinion, the district's demands are not developmentally appropriate. The teachers are also expected to cover more lessons, enter more data, give more assessments and learn more programs, all with less technology and little support. They teach in overcrowded classrooms that lack physical space, without the assistance of paraprofessionals, and are dissuaded from sending children to receive services. Finally, their teaching practices are now reduced to a number, which they are arbitrarily assigned depending on their evaluator.

In Chapter six I will be examining the home-school connection and how the teachers have differing expectations. Even though they recognize that these low-income parents must work multiple jobs in order to make ends meet they still expect them to be very actively engaged in their child's educational studies. Differing views of childhood also play a part in this dissonance between these teachers and their participating families. 


\section{Chapter Six}

\section{Teacher Perceptions of Low-Income Families}

The sun is setting and all the teachers are still sitting around the long wooden table. Some teachers have switched to wine, while others drink bubbly water. The air is still. Ms. Springstein's husband and father are watching television and conferring in the other room. The focus group continues on.

Ms. Franklin: You have parents that work and they are just too tired to sit down and really work with the kids at night. They just want the kids to go and do it. And there are kids...you know...that need support in doing anything.

Ms. Springstein: I feel like that's mostly my parents...I think that at our school we get a bad rap that, oh those parents are just slackers. They're never around and not doing anything.

Ms. Franklin: I don't believe that at all!

Ms. Springstein: I feel they are hard-working and they are not around because they are working so many jobs. And that's why they are not reading with their kids at night...or working the afternoon shift and the kids are in daycare.

[a few minutes later]

Ms. Franklin: We have kids from the neighborhood, the lower socioeconomic...every one of my parents values...I would say everyone wants their kid to be educated. Everyone wants...pretty much...I only had...maybe with the student I picked, but other than that every parent has been supportive of everything I have asked.

Ms. Tager: Do you think it is overwhelming for the parents? 
Ms. Franklin: It's hard to make generalizations, because some years you have parents that are not involved and then you have the cultural piece too...You know some of these...I think

Nigerian children...their parents are like you know it's your deal... you are the teacher.

Ms. Springstein: The professor...they think we are the professor.

Ms. Franklin: Back in my village the teachers made house calls.

Ms. Tager: And you also have the people from Haiti... the school system is pretty bad.

Ms. Franklin: Really bad.

Ms. Tager: And they are coming and they don't really have the background to help the kids with the homework at all.

Ms. Springstein: mmmhhhmmmm (nodding her head)

Ms. Tager: Because they don't have the education.

Ms. Springstein: Right.

Ms. Franklin: And I have a parent... you know who the mother is... She said to me, "It's not like this in Nigeria, you need to be (taps on table hard)... what are you going to do when she doesn 't do her homework?" What am I gonna do? What are you going to do about it? My job is to take care of everything that happens in school and she doesn't do her homework and so I am always talking to the mom about that and she says, "Well I have three children and I am working two shifts." 
During the conversation excerpted above, the participating teachers discussed the teacher-home connection, including their awareness of the impact of low-wage work on parents' time and how it affects school readiness status. They were aware of cultural differences in parental expectations and the impact low-wage work has on the parents' interactions with the school. Parents are too busy working two or three jobs (or shifts) in order to make a living wage and cannot always attend important school functions.

In this chapter I unpack the issue of low-wage work and how it impacts the lives of lowincome Black families and the perceptions of non-school readiness. Time is again a factor, as sustaining a family on low-wage work can involve two or even three different jobs or shifts, leaving limited time for childcare and parental attention to school readiness. Below, I expand on the factors related to the ecology of school readiness that link time, low-wage work, workplace policies, and the different cultural views and expectations of schooling. In addition, the lack of parental involvement in school activities is tied to inflexible and inconsistent work schedules, reliance on extended kin for caretaking and homework assistance, and lack of cultural capital, which affects children's school status.

\section{Parental Involvement and Working Multiple Shifts}

The expectation of the participating teachers is that all parents would be involved in the schooling experience of their children. This is a non-negotiable expectation. There are many books written on this topic (Epstein \& Sanders, 2008; Henderson, 2007; Robinson \& Harris, 2014 and more) and they all advocate a strong home-school connection, which means that parents must be highly active in their children's education. The survey data revealed that these 
teachers agree with the literature and believe that parents should be actively involved in the classroom. Of the teachers who responded to the survey, $81.82 \%$ indicated that it was very important for parents to be involved in class activities and another $86.36 \%$ said that parents should attend Back to School nights and learn about their child's curriculum. ${ }^{97}$ Only $4.5 \%$ of the teacher respondents indicated that the parents of the non-school ready children in their classes were actively involved in their classrooms. Even more surprising, $45.45 \%$ of the teachers stated that they noticed that these parents were not at all active in their child's schooling. This illustrates that although the kindergarten and first-grade teachers felt it was very important for parents to participate, the non-school ready children's parents were not participating at all, or only rarely participating.

Ms. Springstein argued that all class parents, regardless of race or socioeconomic class, should attempt to participate. She would like $100 \%$ parent participation in her classroom. She was, however, aware that this is unlikely given the amount of time her students' parents have to work in order to make ends meet. The participating teachers understand that the parents of the non-school ready low-income Black children have to work several jobs in order to survive and therefore are not always available to help their children read or do homework. Ms. Springstein considered socioeconomic class to be a factor in whether children were school ready or not, simply because the low-income parents work so much and are not physically around to work with their children.

I think it's a factor because I think both parents are working. Parents are working three and four jobs to live in this town so their kids can go to this school.

\footnotetext{
${ }^{97}$ Back to School night occurs at the beginning of each new school year. Parents come to their child's classroom and the teacher explains the school curriculum and practices for their particular grade.
} 
It's expensive to live in this town...even over in our neighborhood (all Black lower-income section of town) the rent is really high. So it's not that they don't want to help their kids...they are probably not even home at night...they're exhausted.

In other words, Ms. Springstein realized that there are valid reasons why these parents are not available to help their children after school or participate in classroom activities. She understands that the parents need to make as much money as possible to live in this particular town. Ms. Springstein's comment above indicates that she is aware of the investment and sacrifices the low-income parents make in order to provide quality education for their young children. Just two blocks away is an urban school district that is known for low-quality educational practices and these parents do not want to send their children to these schools. ${ }^{98}$ To Ms. Springstein, the proximity of the struggling urban school district might be a factor as to why the parents choose to live in this particular town, i.e., so their children can attend Grayson School.

Ms. Franklin also surmised that the non-school ready children's parents are not able to participate in the classroom because they have to work so hard. When I asked her if socioeconomic class might be a factor in whether a child is ready or not for school, she responded:

Well I would say it plays a huge part in it, because there's no one reading to the child at home. There's people working... they're working all the time. They're not home. They're (the non-school ready child) being picked up by neighbors...daycare...and

\footnotetext{
${ }^{98}$ Low quality in this case refers to lower test scores, higher teacher/child ratios, and less academic services and other intervention practices. Materials such as technological tools are also lacking.
} 
there is nobody really holding them accountable for things either.

Ms. Franklin understands, to some extent, why these parents are not around. Later in the focus group, she became irate when discussing how other teachers in the district do not understand her school's population and why parents are not always available to support their children. ${ }^{99}$ "I feel that they (the parents) are hardworking and they are not around because they are working so many jobs, and that's why they are not reading with their kids at night.” Ms. Springstein added, "I think that at our school (Grayson) we get a bad rap that 'oh these parents are slackers...they're never around and not doing anything." Both teachers felt it was important to emphasize that they understood why these parents were not around and that the parents' absence was justifiable. They know that these parents are unfairly judged by others and feel the need to defend them.

Yet these same teachers are disappointed by the lack of parental involvement. "I have a parent I only met once this year," stated Ms. Springstein. Ms. Moore also lamented seeing very little of parents whose children she had identified as non-school ready. All of the teachers concurred that parents of identified non-school ready children were not involved in the school. They wished for more involvement because more parental involvement helps them reach their SGOs. For example, if a six-year old practices reading every night with his or her parent, usually that extra reading helps increase their DRA levels. Because the demands and expectations placed on the teachers have increased, parents are expected to do more, too. Dodson (2009) states, "With increasing demands on teachers and curricula, support is needed and lack of support is resented" (p. 102).

\footnotetext{
${ }^{99}$ Three of the five elementary schools in the district where I conducted the research have very low numbers of students receiving free or reduced lunch, and the parents are mostly middle class (schools 1 and 2 have 6\%, school 3 has $10 \%$, school 4 has $20 \%$ and Grayson School has $43 \%$ of students receiving free or reduced lunch).
} 
Hale (2001), an African American scholar, responds to the expectations of the White teacher by asserting, "Instead of bemoaning the disparity in parental involvement in African American and lower income school districts educators should accept the realities" (p.135). The realities, according to Hale, are that time is highly constrained for parents of low-income Black children; therefore, they should not be judged negatively for non-participation. Interestingly, this time bind, which I described in Chapter 4 as it relates to the teachers, also exists for the parents because they are, for the most part, navigating two or three jobs in order to pay bills. Always on the go, they are not available to support their children at home or participate in school functions. Therefore, limited time directly affects how they interact in their children's education.

\section{Low-Wage Jobs}

These parents, including two-parent families and single mothers, work multiple jobs (or multiple shifts) because their jobs do not pay living wages. They need as many hours as possible in order to make enough money to support their families. They are mostly in the service, retail or caregiving industries, and receive minimum wage ( $\$ 6$ to $\$ 8$ per hour) with no benefits (Polakow, 2007; Luttrell \& Dodson, 2011; Ehrenreich \& Hochschild, 2002). For example, as of the time of the research for this study, Jay's dad was working for a soda company driving their delivery trucks. He was putting in long hours and multiple shifts per day to help pay the bills. He was an hourly employee, only getting paid for the time he actually worked. His wife worked on the retail side of the same soda company and was attending night school, aiming for an associate's degree in healthcare. Jay's parents did not attend either of the two scheduled parent-teacher conferences during his kindergarten year, but instead sent his grandma once to meet with his teacher because 
they were too busy working. Derek's mom was in the caregiving sector, working long hours as a home aid for an elderly woman. She was not around to pick up Derek from school. In many cases, the mother is the sole provider ( $85 \%$ of Black families are headed by a single mother) (Harry \& Klingner, 2003). They need to work even longer hours in order to provide for their children. Luttrell and Dodson (2011) state, "Based on the growth of the service, retail and carework job sectors, many mothers - disproportionately women of color, immigrants and single women—are working in low paying, demanding jobs" (p. 39).

Low-wage work is highly time consuming, because it takes several different jobs or multiple shifts to make enough money just to pay the bills. In her 2001 book, Nickel and Dimed: On (Not) Getting by in America, Ehrenreich took an eye-opening journey working low-wage jobs in an attempt to make a living wage to cover her expenses for food, housing and transportation. Her research revealed that it is very hard for one person or even two people, working low-wage jobs ( $\$ 6$ to $\$ 7$ per hour), to make enough money to sustain themselves or a family (Ehrenreich, 2001). A person in a low-wage job must work more than the average hours per week (approximately 40) in order to make a decent living. If two parents are working and are both earning \$8 per hour for 40 hours of work per week, their combined annual income would be $\$ 34,000$, which is below the poverty line for a family of four (Dodson, 2009). Additional factors, such as high daily transportation costs and expensive housing, make it even harder to survive. Furthermore, parents who cannot afford a car (or gas) most likely rely on public transportation to get to and from work, which can take hours out of each day, hours that they could spend with their children if they were able to drive to work instead.

A large part of low-wage work is in the domestic sphere. These jobs, such as nannies, 
home health aides and maids, are filled primarily by Black and/or immigrant women.

Hochschild (2002) states, "a great many (poor women) migrate to fill domestic jobs" (p. 19). If there are over $72 \%$ women in the U.S. workforce, they need household help while they themselves are out of the house (Ehrenreich, 2002). They come to the United States with friends' and relatives' support and live in communities where other people from their countries live. In the Grayson School's neighborhood, there is a large Haitian, Caribbean and African immigrant population, comprised mostly of women and children. They come from extremely impoverished nations and seek a better life economically. More than $20 \%$ percent of all jobs in the United States are in the growing caregiving sector, which means that most immigrant workers will likely end up working in that industry (Ehrenreich \& Hochschild, 2002).

Many women have been trapped in this kind of work, whether by racism, imperfect English skills, immigration status, or lack of education. Few happily choose it (Ehrenreich, 2002, p. 92).

Ehrenreich was referring to maids and other domestic workers, including nannies. In her own three-week experience as a maid working for a maid service in 1999 , she earned $\$ 6.63$ per hour. Some of the drawbacks to such jobs include no job security, no health benefits, and no sick or retirement pay. The policy of the company for which she worked was that if you missed a day, your pay dropped to $\$ 6$ per hour as a punishment. Also, there were no lunch breaks or any other breaks. The only break a worker had was whens she rode in the van to the next job. This, of course, led to high turnover at the company as people needed to take time off for childcare and other purposes (Ehrenreich, 2012). High turnover is a problem in this industry, precisely because these caregiving jobs include long hours and low wages, with inflexibility in scheduling. 


\section{Lack of Job Flexibility}

Low-wage jobs do not offer flexibility in scheduling. Most low-wage jobs actually have inconsistent scheduling that does not provide workers with set hours week to week. Inflexibility in scheduling means that it is hard to schedule appointments with teachers in advance. It is also hard to know ahead of time if a worker can take time off to visit a school production or performance. Low-wage jobs are not family friendly. Workers' children can suddenly become sick, requiring parents to scramble to find childcare or take a day off without pay. There are no sick days in low-wage jobs. And there is no job security. If a worker takes a day off without much notice he or she can be terminated without warning (Anyon, 2005; Luttrell \& Dodson, 2011). Each day of work is essential to the family's survival and, therefore, cannot be missed. I noticed rather recently that one of my students (a child who could be identified as nonschool ready) was being picked up every day by her grandmother instead of her mother, who had previously done the school pickup. I gave notes to the grandmother to give to the mother and talked to the grandmother about reading with the child at night. It became clear that the grandmother was not giving the notes to the mother or reading with the child. I called the mother on the phone and could only reach her voicemail. A few weeks later the mother came for pickup and told me that she had been busy working double and triple shifts, which was why she had not been available. She also told me that she needed work extra shifts during certain times of the year in order to keep her job. She had no control over her work schedule and therefore required support from other family members. It was clear that she was unhappy with the situation and was apologetic that she had not been present at school for so long. Like Jay's family 
situation, the grandmother of my student was the surrogate parent, not by choice, but because of the parents' inflexible work schedules.

\section{Extended Kinship Networks}

Low-wage work and working multiple shifts demand extended kinship networks. Parents in these circumstances are not always around, so they rely on others for childcare and support. Someone has to pick up the kids from school or after care and sometimes a family member or a close neighbor fills that role. Extended kin are also often needed to take the child to school and before care, as work shifts can also be early in the morning.

The teacher participants lamented that their low-income Black families, who hail from a variety of cultures, were not able to personally pick up their children from school on a regular basis. Many teachers in this study cited this as an issue because they did not have regular communication with the parent. Ms. Moore pointed out:

Someone else is picking up the kid...this person picks up on Mondays...this person picks up on Tuesdays and then a cousin comes....and when they get home the mom is at work.

This working parent strategy (in this case, low-income Black parents) does not line up with the expectations of White middle-class educators. These teachers prefer a partnership with the parent and if a parent is not consistently picking up the child it is harder for them to communicate regularly.

Ms. Moore and others were also frustrated that these children stay at other people's houses, which makes it harder for them to consistently finish their homework. "I see them 
staying with their grandmas...or their aunts," said Ms. Moore, who feels that this interferes with their academic growth. The teachers' expectation that one of the parents pick up the child every day reflects their own backgrounds. They base this expectation on their own family structure, which stems from middle-class norms (Cannella, 1997; Hale, 2001; Randolph, 2013).

Family dynamics and household structures may look different in low-income Black households where parents hold multiple low-wage jobs. They are more likely to include extended family members, which can lead to more interaction with different relatives. Children who live in large households learn how to mediate and are very group orientated, which is a positive life skill (Hale, 2001; Hale, 1986). Such group interaction and the import placed on being a part of a group are contrary to the Western notions of childhood and the importance of the individual. As a result, the ability to navigate a larger group is downplayed in Western culture and is perceived as different and not as worthy. In Stack's (1975) research, she found that kinship networks exist within low-income Black neighborhoods and the "swapping" of goods and services is an obligatory practice. Childcare is not tied to a nuclear family structure, but is extended to all kin, including trusted friends and neighbors (Stack, 1975). There is a different rhythm to life because of the extended kinship in the house (Lareau \& Weininger, 2008). An uncle or neighbor may pick up a Black child from school one day and the great-grandmother the next, as they are all working together to raise the child.

Extended kin networks, therefore, are essential to the survival of low-wage families. As noted in the section above, these low-wage earners cannot simply take a day off if a child is sick. They do not have built-in sick days or job security. They need others to help out or they must send their sick child to school and hope for the best. I have had children who come to school 
sick (the fever is often reduced by over-the-counter medication) and when they are sent to the nurse because they are just too sick, they usually sit in the nurse's office for the rest of the day because no one is available to pick them up. In such instances, parents have to call around while at work to ask neighbors and relatives to cover for them by picking up their sick child because they cannot get away.

The Stigma of Low-Wage Work: Blaming the Parent

Low-wage jobs in the retail, service and caregiving industries are not considered 'good' jobs. Workers in these fields are paid less than in other sectors of the workforce and are stigmatized as less important to the economy as a whole. Low-wage jobs are not considered prosperous or worthy and, as such, can be seen as shameful and degrading (Dodson, 2009). Occupational status is important. If you are a professional, such as a doctor, lawyer or teacher you garner community respect, but if you work at the local McDonald's, you might be considered unworthy or lacking in job status. Parents in such jobs must deal with the everyday stigma attached to low-wage work.

Welfare reform laws have also increased this stigma. Welfare reform, or getting "welfare moms" off support and back into the workforce, did not help the existing deficit-based reputation of the poor welfare recipient. Today, moms are still to blame even though they are working. Instead of taking government handouts, they are working all the time and are not present for their children's schooling. According to Dodson (2009), who encountered many people who argued this point during her research,, working mothers in low-wage jobs are no different from welfare mothers, as both are considered irresponsible and have no understanding of what it takes to be a 
parent.

Going to work was a conservative prescription through which poor mothers were supposed to be exonerated. This is precisely the language of welfare reform: bad women/moms had kids and relied on welfare - good ones went to work. Yet, here we were ten years later, and the central stereotype had survived. Only now, hard at work, the low-wage mother doesn't meet the work-ethic bar since she has so many 'family problems'. She doesn't meet the mother-care bar either, because her kids don't show up at school conforming to a middle class standard of readiness, and neither does she participate properly as a parent (p. 110).

In other words, despite working hard and taking on multiple jobs or shifts, the low-income mother still does not receive the credit she deserves. Before welfare reform, they were classified as lazy and living off of taxpayers' money. Today, post-welfare reform, these mothers are perceived as irresponsible and unfit to parent because they are not involved in their children's education or preparing their children for the rigors of school.

Some of the teachers in this study unknowingly contributed to this discourse of blaming the mothers in their comments about parents not valuing their children's education. Ms. Moore stated, "School is not...it appears to me that school is not as important as it should be." Ms. Springstein followed up on this idea when she said, "And some of the parents are like...well they can just miss school. It's just kindergarten, so they will just miss it. Well, you are missing a lot in kindergarten." Absences were important to these teachers, and some felt the parents' attitudes about missing school proved they did not value their children's education. Again there is an intrinsic conflict in these teachers' responses. While they understand the parents need to work 
several jobs in order to make ends meet, they also desire a cooperative partnership in which the parents work with their children at home, aiding them in school-readiness skills.

Another issue these teachers, especially the kindergarten teachers, brought up was the problem of late registration. When a child starts school later (perhaps a week or two after the start date) it is harder for the teacher to properly assess them. In addition, they also feel every school day is essential to children's academic and social growth. Furthermore, if the parents register their children late, the students will not have attended the kindergarten orientation (which takes place several months before the start of school) or the Briganz screening process day where the teachers score the children on their skills (or lack thereof) in order to create fair and balanced classes.

The teachers in this study blamed the low-income working parents for not being responsible enough to register their young children for school on time. Registration starts in February of the year prior to enrollment and continues throughout the summer. This means there are more than seven months to register. Ms. Watson stated:

The parents need to know that I am moving into a community. It's my responsibility. We can't just keep saying they don't know...they don't know.

Even though Ms. Watson had some sympathy for parents registering their children late, she still felt that all parents (even if they are new to the country and do not speak English) should know when to register their children. Ms. Moore, when speaking about late registrants, looked at her coat rack. The last coat hooks were labeled with the names of children who started school later (as they were not on the original class list). Three out of five of her late registrants attended 
academic intervention. Ms. Springstein divulged that all seven of her late registrants attended academic intervention. Both teachers saw a correlation between late registration and non-school readiness. When I asked Ms. Moore if she thought there was a connection between the two, she stated:

Yes...I do. I feel that the parents that don't register their children for school aren't doing the best to get them ready for school...

Jay, Billy and Derek were late registrants who were subsequently identified as non-school ready. Their parents (all low-wage workers) had trouble registering them in time for formal schooling. There are, of course, many possible reasons for this. The parents might lack official medical records for the children (because they do not have health insurance), they might have only recently immigrated to the U.S., they might not speak or read English or they might not have access to the district website because they do not have computers at home.

Ultimately, although these teachers had some awareness of the struggle these low-wage parents endure on a daily basis, they still employed a blaming discourse that can further widen the gap between the teacher and the low-income parent.

\section{Unequal Childhoods}

Parents who work low-wage jobs have less access to the education and schooling process. In addition to the time constraints that people in low-wage jobs experience, they lack the cultural capital to fully navigate their children's schooling. According to Lareau (2003), in her research on families from different socioeconomic classes, low-wage earners live by a different childrearing logic, which greatly affects their navigation of the schooling process. "Concerted 
cultivation" is a middle-class aspect of childrearing. Lareau defines this as engaging in leisure activities, utilizing cultural capital (networking), educating children in the art of negotiation and fostering a sense of entitlement. Middle-class parents are actively engaged in their children's schooling and help develop their educational interests at home. When speaking about a nonschool ready child in her class, Ms. Moore stated:

There's not a lot of talking about school or even doing homework together or any books being read to them before bedtime.... a bedtime routine... which I think is really important to be ready for school. Get ready and get into bed...let's have a story...Tell me what you did today?

Ms. Moore unknowingly projected her own middle-class logic of concerted cultivation as the cornerstone of childrearing onto the expectations of parenting. Her expectations (as noted later in this chapter) are based on these middle-class value systems and she believes all families, regardless of socioeconomic status, should be incorporating the same values at home.

According to Lareau, working-class parents follow a different childrearing logic. They are committed to providing basic services, such as food and shelter, for their children (Lareau, 2003). They do not have the money or the time to take their children to dance classes or museum outings, but instead give them space to grow and learn by themselves, which she refers to as an accomplishment of natural growth.

Providing a sense of entitlement and verbal negotiation skills gives the middle-class child an advantage in the institution of school.

Because of these patterns of legitimization, children raised according to the logic of concerted cultivation can gain advantages, in the form of an 
emerging sense of entitlement, while children raised

according to the logic of natural growth tend to

develop an emerging sense of constraint (Lareau,

2003, p. 7).

Therefore, working-class children (low-wage workers' children) rarely challenge or question the authority of the adults in their lives. There is instead a general acceptance of directives and they do not generally negotiate or reason with their parents or authority figures. However, they are able to freely create their own leisure-time activities. Parents foster children's natural growth, allowing them to grow at their own pace. Children are able to interact more regularly with their relatives and extended kin and have more free time.

Ultimately, however, there is a distinct advantage for the middle-class child within the institution of school. The cultivation of their time-consuming leisure activities works to their advantage, as does their ability to verbally negotiate. They are able to talk at length about a subject, like they regularly do at home, and are able to communicate with more confidence. When discussing her students' verbal abilities, Ms. Moore stated:

I think what's happening at home determines if you are ready for school. If you're having discussions with your parents...it doesn't have to be a discussion...but if your parents are talking to you...if they're saying it's summertime...it's hot in the summer...just one sentence. I just feel like a lot of homes may be missing that talk.

Ms. Moore's understanding of what happens at home was laced with a concerted cultivation logic, as she felt that there should be more verbal discussions between parent and child at home. Low-income children, according to Lareau (2003), display many more constraints in their 
interactions in school settings. They enjoy less success making the rules work in their favor because they are not trained to question authority. These children are not as comfortable in the institutional setting because they do not feel as valued or heard. They have trouble advocating for themselves and do not always have the communication skills necessary to explain their problems or issues. This can lead to frustration and alienation within the cultural systems of the school.

Low-wage parents also exhibit less skill and knowledge in advocating for their children in school. Knowing and understanding the culture of the school is essential to navigating it and advocating for your child. This includes being aware of school expectations (discussed below) and having the time to attend parent-teacher meetings. This inability to properly advocate for their children is one reason for the high referral rates of low-income Black students to special education settings. Parents do not always know their rights and therefore do not contest or question special education referrals. Harry and Klingner (2006) refer to this as a culture of referral, as their research illustrates the elevated numbers (up to $50 \%$ of the class) of students in all-Black schools who are referred to the special education team. Parents who are low-wage workers do not always show up at these meetings due to work obligations. As a result, they do not have much say in the classification process.

For example, the same parent who had been missing in action because she was working multiple shifts for months at a time was unable to attend her daughter's intervention meeting with the vice-principal and special education team at my school. She actually called the school 20 minutes before the meeting to say she could not leave work in time. Working parents sometimes wait until the last minute to see if they can somehow make it, even though they know 
it is unlikely (Dodson, 2009). At this particular meeting, the vice-principal and the head social worker talked about educational negligence and how this parent, if she was not careful, could be labeled as such. The reading teacher said she could not contact the mom and that the grandma was not doing any reading with this child at home. I was asked if I saw any help or support at home and I (although conflicted) answered no. The child's residence in town was questioned since the mother was no longer picking her up. The head social worker contacted the district office to have her address checked. The fact that all of this happened within ten minutes of the child's mother not showing up for this important meeting illustrates how quickly a working mother can be judged as uninterested or uncommitted to her child's educational progress.

\section{Differing Expectations Between Teachers and Parents}

Even though the teachers in this study had some understanding that parents could not physically be at home because they were working, they still believed that the parents should be more involved in the academic and social progress of their non-school ready children. By expressing these views, they were unknowingly holding all parents to the same standard of behavior regardless of socioeconomic class.

Lareau's research suggests that teachers hold up the cultural logic of middle/upper income families as the standard against which all families are measured, and inevitably lower-income families come up as failing (Dodson, 2009, p. 119).

In their background interviews, all of these teachers stressed the importance of their own parents' involvement in their educational lives. Their parents went to all school functions, came to parent-teacher conferences and meetings, and were seen in and around the school building on 
a regular basis. They shared the same expectations for their students. They did not realize that this constitutes an unfair comparison because of the difference in socioeconomic backgrounds between their own parents and their students' parents.

When I asked Ms. Franklin if she had a theory about why these children were starting school non-school ready, she responded:

My theory is that parents who read to their children all the time and that are home talking to their children and parents that are taking their children to museums and parks and places and you know...having a lot of learning experiences at a very early age. I think they generally do....are more ready for school.

It is interesting to note that Ms Franklin started to say "they generally" and then switched to "are more ready for school," which sounds like a more equitable and non-predictive comment to make about a child. Through her comments, she revealed her awareness of a possible deficit relationship linked to a different childrearing logic.

The theme of childrearing expectations that are based on dominant Western practices relates to Gupta's research on early childhood teachers and how they insert their own values and logic of childrearing in their teacher training and classroom practices. She states:

Teachers construct knowledge through their socio-cultural experience and that they bring this body of knowledge, comprised of practical knowledge and their implicit beliefs, into the college classroom - as well as into the school classrooms they teach (Gupta, p. 3, 2006).

In other words, teachers are unaware that they transfer their own values and ideological ideas about parenting and schooling onto the families they serve. In this research study, I noticed 
almost immediately that the participating teachers had very distinct ideas of what parents should be doing in order to provide the best support for their children. These ideas and expectations were shaped by their own middle-class upbringings.

An example of this is reading. Developing a love for books and reading is a fundamental part of these teachers' shared value system ${ }^{100}$. They expressed an expectation that parents read with their child nightly. Ms. Springstein, Ms. Smith and Ms. Franklin grew up with mothers who valued reading and modeled it in the house. Books surrounded them and they knew that reading was important. Ms Smith stated, "My mom read to us and she read for pleasure and my dad read the newspaper more... he was an architect so he read more technical books.” The following excerpt from my first interview with Ms. Springstein clarified this point:

Ms. Tager: Like what was valued?

Ms. Springstein: I grew up to appreciate reading. I did not love reading when I was younger but I can remember as a child... where I would...we had a huge house. It was a really big house. I can remember walking through our living room and going to our tv room and my mother was reading...so reading was very important.

Even though she did not love reading at the time, seeing her mother read obviously had a great impact on her. She observed that reading was important to her mother and therefore she accepted its importance in her own life.

Ms. Franklin directly linked the importance of reading while growing up to her present life with her own nuclear family.

100 Based on societal middle class value systems 
My mother was a big reader. I

just remember her always reading...

reading...reading all the time. So she

was always curled up with a book and

she was always reading to us. And now

everyone's a big reader in my family...I

made sure (laughs) I read a lot in front of

them, so they can say 'my mother's always

reading.' Maybe I subconsciously did it...I don't

know. It's just books are very important...my

husband is a big reader...a big book smart

kind of guy, and both kids love reading.

It is quite clear that Ms. Franklin felt obliged to share certain values from her own childhood with her children, including a love for books and reading. These values affect how she observes and interacts in the world around her. Like Ms. Springstein and Ms. Smith, nurturing interest in books and reading remains an important part of Ms. Franklin's present value system.

In the district wide survey, $95.45 \%$ of the teachers claimed that parents should read to their children at home on a daily basis. Not one teacher thought it was of minimal importance or not important at all. These White middle-class teachers all agreed that reading at home is essential and non-negotiable, and expected all families to do it regardless of their cultural background.

In Dodson's (2009) research, she found that some teachers, although they sympathized with these low-income children, still felt the parents could be more active in their children's educational progress. She met with teachers who were astounded that some parents did not know that they should be reading with their children on a nightly basis. Blaming the parent was a natural reaction of overworked teachers who felt they just could not do it all (be a therapist, 
social worker, teacher, nurturing parent, etc.) in the classroom (Dodson, 2009).

Those teachers and the teachers in this research study all sought a partnership between the teacher and the parent that would benefit the child. This also leads to an expectation on the part of the teachers that parents should be partners in their children's learning process. The White middle-class teacher hopes for a cooperative learning environment that connects school to home, whereas the low-income parents believe that teaching only needs to happen in the school's physical space.

Several teachers in the study lamented the Nigerian families in their classrooms who refer to the teachers as "professors" and do not do any teaching at home because in their view teaching is relegated to school. The teachers in the study did not like this because they prefer to be in a cooperative partnership with the parents. According to them, this cooperative partnership benefits the child both academically and socially, as teachers contend that they cannot do it all alone. Ms. Franklin claimed:

My job is to take care of everything that happens in school and she (a non-school ready child) doesn't do her homework...so I am always talking to her mom about that. She says I asked her if she did her homework and she says she did her homework (laughs) so I thought she did her homework.

Although she understood that this Nigerian parent must work several shifts in order to survive and feed her family, she still expected her to review her child's homework on a nightly basis. Yet this mom and other Nigerian parents in the school do not believe that they should be a part of the schooling process. Ms. Moore declared:

In the beginning of school she (a Nigerian parent) 
said you make him behave...she said to me...like I teach him...you know it's kinda like a village, you're the teacher (she says), you teach him and then I am going to come and pick him up and take him home.

These teachers said that this is also a problem with Haitian Creole parents who expect the teachers to do all of the teaching at school and that nothing school-related should happen at home. Good behavior is emphasized by these parents more than academic progress. The expectation is that the American school and the American teacher will help children to achieve this success. Ms Watson complained about this added pressure:

And if there is a parent who is just waiting for school to teach them everything...that's what I find. I find that there's a lot of parents that just assume... wait until they are in school they will teach them what they need to know.

There are different sets of expectations between the culture of the school (as described by the teachers in this study) and the parents. Again, these teachers seek partnerships with the parents, who are expected to read with their children, model appropriate language and review their homework. The teachers become frustrated when they encounter different cultures that believe education is the responsibility of the school and not the family. According to Hale (2001), this expectation, based on the dominant culture of the school, can be a problem.

Teachers have been trained in the rhetoric that the schools work in partnership with the families in educating children. This perspective sounds perfectly reasonable on the face of it. However, the attempts to make this concept concrete have produced school success only for some children: 
those who have middle-class mothers who do not work outside their homes and have the skills, the time and the inclination to supplement their children's education, connection to the 'culture of power' to the extent that they can carve out a path for school success for their children regardless of what the teacher does in the classroom (p. 6).

Hale advocates for a change in teacher expectations because, as it stands now, the middle-class White family is able to meet these teacher expectations, yet low-income Black families have less success. I agree with this assertion and feel that this leads to a widening gap between these two populations. Low-income Black families will always be considered deficient within the framework of these specific expectations.

In conclusion, although the teachers were clearly aware that low-income parents are working many jobs, they still desire more involvement in the educational process. These lowincome parents are busy working multiple jobs and shifts in order to make ends meet and provide for their families. They are trapped in low-wage jobs that offer inflexible schedules and do not always allow them to take time off to attend important school meetings. These parents also lack cultural capital and therefore do not necessarily possess the knowledge required to navigate school. Expectations can also be different due to cultural differences. Parents who come from other countries, such as Nigeria and Haiti, have different expectations of schooling and their own involvement in their children's schooling. I found that the teachers were interested in a mutual partnership with parents and were therefore disappointed when parents were not physically available to support the children. Because the demands on the teachers are higher, they have higher expectations of the parents and lament that parents are not doing enough at home. All of 
these factors relate to perceptions of school readiness on the part of the White middle-class early childhood educator.

In the next chapter, I unpack and examine the added discourse of race and how it influences perceptions of school readiness. Elements of the discussion include color-blindness, the variety of race ideologies, White teacher discomfort, and the combination of race and socioeconomic class, and how these factors combine to affect teachers' perceptions of school readiness in low-income Black children. 


\section{Chapter Seven}

\section{“That's a Tough Question": Issues of Race and School Readiness}

We are all standing around and looking at the different charts (data) taped to wood paneled dining room walls. Teachers have post-its and pens in their hands and as they walk around make notes on the charts.

Ms. Tager: This is pretty interesting over here (I point to a chart). Number 5 (Ms. Moore) was the only one who thought that race was maybe an issue and she talked about three different kinds of Blacks in her classroom.

(laughter)

Ms. Moore: That makes me sweaty.

Ms. Franklin: You're the only one.

Ms. Tager: No, I thought that was interesting.

Ms. Moore: It was just an observation.

[The topic changed.]

The focus group lasted $1 \mathrm{hr} 44 \mathrm{~min}$, transcribed to 76 pages and the exchange reproduced above was the only conversation related to race. This was revealing in itself, as the participants were anxious to talk about all matters related to school readiness except this one. Discomfort and silence surrounding race were omnipresent in all the individual interviews as well.

In this chapter I unpack and examine the complex understandings and multiple layers of race and how race relates to school readiness discourse. Different discourses emerged when the 
participants responded to this tough issue of race, including color-blindness, race as a non-factor, white discomfort, race and meritocracy, race ideologies (including Shades of Gray and race and socioeconomic class.

The following discourses on race were a component of the findings within this research study. They reveal the complexity of the issue and together provide a clearer picture of how these particular White female teachers responded to race.

\section{Color-Blind Discourse}

Color-blind discourse, as defined by Frankenberg, is "thinking about race organized around an effort to not see or at any rate not to acknowledge race differences" (Frankenberg, 1993, p. 142). The system of racism is invisible, and therefore embedded in the institution of the school (Frankenberg, 1993; Randolph, 2013; Bonnila-Silva, 2006, Leonardo, 2009).

This discourse is built into academic standards. Unbeknownst to these teachers, they perpetuate colorblindness by trying to meet the higher demands of the district. There is no time to differentiate among children as they are all expected to meet the same standards, regardless of the history of racial marginalization within education. Thus, a low-income Black child like Billy, who had no preschool experience, is expected to achieve the same level in reading by the end of first grade as a White middle-class child who attended a top-tier preschool. Furthermore, Billy's teacher, Ms. Smith, who was wrapped up in the district discourse of expectations, did not necessarily realize that this child, because he is Black and from a low-income family, was more likely to be perceived as non-school ready. She simply saw that he had not met the expectations of the district and was lagging behind the other students. When I asked her about race and how it could possibly affect school readiness, Ms. Smith was not aware of any relationship. 
I don't think so because it can't be...but I have seen families...different races of families that are... even if they might not speak the language...there is pride in education...educating and learning and a respect for the school community...I just don't see it that way, because I have taught all the colors of the rainbow kids...I am actually looking at the person... I am looking at the family as a unit...

She was unaware that she was perpetuating a color-blind discourse with her comments that she has "taught all the colors of the rainbow kids" and felt that race was a non-issue as long as the children's parents take pride in education. Ms. Smith saw children as universally the same.

This was a common reaction of the teacher participants in my study, as they were more focused on meeting the high expectations of the district instead of examining the social strictures of a color-blind society. In the districtwide survey, $81.82 \%$ of respondents believed that the teachers should ensure the students know that they are all the same even if they have different skin colors. This conveys sameness of all, yet it is more complex than an oversimplification of one size fits all.

In Bonilla-Silva's (2006) research findings, he contends that at the heart of color-blind discourse lies a myth, "the idea that race has all but disappeared as a factor shaping the life chances of all Americans" (Bonilla-Silva, 2006, p. 208). This color-blind ideology maintains and perpetuates White privilege in and out of the classroom. He contends that the "White habitus" conditions and creates White people's perceptions, and reinforces their views on race (BonillaSilva, 2006). Part of the White habitus is that Whites are not around Blacks on a day-to-day basis. He found that fewer than $10 \%$ of Whites have Black friends or Black people in their lives (Bonilla-Silva, 2006). Whites, for the most part, live in majority White neighborhoods due to 
racial housing segregation (Massey and Denton, 1993). "Residential segregation is not a neutral fact. It systematically undermines the social and economic well-being of Blacks in the United States" (Massey and Denton, 1993, p. 104). It is interesting to note that $78.26 \%$ of the White teachers in this district live outside of the district. Even more revealing is that none of the five participating teachers live in the same neighborhood as the school (an all-Black neighborhood). I also do not live in my school's neighborhood, but instead travel 25 minutes by car daily. The survey asked these teachers if they thought teachers should live and work in the same area, and $63.04 \%$ said that this was not important at all (0 said it was very important and 0 said it was important). In addition, all five participating teachers grew up in a primarily White town. Thus, living outside the neighborhood of the school at which they work and growing up in primarily White towns might have affected how these teachers view race. Anyon (2005) states,

The average White person in metropolitan America lives in a neighborhood that is $80 \%$ White...Blacks live in neighborhoods where they are absolute majorities... Whites then live in neighborhoods with few minorities, while minorities live in neighborhoods with high minority representation (Anyon, 2005, p. 79).

This translates to suburbs of large cities as well. Anyon notes that at-risk suburbs also have segregated neighborhoods, as over the last 20 years more low-income populations have moved to the suburbs, much like the one in this study.

\section{$\underline{\text { Race Is Not a Factor }}$}

It seems understandable to me that these participating teachers do not believe that race is a factor in labeling a child non-school ready, precisely because they do not want race to be an 
issue. As liberal educators, they believe that all children possess an equal capability to achieve in school. They would be horrified to think that race is an issue for young children. When I asked Ms. Springstein if race has anything to do with a teacher's perception of a non-school ready child she quickly stated:

I don't think race... race doesn't have anything to do with it...because I feel like you can have African American parents who work with their kids and you can have White parents who don't work with their kids...it's all a matter of... are the parents putting as much into it at home as I am putting into it at school.

Ms. Springstein dismissed the idea that the racial background of a child had anything to do with the child being perceived as non-school ready. Instead, she believed that the parents' actions, regardless of racial backgrounds, have more of an influence on children's school readiness status.

At times it seemed that simply mentioning race put these teachers on guard. For example, in a conversation about Lina's parents, Ms. Franklin showed discomfort discussing the issue of race.

Ms. Franklin: They (Lina's parents) are not really behind me...I am not used to that...all of my parents...usually I develop a relationship with them.

Ms. Tager: Do you think it has to do with the fact that they are upset because she is in AI (academic intervention)?

Ms. Franklin: Yes and...I ...I...I think that they feel it was a bit of a racial issue.

Ms. Tager: Did they say that to you?

Ms. Franklin: They did not say that to me...but they said it to 
another parent... who told me.

Ms. Tager: And did you talk to them at all about this?

Ms. Franklin: No but...I ...I didn't talk to them straightforward about it but I talked to them about how...I felt that they were just worried...they were worried about her and I said...just because you go into AI doesn't mean...it's just extra help...why wouldn't they want that.

Ms. Tager: They didn't want her to be labeled? Or something?

Ms. Franklin: Yeah...I think they thought she was classified ${ }^{101}$.

The above is an example of race avoidance on the part of both Ms. Franklin and Lina's parents, as Lina's parents did not directly confront Ms. Franklin on this topic. Ms. Franklin, a person who considers herself fair on racial matters of difference, was very upset that the parents might think that she was insensitive to matters of race in her own classroom. She builds trusting relationships with all of her parents and was confused by Lina's parents hostile response to her. She believed that they were just concerned because Lina was being pulled out for academic intervention and were worried that Ms. Franklin was trying to classify her because of her racial background. Ms. Franklin was uncomfortable with another parent coming to her and telling her that Lina's parents believed she had issues regarding Lina's race. She was so uncomfortable that she would not even bring it up with the parents, but instead addressed their concerns and worries about Lina's lack of academic progress.

${ }^{101}$ A child is classified when they go to the child study team and receive an IEP (individual educational plan). This is considered special education. 


\section{White Discomfort}

Research shows that Whites in general are not used to thinking about themselves as racial identities (Frankenberg, 1993). Thus, the discomfort that the teachers in this study displayed when referring to a child's race and how it might or might not affect the teacher's perception of the child's school readiness status follows this trend. Their discomfort around the topic of race is in itself a product of the color-blind discourse perpetuated throughout the school district. When I asked Ms. Franklin about race and how it might be a factor in a student's school readiness status, she stated:

That's a tough question...uh...that's a tough one... I don't know...I have to think about that.,.I can't just answer like one second later...

This is a tough question. Her answer might be directly related to how the question was phrased in the interview guide. The framing of the question, "Does race play a factor in school readiness status?," is not the same as asking, "Does racism play a role in whether students are identified as school ready?" The latter phrasing could have made Ms. Franklin even more uncomfortable and less likely to respond. The similarity between her hesitant response to my question above and her concerns about Lina's parents' perception that her categorization of their child as non-school ready had racial undertones, reveals her discomfort of the topic of race. Interestingly, I noticed more pauses during the teachers' discussions on race. Their speech was uniformly hesitant, illustrating their extreme discomfort with the topic.

Just talking about race or matters concerning race can make White teachers uncomfortable, especially if the majority of the children in their classrooms are Black. The participating teachers wanted to be fair and reasonable, and did not want to be perceived as or 
even suspected of being racist in any context. For example, Ms. Moore, stated during the focus group , "that made me sweaty," when I brought up the fact that she was the only teacher participant who talked about three different populations of Blacks in her classroom. She did not want to generalize about her specific Black populations but she recognized differences and felt a need to talk about them.

My honest thoughts...I have a lot of problems...not problems I notice a lot with Haitian children that there is...it is not just a difference in language...I am speaking English you are speaking Creole...it's a cultural difference... and maybe he can understand me clearly, but he's [Derek]...but maybe he's not talking to anyone at home...in his own language...lots of times it is hard for me to connect with him...I see the Haitian children and then I see African American children and then I see the children...maybe first generation from Africa...Nigeria...Kenya...mostly what I see is the African American parents don't really show up for things...they are not always helping at home.

She did not lump all of her Black students altogether and was aware of variations in cultural expectations. She was clearly nervous that she was the only one who noticed these differences and did not want to stand out for describing her Black children differently. In the focus group, Ms. Franklin responded, "You are the only one" to Ms. Moore. Ms. Moore was quiet and then said, "It was just an observation." The topic then shifted, as it quickly did every time the issue of race was raised.

For her research in a large mid-western city, Randolph (2013) interviewed White and Black teachers on the topic of race and the perpetuation of "multicultural" color-blind discourse. She noticed that many of the White teachers in her study assumed that the Black children in their classes were African Americans. 
The assumption that Black means African American is common in most major Eastern cities, except for New York (and perhaps New Jersey), where teachers have more awareness of Black ethnic diversity (Randolph, p. 19, 2013).

She essentially found that White teachers were not able to differentiate between different types of Black populations. Note that my research took place in the New York Tri-State area where White teachers were noted by Randolph for being more aware of the differences in Black populations.

I noticed that there were times that the teacher participants were confused about the different Black populations they were discussing. Some teachers had trouble defining the background of the Black students during our conversations. The following is an excerpt from my second interview with Ms. Smith. I asked her about the students who were pulled out of her class for academic intervention.

Ms. Tager: Are they all Black?

Ms. Smith: Three.

Ms. Tager: Three out of five?

Ms. Smith: There was four...so three out of four.

Ms. Tager: I am sorry...so [Black Children] were the majority?

Ms. Smith: Mmmhhhmmm.

Ms. Tager: And there is one White kid? Is that what you are saying?

Ms. Smith: Yes and also the education of the parent. 
Ms. Tager: Of the parent?

Ms. Smith: Yeah.

Ms. Tager: Explain.

Ms. Smith: One of the children...the parents have a higher education...the other three children...the three of them

Ms. Tager: Did they graduate high school?

Ms. Smith: I don't know...that I don't know. I know they speak another language...but I know this other family so I know...but the other three families...one I know speaks another language and the other two have accents so clearly they do speak another language....

Ms. Tager: Where are they from?

Ms. Smith: I want to say...two are from Haiti and where is the other little guy from? Oh this is terrible...I can't remember and it's not Haiti though..it's not.

Ms. Tager: Is it Africa?

Ms. Smith: I don't think so.

Ms. Tager: Okay.

Ms. Smith: And he mentioned it and now I can't think of it.

It clearly bothered Ms. Smith that she could not identify the country of origin of the Black child in question. She was also unsure about which parents spoke another language at home or just 
had accents. She was perplexed about the origin of the accents but because there is a large population of Haitian children at the school, she believed they were likely Haitian.

In another example, when talking about her two past retentions, Ms. Franklin mislabeled the boys as African American and then later remembered that they were Haitian.

Ms. Tager: Was he African American?

Ms. Franklin: Yes, he was.

Ms. Tager: You have retained two people and they were both

African American?

[Ms. Franklin nods her head.]

[Later]

Ms. Tager: Do you have kids with language issues who are non-school ready?

Ms. Franklin: [Pause] No...none that I know of...[pause] not this year...I am trying to think.

Ms. Tager: Did you have kids from Haiti who had issues in the past?

Ms. Franklin: For school readiness?

Ms. Tager: Yeah.

Ms. Franklin: I haven't had any kids that weren't school ready so...I...you know...I had two African American kids and they were both Haitian...They're not African American... They're Haitian. 
Ms. Tager: Okay...that's interesting...they were both Haitian

Ms. Franklin: They were not African American

During the course of the interview, Ms. Franklin corrected herself. She was aware that she had mistakenly labeled her most recent two retentions as African American and wanted to be sure that they were correctly identified as Haitians. This illustrates a subtle example of how White teachers are sometimes unaware of the different Black populations in their classrooms.

Randolph claims that there is recognition of the different ethnic groups of Whites (or Latinos), but not of the diverse populations of Blacks. She claims that this bias leads to a multicultural color-blind discourse that perpetuates a hierarchy among student populations. The White non-immigrant comes first, followed by the White immigrant, the non-White immigrant (Latino) and finally, all Black populations., She concludes that Blacks (whether immigrants or not) are the lowest in this hierarchy and therefore further marginalized. Randolph maintains that these teachers value ethnicity more than skin color, which results in the perception that Black children are more deficient (Randolph, 2013).

Leonardo, in his most recent work, Race Frameworks: A Multidimensional Theory of Racism and Education, states that a "color-mute" discourse in schools "testifies to a fundamental discomfort" that Whites feel when involved in race discourses (Leonardo, p. 125, 2013). The silence on this topic indicates that it is an issue that remains difficult for Whites to contemplate. Whether race is talked about or not, it is still present. This race evasion primarily exists because of White discomfort. 


\section{$\underline{\text { Race and Meritocracy }}$}

Ms. Watson's response to the question of race and how it relates to the classification and/ or perception of school readiness was interesting because she believes that race does not hinder children and is not a factor in their learning trajectory. In her opinion, all children can rise above any obstacles in their way and achieve in school. When I asked her about race she stated:

$$
\begin{aligned}
& \text { No...I mean...I shouldn't say no...I am sure it (race) } \\
& \text { does...again there are shades of gray but I have a child } \\
& \text { who comes from a single parent...strong family values... } \\
& \text { couldn't afford preschool...but the mom is working with him } \\
& \text { and he's my top reader...he's my top mathematician...he's } \\
& \text { my top....and he's Black and he's male and he's doing great. }
\end{aligned}
$$

To her, this low-income Black child exemplified the notion that all children, regardless of their backgrounds, can succeed with hard work. She used this example when discussing whether race was a factor in non-school readiness because it proved to her that it was not about the color of the child's skin; rather it was about hard work and making an effort to achieve. However, this was an exception. In the above excerpt, Ms. Watson demonstrated she was aware of race and how it could impact a child's learning trajectory. She believes that success depends on the child's parents and how involved they are in their child's schooling and progress. Ms. Watson contended that this particular low-income Black child sat at the top of her class specifically because his mother worked so hard with him at home. In this meritocratic discourse, which perpetuates the color-blind discourse, the child's skin color has nothing to do with his or her success or lack of success in school. Furthermore, the context of the racist society in which these children live is not taken into account. 
On the other hand, Ms. Franklin had different views on the issue of meritocracy. "It's not a level playing field," she stated in an interview. To her the "American Dream" is not real and cannot be realistically attained by all populations. In one of her interviews she made the point that she had to provide more schema ${ }^{102}$ for low-income Black children in order for them to catch up with the rest of the class.
A lot of these children come here without life experience...no schema...very little schema because they haven't gone anywhere... seen anything...I think the SMART Board ${ }^{103}$ has helped these kids... with their nonfiction reading and has given them a lot of schema. I think the next best thing to being there is actually taking these virtual tours and it is wonderful.

According to Ms. Franklin, the playing field is uneven and certain children (i.e., low-income Blacks) start school without the necessary schema. In her opinion, technology can help level the playing field when used properly. Providing new experiences, new vocabulary and exposure to new places and ideas can help these children rise above their limited backgrounds. She believes that if low-income Black children start at a deficit (lacking schema), it is up to the teacher and the parents to help them overcome the obstacles of institutional racism and achieve more. Therefore, although she believes in the power of hard work for a child to achieve success, she is also somewhat aware that institutional racism and poverty are factors in a child's academic progress and schooling potential.

\footnotetext{
102 Schema is a common word utilized in this particular school district. It pertains to background knowledge. See glossary.

103 The SMART Board is a new technology used in classrooms. It works just like a computer but can project onto a larger screen. It can also be used as a giant iPad.
} 


\section{Race Ideologies: Shades of Gray}

Frankenberg's research identifies three different possible race ideologies that White women can adhere to in discussions on race: "essentialist racism," "color evasion/power evasion" and "race cognizant" (Frankenberg, 1993). Essentialist racism is what the United States was founded upon. It utilizes race as a hierarchal structure and emphasizes biological differences that are deficit-based. Color evasion/power evasion emphasizes sameness in all humans and renders race a non-issue. Race cognizant is the awareness of inherent structural differences in race that lead to inequalities (Frankenberg, 1993). One might think that many teachers working in this particular district fall into the color evasion/power evasion category because they emphasize sameness in all their children regardless of skin color. Yet it is more complex than that.

During the research process I uncovered another race ideology that I refer to as "shades of gray" and that best relates to these teachers' views. This ideology is distinguishable from Frankenberg's because it reveals some awareness of race and racial identity. It presents a counternarrative to conventional stereotypes and manifests itself on a case-by-case basis. In other words, its determination depends on the individual and how the teachers perceive that particular individual. There is still discomfort involved, but it is not a straight color-blind discourse.

As noted in the last section, Ms. Watson was somewhat aware of race and how it affected her kindergarten classroom. She discussed the Black boy who was at the top of her class in all subjects in order to counter the negative perception of Black children as learners. She wanted to 
dispute this stereotype. In our second interview, Ms. Watson repeated the phrase, "there are different shades of gray" several times to emphasize the complexity of the issue.

She was a single parent and she really has worked with him and he's one of my top readers so...yes again...there are many shades of gray...everything has to be taken on a case-by-case basis.

Above, Ms. Watson implied that she knew of the unwritten assumptions about Black children in single-parent households. Yet she has worked with children who defy this assumption.

According to her, things are not so simple and "everything has to be taken on a case-by-case basis." She later stated:

But I guess I still marvel at this one young man (Black child) who comes in with a single parent...that just says that if you really want your child to succeed no matter what your race...no matter what your socioeconomic...you can do it... you know...

For Ms. Watson, this exception demonstrates that race is complex yet simultaneously not a factor. Hers is not a straightforward color evasion discourse, because she is aware of the stereotypes and negative discourse that threaten the academic achievement of young Black boys. Furthermore, her remarks illustrated that White teachers can harbor conflicting thoughts ("shades of gray") when reflecting on issues of race in their classrooms.

$\underline{\text { Issues of Race and Socioeconomic Class }}$ 
As a teacher of young children, I think it is important to examine the social context of low-income Black children in the classroom. Institutional racism and poverty coexist in this country and have a strong impact on the schooling experience of low-income Black children. If families suffer job-related and housing discrimination and other forms of institutional racism, those negative experiences are bound to affect young Black children and their school readiness. In Anyon's research findings she posits that true educational reform cannot occur without the examination of the macroeconomic inequities within the school community itself (Anyon, 2005). Low-wage jobs of Black parents affect their children's schooling experience (see Chapter 8). Blacks earn less than Whites, even in minimum wage jobs (Anyon, 2005). Residential segregation and unfair housing practices, such as redlining (steering Blacks into one area), affect the everyday lives of these young children. Lack of health insurance and poor overall health can also plague low-income populations.

In my first-grade classroom I teach large numbers of Black children who qualify for free and reduced lunch (43\% school-wide). ${ }^{104}$ They arrive some mornings complaining of stomachaches and headaches because they have not eaten breakfast. Hungry young children have trouble focusing or attending to their work. My colleagues and I keep snacks on hand just in case. Children have told me over the years that they get very little food outside of the school building. ${ }^{105}$ They often store or hoard what they receive and save it for later. A first-grade teacher in the interpretative focus group (\#8) stated, "They are hungry...in the morning." Another firstgrade teacher (\#11) followed with, "They are always hungry." A low-income Black household

$10443 \%$ are all Black children.

105 School breakfast and lunch are provided as part of the free and reduced lunch program. However, the breakfast is very early and many students cannot make it to school early enough to receive it. 
might not have much food, which can directly affect children's school readiness status. Lack of food is just one example of how low-income Black populations are affected by the social context in which they are living.

In conclusion, the "tough question of race" is embedded into perceptions of school readiness and in different ways through color-blindness, race as a non-factor, White discomfort, race and meritocracy, race ideologies (the complexity of different shades of gray) and race and socioeconomic class. I found that all of these play a role in White teachers' perceptions of school readiness. This is a complex and multi-layered topic, one that cannot be defined as a straightforward color-blind discourse. Race and perceptions of race constitute, however, an important part of any topic related to schooling and school readiness, as $83 \%$ of all public school teachers are White women (Randolph, 2013). Children are sorted and classified daily, and race is a contributing factor to the identification of children who are non-school ready, have special education needs or learning disabilities, are subject to retention or suspensions, etc. (Harry \& Klingner, 2006). It is essential that this "tough question of race" be further examined and dissected in order to address inequalities within schooling populations.

In the next chapter I explore the significance of this research on school readiness and propose a call to action that provides educators of young children a way to respond to this topic. Listening to the teachers in this study made me reflect on my own teaching experience, and gave me a new way to think about school readiness. I believe the time has come to reimagine this topic and work on ending the deficit discourse attached to it. 


\section{Chapter Eight}

\section{A Call to Action: Empowering the Early Childhood Educator}

Now that I have critically examined school readiness and how it negatively impacts the daily lives of early childhood educators, it is time to propose a future action plan. It is not enough to deconstruct school readiness discourse and describe the hardships that early childhood educators face when trying to meet the demands of the district. There has to be a call to action, a way to empower early childhood educators and pre-service teachers, so they can fully serve the different non-White populations they teach.

In this final chapter I try to imagine new, more positive and empowering approaches. I explore the options that the teachers in this study have discussed or considered themselves, as they are in the trenches and know what is needed to combat this issue. This chapter also includes a model letter to any local school district that utilizes testing, accountability or Common Core standards. It is my hope that such a letter will start a dialogue that will eventually lead to a better understanding on the recipient district's part of what early childhood educators endure in order to get their students ready for school. With this new understanding, perhaps public school districts can temper their demands and standards knowing that other options exist. This in turn, will greatly impact the present deficit discourse surrounding the issue of school readiness. 
Furthermore, I end this dissertation by addressing the bigger picture of early childhood education in the United Status (in terms of policy and future policies), hoping that my call to action will help reconceptualize ${ }^{106}$ early childhood education as it stands today.

\section{Dear Local School District:}

On behalf of the early childhood educators who participated in my research study, I would like to present alternative options to address the increased demands put on teachers to identify and perceive school readiness skills in very young children.

Five years old is five years old and six years old is six years old. Please be aware that developmentally appropriate practices (see Braekemp \& Copple, 1997, 2013) must be utilized when teaching. Preschools should not be considered extensions of kindergarten or first grade. Developmentally appropriate practices, such as free play, puppetry, block play, imagination stations, and other creative group play that foster social skills in young children are more important to their future as students than the pushing down of reading and writing curricula. Just recently, The Washington Post published an article (by V. Strauss) entitled "Requiring Kindergartners to Read as Common Core Does - May Harm Some." This article states that forcing young children to read can actually be harmful, as it is not necessarily developmentally appropriate at the kindergarten level. The author cites varies studies, including the report (put out by the Alliance for Childhood) Reading Ink: Little to Gain and Much to Lose (2014), which posits that there is no evidence to support the belief that children who read earlier (in pre-

\footnotetext{
106 This term is utilized in terms of reconceptualizing early childhood curricula and is a critical approach to dominant paradigms (Bloch, et al, 2014).
} 
kindergarten and kindergarten) achieve more academic success later on (2014). Actually, the research shows that there are greater academic gains related to children in play-based programs (2014). This report argues that pushing children to read at an earlier age (as per Common Core standards) is an unrealistic goal that can be detrimental to young children. I agree with the premise of this article and call for early childhood educators to rewrite the Common Core standards for kindergarten by including more developmentally appropriate practices.

In this letter, I present a variety of alternative practices, discourses and ideologies that will help empower early childhood educators in your district and help them to become more selfreflective in their assessments of school readiness in low-income Black populations. These suggestions are based on the solutions and ideas proposed by the teacher participants in this study. This in turn, will help your district to bridge the large (and ever-widening) achievement gap between White middle-class populations and low-income Black populations.

First and foremost, reduce class sizes (to more acceptable levels of 15-18) and add more personnel to the classroom. Early childhood classrooms need more than one educator in the room. A class with 23 five-year olds and one educator is an unacceptable practice. Developmentally appropriate practices call for one educator per 10 students; therefore, you need at least two full-time certified teachers in kindergarten and first-grade classrooms. It would also be very helpful to have at least one paraprofessional per room, as there are children who demand one-on-one assistance due to various learning and emotional issues.

Stop adding to the curriculum. There is no more time in the day. Teachers have too much to cover as it stands. If you add something, you must remove something. The time factor currently constrains their daily teaching. Teachers need more flexibility in their schedule, not 
less. Time needs to slow down so that the children can process what they are learning. Let teachers decide how to schedule their days. There is no need to enforce a specific amount of time per content area (e.g., 90 minutes of math daily). Such rigid schedules are very restrictive and confine teachers to a needlessly specific teaching time. For example, teachers might include only 30 minutes of formal math instruction on some days, but ensure math is infused in other areas (e.g., math centers, math in reading, math in science, etc.). On other days, teachers might include 60 minutes of formal math lessons, including math games and ST Math. As long as the curriculum is covered in a timely fashion, this should not be a problem. Schedules need to devote more time to free play. Block building, imagination stations, puppetry, game stations and other free play activities are essential to learning socioemotional skills and are an appropriate practice for young children. It is also crucial that young children learn in groups and partnerships, so they can build socioemotional skills that are necessary for later school success (and life success). The new and increased emphasis on individualized instruction within the structure of the Common Core is not developmentally appropriate for this age group.

Address issues of poverty within your district. If there are Title One schools located in your district, you must constantly be thinking of ways to provide equitable resources to that school. This means distributing district resources with this in mind and potentially providing additional funding to such schools. It also means that you must support the low-income parents and families in the district by providing a variety of times for parental involvement (especially since low-income parents often work two and three jobs with schedules that differ from other parents). This could mean a morning PTA meeting instead of the usual evening PTA meeting. It could also mean morning parent-teacher conferences or conferences at the teachers' discretion 
(since they are more aware of their parents' work schedules). Pay attention to language differences and provide districtwide memos and websites in a variety of languages. Most important, provide food for the community. Participate in food drives and host a variety of community functions with food at the schools located in the poorer areas of the district. Give back to the community and have classrooms go into the community to provide much-needed services (e.g., fixing up a community garden that provides free vegetables to the public, providing space in the schools for community meetings, etc.). The community surrounding the local schools needs to be a part of the learning process. Have parents come in when they are available to share their knowledge, culture and life experiences with the students. Participate in local theater groups, musical performances and other venues that are important to the community. Be present. District personnel need to be physically present in the local schools and community. Attend more school activities, community functions and parent workshops. Home visits by teachers are also an important component.

Tests and data should not drive the curriculum. Early childhood education is about the education and the pedagogical practices of working with young children. Children are learning for the sake of learning and to acquire enough knowledge to be good global citizens. Young children are not numbers. Young children need time and space to learn and grow. If you take the pressure off the early childhood educators, the pressure on the young children will decrease as well.

It is also important to be aware of the racial composition of the students and the teachers in your district. Schools with a majority of White teachers and a majority of Black students need to be especially reflective of their pedagogical practices. It may be uncomfortable, to discuss 
issues surrounding race and racial inequalities but race needs to addressed. Workshops and professional development days need to be devoted to this topic. Building awareness is the key to understanding embedded perceptions within the White teachers' practices. It is also essential to future anti-deficit discourses and practices.

Please consider these ideas and options when evaluating and reforming your district practices and policies (see Table 6 ).

Thank you.

From the participating K-1 teachers in this study

The Bigger Picture - Policy and Early Childhood Education

School reform of any kind, including the inherent issues of inequity in school readiness, must first be addressed on the macroeconomic level. Anyon, a noted education policy researcher, expresses strong opinions on this topic, as her research in Radical Possibilities calls for a national movement on school reform that centers on bridging societal inequalities and inequities (Anyon, 2005). Future early childhood policy that involves reform (including the notion of universal preschool) has to be designed with the bigger picture in mind. 
Table 6

Ideas for addressing non-school readiness from the teacher participants:

\section{\#1 Ms. Springstein}

Need more administration support

Need more district support

Parent education workshops

Summer school for entering K

More physical space in classroom

Smaller class size

\#3 Ms. Watson

Need more preschools

Need more administration support

Need more district support

Parent workshops

Two teachers per K class

One special education teacher (floating)

Transitional kindergarten
\#2 Ms. Franklin

Need more preschools

Need more district support

More technology

More field trips

Learning camp in summer

Smaller class size

\section{\#4 Ms. Smith}

More preschools

More district support

Parent workshops

Better communication (Parent-Teacher)

More early interventions

Smaller class size

\#5 Ms. Moore

More preschools

More district support

Better parent-teacher communication

Two teachers per class in kindergarten

Transitional kindergarten

Summer school for incoming kindergarten 
Therefore, issues of race and class, and the local context of early childhood programs are essential to any policy reform. As I discussed in Chapters 7 and 8, perceptions of children are tied to issues of socioeconomic class and racial background. Administrators of early childhood programs must be aware of this and cater to their varied local populations. Being culturally responsive is imperative in this context. Such sensitivity translates into early childhood educators and school districts at large that are more aware of the needs of their local community. Measures to address community needs include initiatives such as providing information in multiple languages, providing local community services, changing hours of operation to coincide with low-income working parents' many jobs, aiding parents in school registration, providing parent workshops, promoting school-home visits, having book and food drives and fundraisers for the community. The local schools should be part of their communities and serve as partners in learning.

Furthermore, new policies should not be one size fits all, as a single program will never fit every local community's needs. Flexibility and adaptability are key to serving differing populations nationwide. The location of the program is paramount. The needs of each particular community are what matters. New standards that are universalized are suspect and do not conform to this vision. New and improved nationwide standards in early childhood education are not the answer. Studying the local climate should instead be the focus. This can only be achieved if we, as early childhood teachers and researchers, look at the purpose of early childhood education. 


\section{The Purpose of Early Childhood Education}

It is important that the U.S. as a whole and the individual local school districts focus on the purpose of early childhood education, which is the education of the student. Schools and programs need to focus on providing an education for their young children in ways that give all children equal access to education, as President Roosevelt envisioned in his 1930s address to the nation (Roosevelt, 2008). In a working democracy, providing equal access to quality early childhood programs is essential. The two-tiered system of preschool needs to be eliminated. The goal is to challenge all deficit discourses and work towards equity in early childhood access.

It is important that future research critically challenge early childhood education discourses. Such studies must also be recognized as one of many legitimate contributions to scholarly research. This refers to researchers involved in the creation of the annual international conference "Reconceptualizing Early Childhood Education" (Bloch et al, 2014; Hatch, 2014; Cannella, 1997; Lubeck, 2001; Kessler, 2014; Wright, 2014; Polakow, 2014 and etc.). In Reconceptualizing Early Childhood Care and Education: A Reader, Bloch addresses the important connection between critical research and political action. Reimagining early childhood education is in itself a political action. After 21 years of committing to the idea of reconceptualizing early childhood practices, these researchers (including me) believe that this is an emancipatory process that challenges dominant discourses and provides alternative views of related discourses. In this tradition, I challenge the dominant discourse of school readiness and call for a new reimagined view of this term, one that better aligns with the purpose of early childhood education. 
In conclusion, school readiness is currently a term that perpetuates a deficit discourse within early childhood education. Perceptions of school readiness are embedded in a variety of circulating discourses (socioeconomic class, race, standards and accountability, and measure and demands). These discourses need to be reconceptualized in order to challenge deficit perceptions. We must challenge the concept of school readiness based on the constructions expressed by the teacher participants in this study. In the end, even though the teachers were ambivalent about the term school readiness, they were clear about the fact that higher expectations and constant demands directly impact their children by causing increasing numbers of students to fall behind. In order to move forward by designing and implementing new and more equitable early childhood programs nationwide, we must question the assumptions and perceptions that are based on deficit notions. If this is not accomplished our country will continue the pattern of reinventing new early childhood policies and pedagogical practices that further contribute to this overall deficit theme.

A call to action to reconceptualize how we think about early childhood education is critical at this point in history. In order to counteract the deficit-based discourse surrounding school readiness, it is essential that we empower early childhood educators. They are highly trained and qualified, and they know what works best for young children. Early childhood teachers need the space and time to teach culturally responsive pedagogy without all of the outside demands and pressures. It is time to rethink policies that are deficit-based (NCLB, Race to the Top, Common Core) and re-imagine a more inclusive environment for all our young children. 


\section{Glossary of Terms}

504

A 504 is an action plan based on a medical diagnosis. A student needs to be diagnosed with a medical condition in order to be considered for a 504. Such conditions include attention deficit disorder, heart conditions, diabetes, sensory disorders, etc. A plan, such as an IEP, is developed to specifically help accommodate the child's medical needs. For example, a child with ADD can get a special cushion seat that helps him or her sit better in a chair.

\section{AI - Academic Intervention}

Academic intervention is a service provided by the district to help struggling readers improve in reading. Each school has at least two academic intervention or reading specialists who pull children out of the classroom for 30 minutes per day in order to work with them in small groups. Children are referred to the AI team based on their first DRA scores in September. Children can exit AI at any time in the year if they reach grade level in reading. Parents have the option to refuse AI services at any point.

\section{Benchmarks}

Each grade has different benchmarks in reading at different points of the year. If a child tests below these benchmarks, they are considered below grade level and action needs to be taken (e.g..; academic intervention, school interventions, referrals to the child-study team, etc.). These benchmarks occur three times per year, coinciding with report cards.

\section{Briganz Screening}

The Briganz screening is for incoming kindergardeners in the district. It is a an assessment that is evaluated and scored by kindergarten teachers. Some questions are easier than others (e.g., What is your full name?) and some are hard (e.g., pointing to a part of the body and asking the child to name it). The test also asks the child to draw and identify shapes and identify the letters of the alphabet. The scores range from 1 to 100. After scoring all the kindergarten teachers get together and break the incoming children into class sets. They try to make the classes even by distributing the children by level (all 90s split up, all 30s split up, etc.)

\section{Charlotte Danielson Teaching Evaluation System}

This is a specific method for evaluating teacher professionals. The teacher is required to be evaluated in different areas during each observation. See the definition for "observations" below. Teachers can receive a 1, 2, 3 or 4 from their evaluator (4 is the best score). The score is then added to the teacher's district file. 


\section{Child Study Team}

A team of district educators who evaluate and determine if a child is eligible for special education testing. When a child is deemed eligible the team has 90 days to test the child. The team includes a social worker, psychologist, education specialist and a special education teacher.

\section{Common Core Standards}

The new state standards utilized in 43 states that were developed by state education chiefs and state governors. The purpose of the standards is to ensure that high standards are consistent state by state so that American children can be globally competitive by systematically acquiring knowledge especially critical thinking skills. Retrieved on July 9th 2014 www.corestandards.org

\section{Developmentally Appropriate Practices}

Developmentally appropriate practices are based on Western developmental child psychology and child development experts (Piaget, Erikson, etc.) and are considered normative expectations in the teaching of young children.

\section{DRAs or Developmental Reading Assessments}

A reading test given to each student (grades K-2) three times per school year. Levels are associated with numbers and the teacher is obligated to get the child to a certain number by the end of the year $(\mathrm{K}=4$ and grade $1=18)$. This particular district also inputs the DRAs into an iTouch device so that the data is stored at the district. It is a standardized tool to evaluate a child's independent reading levels.

\section{English Language Learner (ELL)}

A child who speaks English as a second language may be eligible for ELL services. They must first be evaluated by ELL specialists in the district. If the child passes this test, they are eligible for a free bus to the ELL program in the district (located at one of the district's elementary school).

\section{Free and Reduced Lunch}

At the beginning of each school year lunch forms are sent home to all of the families with children in the schools. The parents complete them and include their annual salaries and a list all the people in their household. If their salaries fall below a certain threshold (low-income or poor), the child is eligible for free lunch and breakfast. If the salary is above this threshold but still lower than middle class standards, the families receive reduced lunch rates. Schools require these lunch forms in order to qualify for extra state funds.

\section{Guided Reading}

This is a part of the reading workshop. Children (usually in groups of 4 or 5) are called to the teacher's desk (or reading table) to read with the teacher. The teacher reviews one important reading skill (e.g., context clues, inferencing, etc.) with the group for a short period of time. During guided reading sessions, the rest of the class is on task working on another reading 
activity and the children are trained not to bother the teacher during this time. Groups usually meet once or twice a week, depending on how many groups the teacher has made.

\section{IEPs or Individualized Education Plans}

Educational plans that are developed for special education (classified) students. In order to get an IEP the child must be eligible for testing and found eligible for services. IEPs include specific learning plans to help the student (e.g..; longer time to take tests, modified homework, small group work, preferential seating, etc.). IEPs are reviewed annually and involve parent input as well.

\section{Inclusion}

Inclusion classrooms have two certified teachers (one regular education teacher and one special education teacher). The model includes special education students and students with $504 \mathrm{~s}$ in regular education activities. This is a mainstreaming technique but has built-in support because the experienced special education teacher is in the classroom. Some teams work together and plan and teach together, and others split the class into groups and work separately.

\section{Interventions}

This occurs when a classroom teacher fills out forms so a child can have an intervention meeting. This is for behavioral or academic reasons. The team in Grayson includes the viceprincipal, a rotating special education teacher, the school social worker, the classroom teacher, the AI teacher (if in this program), usually the school nurse and the child's parents. The team creates an action plan (written record) of classroom strategies that will aid the child in learning. The team can meet multiple times for each child (as follow-ups) during a year. A child must attend multiple intervention meetings before they will be deemed a possible candidate for the child-study team.

\section{Narratives}

This is mandatory in this district for all K-2 teachers. A narrative is a written comment about how a child is progressing in school. In Grayson the narrative has to be at least one page long and include paragraphs on each subject. It is included with the report card and given to the parent.

\section{Observations - Announced and Unannounced}

Each teacher, regardless of tenure, now has three observations by an assigned administrator each year. Tenured teachers, however, only have one announced (unlike the nontenured teacher who has two) observation with a pre-observation conference, the observation (1 hour) and a post-observation conference. The teachers are evaluated according to Charlotte Danielson's domains of effective teaching and are told which four domains will be observed during the lesson. The evaluator then reviews the teacher's lesson and scores the teacher in these four domains. The evaluator also prepares a summary for each domain and gives recommendations for further teacher growth. The unannounced observation (two for tenured teachers) can happen at any point of the day during a two-month window. The teacher must 
present his or her lesson plan when the administrator walks in and is then observed for 20 minutes (this could be at any point in a lesson). Again the evaluator assesses four domains but this time the teacher does not know which ones are being assessed. There is a post-observation conference with the same scores and written evaluations. This also is arbitrary depending on which administrator is assigned to the teacher for each observation.

\section{Paraprofessional}

This is a classroom aide. They are not necessarily certified teachers but have to attend a variety of training sessions and need to have a certain number of college credits in education. Some paraprofessionals are at the beginning of their teaching careers or are retired teachers. This particular district outsources paraprofessionals who are paid on an hourly basis and receive no benefits).

\section{PDP $=$ Professional Development Plans}

Each year teachers in this particular district must develop a professional development plan. The plan includes one or two written professional goals. Teachers must decide on the areas in which they would like to improve (formally known as the PIP, or professional improvement plan) and effectively utilize the new knowledge they acquire in the classroom. The teachers are required to list all the possible things they will do in order to achieve this goal (e.g., observe other teachers in this area, read a specific book, attend professional development workshops, etc.).

\section{PLC $=$ Professional Learning Communities}

These are professional groups that teachers form at the beginning of each academic school year. They are discussion groups centered around a shared interest (e.g., vocabulary building, character development, improving decoding/phonics, etc.). The teachers (across grade levels) can choose any group and meet with them during PLC times (after school on Tuesdays for one hour twice a month). These discussion groups can focus on a book or a series of articles and are sometimes asked to share their new knowledge with the entire staff at faculty meetings.

\section{Power School}

This is a computer program that is utilized and regularly monitored by this district. Teachers record their attendance, report card grades and other data input.

\section{Responsive Classroom}

A management method that teachers use to promote positive behavior. For example, at morning meeting time there are specific activities a teacher employs to promote sharing with and caring for others. 


\section{Retention}

A teacher can refer a child for retention (repeating the same grade twice) if the child is sufficiently behind his/her peers academically. The parent must be notified of a possible retention by March and the principal makes the ultimate decision by June.

\section{Schema}

A cognitive-based concept related to a student's background knowledge. Students come to a lesson with their own schemas or lack thereof, which may affect their academic success in that lesson.

\section{SGOs $=$ School Growth Outcomes}

Every teacher in this state is required (starting with the 2013-2014 academic year) to have one SGO in math (two in 2014-2015) and one SGO in reading. It breaks down the teacher's class into three leveled groups (low/medium/high) and calculates how much the groups will grow in each subject area. For example, in reading it is not uncommon to list a goal of a fivelevel increase in the DRA for the low group and only a two-level for the high group. At the end of the year, the teacher enters the data, which is then calculated to determine a statistical score based on whether the teacher sufficiently achieved his or her goals.

\section{ST Math}

A computerized math program for children. It offers different levels like a video game and is password protected. Children are expected to work on the program at home and at school for a specific amount of time. Sometimes the program is utilized in place of math homework. The teacher has access to the computerized reports and can see who is actually working on the program at home and how they are progressing.

\section{Student Teacher}

This is a pre-service teacher in training. Student teachers are in an undergraduate or graduate education program and are required to volunteer in a K-5 classroom. Student teachers come three to five times a week and are usually only assigned to one classroom per semester. They teach lessons in the classroom and are evaluated by their college professors.

\section{Summatives $=$ Teacher Evaluations}

At the end of the school year, teachers meet with their assigned administrators. The teachers must rate themselves according to the Charlotte Danielson domains of good teaching (ineffective, partially effective, effective, highly effective) and present their proposed scores to the administrator. If the administrator disagrees with the teacher's proposed score (they usually do), the teacher must provide physical evidence that proves that he or she deserves that score. For example, if teachers rate themselves as effective in classroom engagement they must provide materials that show that their children are actively engaged at all times. The administrator then takes these scores (that he or she may change) and records them together with the teacher's SGO, PDP and three observation scores in order to calculate a final score for the teacher $(1,2,3$ or 4$)$. 
This score goes in the teachers' files for that school year. If they are rated a 1. (ineffective) or a 2 , the teachers are immediately placed on probation and have only one year to improve. These summative scores are highly arbitrary depending on the administrator you are assigned.

\section{Tenure}

After working four years in the same district, teachers come up for tenure review. If they have good scores (based on previous observations and summatives), the principal recommends them for tenure status, which means they have job security and cannot be fired arbitrarily. Tenured staff who take leaves of absence are always given a job in the district when they return (although not necessarily the same job or school).

\section{Title One School}

A Title One designated school is based solely on the percentage of children receiving free and reduced lunches. If a school has over $40 \%$ of students receiving free and reduced lunches, it is eligible for this status, which entitles the school to extra Title One funds from the state and federal governments.

\section{Transitions}

This is a term that describes the movement of students from one activity or place in the room to another. In early grades there are a lot of transitions from the tables to the rug area.

\section{Writer's Workshop}

This is a method of writing designed by Lucy Calkins and Teachers College. The purpose is for children to learn the writing process by writing and publishing their own original stories. Teachers are trained in this method by attending a variety of workshops. 


\section{References:}

www.abcmouse.com

Adair, J.K. (2014) "Agency and expanding capabilities in early grade classrooms: What it could mean for young children" in Harvard Educational Review. 84 (2), 217-241.

Allen, E. (2010). Policy Discourses, gender and education: Constructing women's status. New York: Routledge.

Ames, L. \& Ellsworth, J. (1997). Women reformed, women empowered: Poor mothers and the endangered promise of Head Start. Phil. PA: Temple University Press.

Anyon, J. (2005). Radical possibilities: Public policy, urban education and a new social movement. New York: Routledge.

Barnett, S. \& Boocock, S. (Eds.) (1998). Early care and education for children in poverty: Promises, programs and long term results. Albany, NY: State University of New York Press.

Barnett, W. S. (1998) Long-term effects on cognitive development and school success, In S. Barnett \& Boocock (Eds.) Early care and education for children in poverty: Promises, programs and long-term results. pp. 11-44. Albany, NY: SUNY press.

Bartik, T. (2011). Investing in kids; Early childhood programs and local economic development. WE Upjohn Institute.

Beatty, B. (1995). Preschool education in America: The culture of young children from the colonial era to the present. New Haven: Yale U. Press.

Becker, G. (1994). Human Capital: A theoretical and empirical analysis, with special reference to education (3rd edition). Chicago: U of Chicago Press.

Bloch et al (2014). Reconceptualizing early childhood care and education: a reader.

Bloom, B. (1964). Stability and change in human characteristics. New York: Wiley Pub.

Bloom, B. and et al. (1965). Compensatory education for cultural deprivation. New York: Holt, Rinehart \& Winston.

Bonilla-Silva, E. (2006). Racism without Racists: Color-blind racism and the persistence of racial inequality in the U.S. (2nd edition). Rowman \& Littlefield Pub.

Booth, A. \& Crouter, A. (Eds.) (2008). Disparities in school readiness: How families contribute to transitions into school. New York: Lawrence Erlbaum Associates.

Bredakamp \& Copple (1997). Developmentally Appropriate Practices in early childhood programs. (revised edition). Washington D.C: NAEYC 
Cannella, G. (1997). Deconstructing early childhood education: Social justice and revolution. New York: Peter Lang.

Charmez, (2014). Constructing Grounded Theory. Sage publications

Coley (2002). School Ready.

Danielson, C. (2009). Implementing the framework for teaching in enhancing professional practice. Virginia: ASCD.

Davis, M. (1933). Business meetings - proceedings of the 6th conference of the National Association for Nursery Education.

DeVault, M. (ed). (2008). People at work: life, power and social inclusion in the new economy. New York: NYU press.

Dodson, L. (2009). The Moral Underground: How ordinary Americans subvert an unfair economy. New York: New Press.

Dodson, L. \& Schmalzbauer, L. (2010). Poor mothers and habits of hiding: Participatory methods in poverty research, In W. Lutrell (Ed.), Qualitative educational research: Readings in reflexive methodology and transformative practice. pp. 313-326. New York: Routledge.

Edwards, D. (1999). Public factors that contribute to school readiness, in Early childhood Research and Practice, Vol. 1 (\#2).

Ehrenreich, B. (2011). Nickel and dimed: On (not) getting by in America. (10th Anniversary edition). New York: Picador

Ehrenreich \& Hochschild (2002). Global Woman: Nannies, maids, and sex workers in the new economy. New York: Holt publishing.

Emerson, et al. (1995). Writing ethnographic field notes. Chicago: U of Chicago pr.

Entwisle, D. \& Alexander, K. (1998). Facilitating the transition to First grade: The nature of transition and research on factors affecting it in The elementary school journal, 98. p. 351.

Erikson, E. H. (1950). Childhood and Society. New York: W.W. Norton.

Ferguson, A. (2001). Bad Boys: Public schools in the making of Black masculinity. University of Michigan Press.

Frankenberg, R. (1993). White women, race matters: The social construction of Whiteness. Minneapolis, MN: U of Minn. Press.

Froebel, F. (2005). The Education of Man. New York: Dover pub.

Grau, E. (1993). Ready for what? Constructing meanings of readiness for kindergarten. Albany: SUNY Press.

Grau, E. \& Hawkins, M. (2010). "I always feel they don't know anything about us": diverse families talk about their relations with school, in M. Marsh \& T. Turner-Vorbeck (Eds.), (Mis) understanding families: Learning from real families in our schools. pp. 109-125. New York: Teachers college press.

Gray, S. \& Klaus, R. (1965). An experimental preschool program for culturally deprived children, in Child Development, 36 (4), pp. 887-898.

Gupta, A. (2006). Early childhood education, postcolonial theory, and teaching practices in India: Balancing Vygotsky and the Veda. New York: Palgrave Macmillan. 
Gupta, A. (2006). Early experiences and personal funds of knowledge and beliefs of immigrant and minority teacher candidates dialog with theories of child development in a teacher education classroom, in Journal of early childhood teacher education, 27, p. 3-18.

Hale-Benson, J. \& Hilliard, A. (1986). Black children: their roots, culture and learning styles. Baltimore, MD: John Hopkins U. Press.

Hale, J. (2001). Learning while Black: Creating educational excellence for for African American children. Baltimore, MD: John Hopkins U. Press.

Harrington, M. (1962). The other America: Poverty in the United States. New York: Touchstone (S\&S).

Harry \& Klngner (2006). Why are so many minority students in special education? Understanding race and disability in schools. New York: Teachers college press.

Harvey, D. (1989) The Condition of Postmodernity. Mass: Blackwell pub.

Hatch, J. (2002) Doing qualitative research in education settings. Albany: SUNY Press.

Hatch, J. (Ed.) (2007). Early childhood qualitative research. New York: Routledge.

Hays, S. (1998). The Cultural Contradictions of Motherhood. New Haven; Yale University Press.

Heckman, J. (2013). Giving kids a fair chance: A strategy that works Mass: MIT Press.

Herrnstein \& Murray (1994). The Bell curve: Intelligence and class structure in American life. New York: Free press.

Hill, N. (2001). Parenting and academic socialization as they relate to school readiness: The role of ethnicity and family income, in Journal of Educational Psychology 93 (4). pp. 686-697.

Hill, (2004). The impact of child welfare policies on African American families, In J. Everett et al. (Eds.), Child welfare revisited: An afrocentric perspective. New Brunswick, NJ: Rutgers U. Press.

Hunt, J.M. (1964). The psychological basis for using preschool enrichment as an antidote for cultural deprivation, In Quarterly of behavior and development 10 (3), page 209-244.

Hunt, J.M. (1961). Intelligence and experience. New York: Ronald Press.

Jordan (2009).

Karoly, L. (2009). Preschool adequacy and efficiency in California: Issues, policy options and recommendations. Santa Monica, CA: Rand Corporation.

Karoly, L \& Bigelow (2005) The Economics of Investing in Universal Preschool Education in California. Santa Monica: Rand corporation.

Keddie, N. (Ed.). (1973). The myth of cultural deprivation. New York: Penguin education. 
Keeley, B. (2007). Human capital: The power of knowledge. New York: OCED.

Kolhatkar, S. (2014). "Studies confirm the dehumanization of Black children and the preschool-to-prison pipeline" in TruthDig. com (April 4th, 2014).

Konald, T. \& Pianta, R. (2005). Empirically derived person oriented patterns of school readiness in typically developing children: Description and prediction to first grade achievement, in Applied developmental science, 9. p. 174-187.

www.Kuman.com

Labov, (1973). The logic of nonstandard English, in Keddie (Ed.). The myth of cultural deprivation. New York: Penguin education.

Lara-Cionisomo, S. et al. (2004). Are L.A.'s children ready for school? Santa Monica, CA: Rand Corporation.

Lareau, A. (2000). Home advantage: Social class and parental intervention in elementary education. Lanham, MD: Rowman \& Littlefield Pub.

Lareau, A. (2003). Unequal childhoods: Class, race and family life. Berkeley, CA: U. of California Press.

Lareau, A. \& Weininger (2008). The context of school readiness: Social class differences in time use in family life, in A. Booth \& Crouter (Eds.), Disparities in school readiness: How families contribute to transitions into school.

New York: Lawrence Erlbaum Associates.

Leonardo, Z. (2009). Race, Whiteness and Education. New York: Routledge.

Leonardo, Z. (2013). Race Frameworks: A multidimensional theory of racism and education. New York: Teachers college press.

Linder, S., Ramey, M. and Zambak, S. (2013). Predictors for school readiness in literacy and mathematics: A selective review of the literature, in Early childhood research \& practice, vol. 15 (no. 1)

Lowell, J. (1883) letters in Waugh, J. Unsentimental Reformer: The Life of Josephine Shaw Lowell. Cambridge, Mass; U of Harvard press.

Lubeck, S. (2001). The role of culture in program improvement, in Early childhood research quarterly. 16, pp. 499-523.

Luttrell, W. (Ed). (2010). Qualitative educational research: Readings in reflexive methodology and transformative practice. New York: Routledge.

Luttrell \& Dodson (winter 2011) "Families facing untenable choices" in Contexts 10 (1), 38-42.

MacNaughton, G. \& Hughes, P. (2007). Teaching respect for cultural diversity in Australian early childhood programs: A challenge for professional learning, in Journal of early childhood research. June, 2007 (5), pp. 189-204.

MacNaughton, G. (2005). Doing Foucault in early childhood studies: Applying poststructural ideas. London: Routledge.

Magnuson, K. et al. (2004). Inequality in preschool education and school readiness, in American educational research journal, (41), pp. 115-157. 
Massey and Denton (1993). American Apartheid: Segregation and the making of the underclass. Cambridge, MA: Harvard U. press.

Maxwell, J. (2005). Qualitative research design: An interactive approach (2nd edition). Thousand Oaks, CA: Sage publications.

Meier, D. and et al. (eds). (2004). Many children left behind. Boston: Beacon Press.

Moses \& Cobb (2002). Radical equations: Civil rights from Mississippi to the Algebra Project. Boston: Beacon Press.

Moynihan (1964). "The Negro Family: The case for national Action" in Rainwater \& Yancy's, The Moynihan Report and the politics of controversy. Mass: MIT Press.

NAEYC (2009). Developmentally Appropriate Practice in early childhood programs serving children from birth through age 8. (revised position statement). NAEYC.

www.nces.ed.gov

www.nctm.org

OCED (2007) Human Capital: How what you know shapes your life. OCED publications.

Omi, M. \& Winant, H. (1994). Racial formation in the United States, from the 1960s to the 1990s (2nd edition). New York: Routledge.

Pearl, (1997). Cultural and accumulated environmental deficit models, in Valencia, The evolution of deficit thinking: Educational thought and practice. New York: Routledge.

Penn, (2008). Early education and care in southern Africa: A perspective report U.K. CFTB Educational Trust.

Picciano, A. (2004). Educational research primer. New York: Continuum.

Polakow, V. (2007). Who cares for our children? The childcare crisis in the other America. New York: Teachers college press.

Postman, N. (1973). The politics of reading, in N. Keddie (Ed.) The myth of cultural deprivation. New York: Penguin Education.

Rainwater \& Yancy (1967). Moynihan Report and the politics of controversy. MIT press.

Ramey, C. \& Ramey, S. (2004). Early learning and school readiness: Can early intervention make a difference? in Merrill-Palmer quarterly, 50. p. 471-491.

Randolph, A. (2013). The wrong kind of different: Challenging the meaning of diversity in American classrooms. New York: Teachers College Press.

Ravitch, D. (2010) The death and life of the great American school system: How testing and choice are undermining education. New York: Basic Bks.

Riessman, C.K. (2007). Narrative methods for the human sciences. London: Sage publications. 
Riessman, F. (1962). The culturally deprived child. New York: Harper \& Row.

Rock \& Stenner (2006). Assessment issues in the testing of children at school entry, in The Future of Children - School Readiness: Closing racial and ethnic gaps, vol. 15, no\#1, spring.

Roosevelt, F (2008). Fireside chats: Radio addresses to the American people (1933-1944). Red and Black Publishers.

Rubin, H. \& Rubin (1995). Qualitative interviewing: The art of hearing. California: Sage publications.

Ryan, W. (1976). Blaming the victim (2nd edition). New York: Vintage press.

Saldana, J. (2013). The Coding manual for qualitative researchers. Sage pub.

Seidman, I. (1998). Interviewing as qualitative research: A guide for researchers in education and the social sciences (2nd edition). New York: Teachers college press.

Stack, C. (1975). All our kin: Strategies for survival in a Black community. New York: Harper and Row publishers.

Steinfels, M. (1973). Who's minding the children? The history and politics of day care in America. New York: Simon \& Schuster.

Strauss, V. (2015). "Requiring kindergartners to read as Common Core does may harm some" (Washington Post online).

Tager, M. (2013) Non-School Ready: A critical approach to how White middle-class educators perceive school readiness in low-income Black children. Proposal for dissertation at CUNY Graduate Center.

www.topicalteaching.com (retrieved in 2012)

Tyack, D. (2007). Seeking common ground: Public schools in a diverse society. Cambridge, MA: Harvard U. Press.

Valencia (1997). The evolution of deficit thinking: Educational thought and practice. New York: Routledge.

Valencia, R. \& Solarzano (1997). Contemporary deficit thinking, in R. Valencia, The evolution of deficit thinking: Educational thought and practice. New York: Routledge.

Valencia, R. (2010). Dismantling contemporary deficit thinking: Educational thought and practice. New York: Routledge.

Waugh, J. (1997). Unsentimental reformer: The life of Josephine Shaw Lowell. Cambridge, MA: Harvard University Press.

World Bank (2003). Lifelong learning in the global knowledge economy: Challenges for developing countries. Washington,DC: World Bank.

Wright, J. et al. (2001). The relations of early television viewing to school readiness and vocabulary of children from low-income families: The early window project, in Child development, 72. p. 1347-1366.

Wu, F. \& Qi, S. (2006). Longitudinal effects of parenting on children's academic achievement in African American families, in Journal of Negro education, 75. pp. 415-429. 
Zigler, E. \& Muenchow, S. (1992). Head Start: The inside story of America's most successful educational experiment. New York: Basic Books.

Zigler, E. (2006). Vision for a universal preschool education. New York: Cambridge U. Press.

Zigler, E. \& Styfco, S. (2010). The hidden history of Head Start. New York: Oxford U. Press.

Zigler, E. (2011) The Pre-k debates: Current controversies and issues. New York: Brookes pub. 